University of Denver

Digital Commons @ DU

8-1-2013

\title{
The Journey to Teaching Online: A Case Study of Faculty Preparation and Experiences in Online Teaching
}

Angel Chi

University of Denver

Follow this and additional works at: https://digitalcommons.du.edu/etd

Part of the Higher Education Commons, and the Online and Distance Education Commons

\section{Recommended Citation}

Chi, Angel, "The Journey to Teaching Online: A Case Study of Faculty Preparation and Experiences in Online Teaching" (2013). Electronic Theses and Dissertations. 126.

https://digitalcommons.du.edu/etd/126

This Dissertation is brought to you for free and open access by the Graduate Studies at Digital Commons @ DU. It has been accepted for inclusion in Electronic Theses and Dissertations by an authorized administrator of Digital Commons@DU. For more information, please contact jennifer.cox@du.edu,dig-commons@du.edu. 
THE JOURNEY TO TEACHING ONLINE:

A CASE STUDY OF FACULTY PREPARATION AND EXPERIENCES IN ONLINE TEACHING

\author{
A Dissertation \\ Presented to \\ the Faculty of the Morgridge College of Education \\ University of Denver
}

\begin{abstract}
In Partial Fulfillment
of the Requirements for the Degree

Doctor of Philosophy
\end{abstract}

by

Angel Chi

August 2013

Advisor: Dr. Bruce Uhrmacher 
CCopyright by Angel Chi 2013

All Rights Reserved 
Author: Angel Chi

Title: THE JOURNEY TO TEACHING ONLINE: A CASE STUDY OF FACULTY PREPARATION AND EXPERIENCES IN ONLINE TEACHING

Advisor: Dr. Bruce Uhrmacher

Degree Date: August 2013

\begin{abstract}
When Bill Gates published his book “The Road Ahead” (1995), he summarized the transformative implications of the personal computing revolution and described a future profoundly changed by the arrival of a global information super highway. Almost twenty years later, the tsunami of online programs and the MOOCs (massive online open courses) is impacting the structural integrity of postsecondary institutions and changing the competitive landscape of higher learning at an unprecedented pace. When Allen and Seaman (2013) asked the question of whether faculty acceptance of online education increased in their Sloan Consortium annual report, only $30.2 \%$ of chief academic officers believe their faculty accept the value and legitimacy of online education. This rate is even lower than the rate recorded in 2004. With an apparent widening gap between institutional strategy and faculty acceptance, each organization needs to conceptually map its road ahead. However, only an institution as a whole can decide for itself what kind of change is needed and define what constitutes evidence of lasting change. This implies a unique transformation of institutional philosophy, culture, strategy, and reward systems for faculty members.

Complex adoptive system (CAS) theory (Olson \& Eoyang, 2001), suggests
\end{abstract} that the most powerful organizational transformations occur not at the macro level but 
rather at the micro level where behaviors and changes began to emerge. Thus, instead of trying to measure, evaluate, or categorize which faculty member fits into which stage of online faculty development under which framework, this study asked four tenured faculty members to reconstruct their experiences on why they teach online, how they learn to teach online, and what factors influences their journeys to teaching online. Their narratives painted a landscape of faculty acceptance in institutions and the online learning phenomena in our society. Ultimately, their stories are really about change. By studying the "change agents" in a changing organization in a changing industry, this study is not an exercise to identify the best practices. Rather, this study hopes to inspire new ideas for new ways to conceptually frame the problem facing the faculty, the institution, and the industry in their road ahead in teaching online.

The researcher hopes that this study may be used by institution leaders, faculty developers, and other faculty members to: (1) assess the level of progress of their current and future distance learning program, (2) determine how distance learning programs should be established, (3) evaluate faculty development efforts, (4) improve strategies and implementations for institutionalization of their distance education programs, including academic programming and faculty reward structure, and (5) improve online student retention and learning outcomes. 


\section{Acknowledgements}

First of all, I want to express my deepest appreciation to my advisor Dr. Bruce Uhrmacher, my committee members Dr. Kathy Green and Dr. Paul Michalec for their interests, time, and invaluable input.

I am extremely thankful to all the professors I interviewed for their generosity and willingness to share their personal and professional journeys in learning to teach online. I am also grateful to my family, friends and colleagues, whose love and encouragement helped sustain me in my pursuit of knowledge. Last but not least, I want to dedicate this study to my father, the beloved professor Chi by all his students, who encouraged me to pursue my doctoral study a few months before he passed away. Dad, this one is for you! 


\section{Table of Contents}

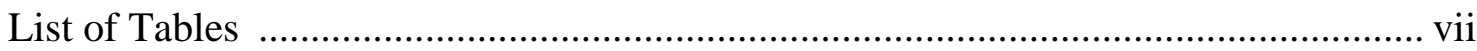

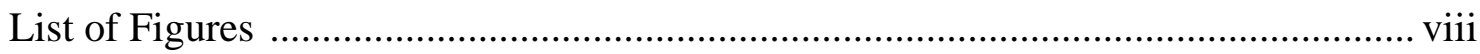

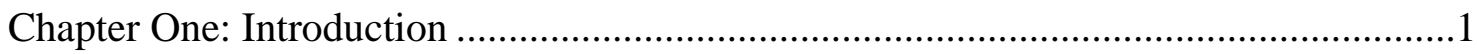

Background .............................................................................................

The Problem ...................................................................................................

Significance of the Study ................................................................................

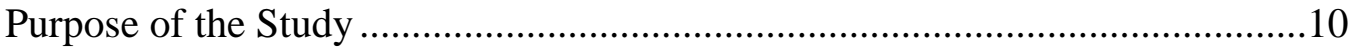

Organization of the Study …………………………….................................12

Background of the Researcher ........................................................................15

University of Denver......................................................................................17

Definitions of Terms Used................................................................................19

Chapter Two: Literature Review ………………………...........................................25

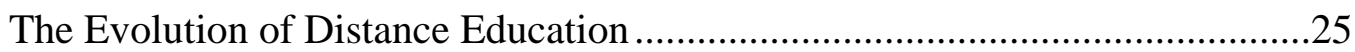

The Relationship of Educators, Learners, and Society ......................................27

Living and Learning in The Digital Age..............................................................30

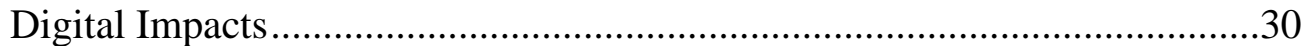

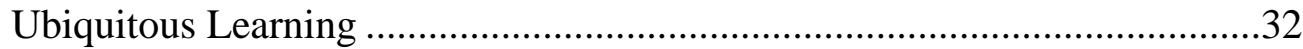

New Literacy............................................................................................

Promise and Perils in Reconceptualizing Education in The Digital Age ............37

Issues in Distance Education Research............................................................44

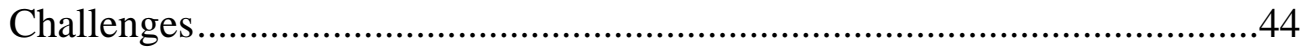

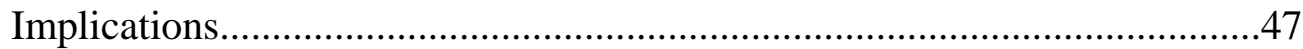

Examples of Current Practice ...........................................................................48

Issues in Institutionalizing Distance Education ...................................................52

Issues in Online Faculty Development ......................................................53

Online Faculty Development Models ..............................................................56

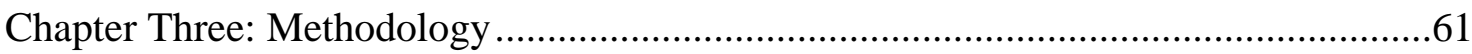

Research Design .........................................................................................62

Research Questions .......................................................................................64

Environment and Sample................................................................................65

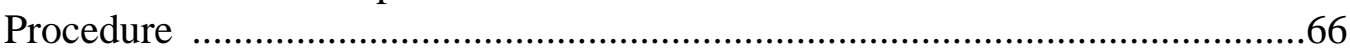

Interview Questions ...................................................................................67

Data Analysis .........................................................................................69

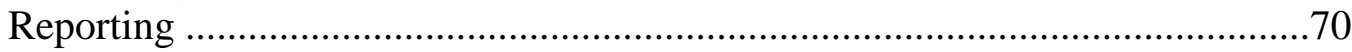




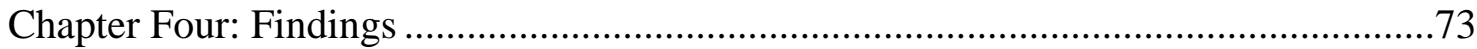

Participant 1 - Holly, the Sociologist ...............................................................74

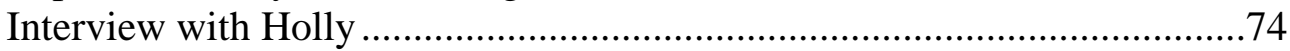

Summary for Holly .........................................................................86

Participant 2 - John, the International Journalist...........................................88

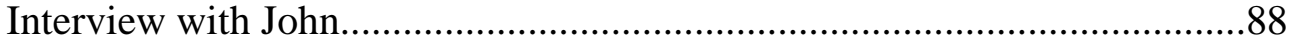

Summary for John............................................................................98

Participant 3 - Bill, the Organizational Management Consultant ......................99

Interview with Bill ...............................................................................99

Summary for Bill ...............................................................................115

Participant 4 - Mary, the Marketing Guru and Online Expert ........................118

Interview with Mary .......................................................................118

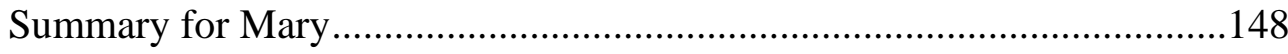

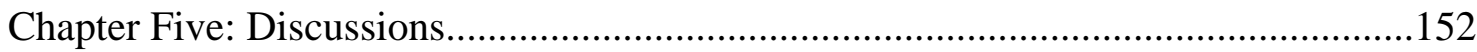

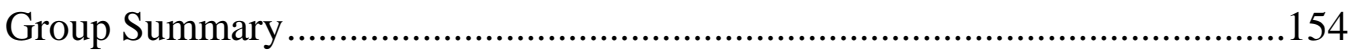

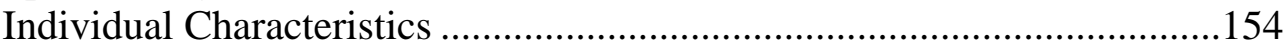

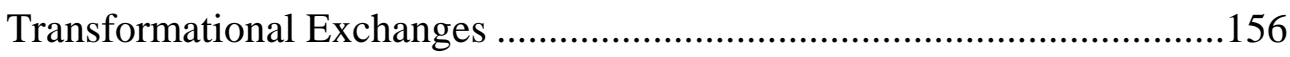

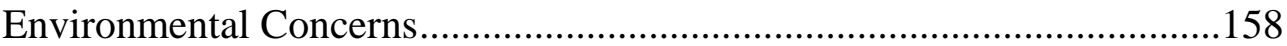

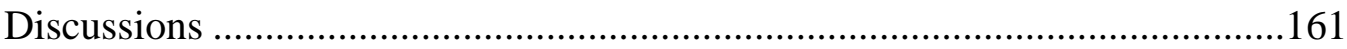

What Has Changed? ............................................................................162

Shared Context of Change Has Changed..................................................162

Change Is No Longer A Choice, It's A Must ............................................164

What Do We Need to Change? ......................................................................166

Observations for Online Course Development .........................................166

Considerations for Online Faculty Development ....................................168

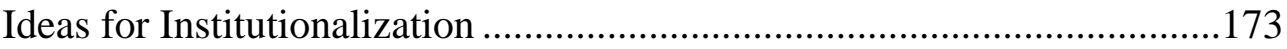

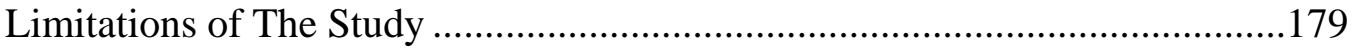

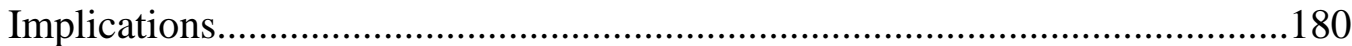

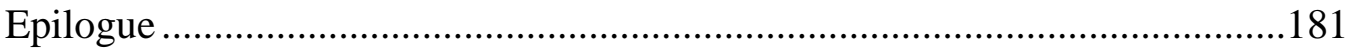

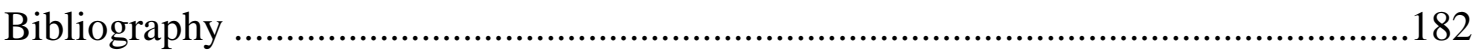




\section{List of Tables}

Table 1. Basic Types of Design for Case Studies ..................................................13

Table 2. Case Study Method ......................................................................... 14

Table 3. The 5 Pillars Sloan-C Quality Framework .................................................20

Table 4. Definitions of Types of Courses ............................................................23

Table 5. Traditional Medium vs. Other Media ...........................................................36

Table 6. List of Teaching Online Study Participants ................................................73 


\section{List of Figures}

Figure 1. The Education System, Society and the Curriculum...................................28

Figure 2. Five Dimensional Model of Education.................................................29

Figure 3. Moving from a Teacher-Centered to a Learner-Centered Approach ..............29

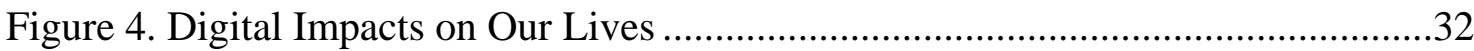

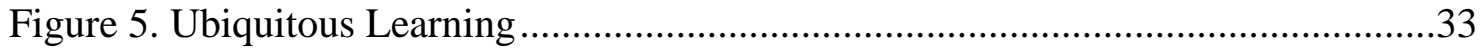

Figure 6. An Emerging Model of Change Agency in Instructional Design ..................42

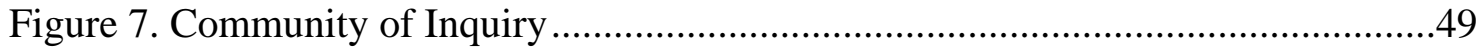

Figure 8. Stages of Blended Learning Faculty Development ....................................57

Figure 9. Phases of Online Faculty Development $\quad$................................................60 


\section{Chapter One: Introduction}

"We live in a moment of history where change is so speeded up that we begin to see the present only when it is already disappearing.”- R. D. Laing

\section{Background}

When Bill Gates published his book “The Road Ahead” (1995), he summarized the transformative implications of the personal computing revolution and described a future profoundly changed by the arrival of a global information super highway. However, even with all the benefits Microsoft could potentially receive from the predicted Internet boom, Bill Gates resisted changing his corporate mission to be an "Internet focused” company for years. When Microsoft finally debuted its own Internet browser, it was with great pain that Gates admitted that his company was no longer the leader in that space. Similarly, Warren Buffet for decades refused to include any technology stocks in his Berkshire Hathaway holdings. Only after he befriended Gates did Buffet begin to dip his toes in the digital water by investing a small percentage of his fortune in technology companies that he once would not have imagined an association with. If two of the richest men on earth hesitated to embrace new technology, is there any great urgency for us as educators to worry about adopting the latest innovations in our professions? 
A few years later, we entered the $21^{\text {st }}$ century. Google became a household name within a matter of months (not years) after its introduction in the mid-2000s. Video-conferencing was so cost prohibitive in the late 1990s that fortune 500 companies would only consider using it when they were in a real pinch. A decade later anyone with a "smart" phone can videoconference and share files at the same time. When my sister’s family visited Disneyland, my five-year-old niece asked her mother to use her smart phone to take pictures of Mickey Mouse and my niece together and emailed those pictures to her grandparents from her mother's phone. My niece may not know how to spell a lot of words yet but she managed to demonstrate her knowledge of using a smart phone for multi-media asynchronous communication purposes for our family network. When she goes to school will her teachers know how to leverage her "prior knowledge” of utilizing a smart phone (along with Mickey Mouse) for asynchronous communication to enhance her educational experience? It challenges the imagination to consider what technology we will be utilizing when my niece goes to college a little more than a decade from now. What about the students in college now? All of them were basically born after the Internet became commercially available on a global scale in the mid-1990s. Are professors leveraging students "prior knowledge” of Internet and smart personal devices to enhance their educational experience?

While many higher education leaders agree that providing online access for students is essential in securing their institutions' future, few have acknowledged a clear vision on how to achieve such an aim. The Sloan Consortium (Sloan-C 
hereafter), the professional group consisting of individuals, institutions, and organizations committed to quality online education, has published annual reports on the state of online higher education in the United States since 2003. Two recent consecutive annual reports (Allen \&Seaman, November 2010 and 2011) have shown an exponential increase in student enrollment as well as robust growth in institutional investment in online learning. However, in those same reports, faculty acceptance of online learning has not shown significant change since 2003. In Allen and Seaman's (2013) latest report, the numbers of online enrollment in degree-granting postsecondary institutions has increased from 1,602,970 (9.6\% of total enrollment of 16,611,710) in 2002 to 6,714,792 (32\% of total enrollment 20,944,113) in 2011. Similarly, the U.S. Department of Education (October, 2011) reported that over 30\% of U.S. postsecondary students took courses online during the 2010-2011 academic year. For the postsecondary institutions, whether they are ready or not, the student demand for online offerings is likely to continue to grow now that it is over "the tipping point” (Gladwell, 2000). The vision of higher learning blurring the limitation of space and time becomes not only real but also progressively inescapable. In addition, the prestige of a college degree no longer carries with it a guarantee of employment. Especially after the Internet bubble in the early 2000s and the global economic crises in the last five years, many professionals find themselves going back to school in order to stay competitive in the workplace. Some of the forprofit higher learning institutions made the distance education model workable and lucrative on a large scale very quickly, leading to suspicions among not-for-profit universities and potential employers about the quality of the online courses or 
degrees. Of the 4000 plus $^{1}$ colleges and universities in the United States surveyed by the Sloan Consortium for their annual report on distance education (Allen \& Seaman, 2002-2013), 77\% of chief academic officers rated the learning outcomes for online education "as good as or better" than those in face-to-face instruction. So, $23 \%$ of academic leaders still consider online education to be inferior to face-to-face instruction. No comparable reports from employers are available at this time. However, the image and perception of higher learning are changing along with changes in how an institution functions in the digital age.

John Dewey commented in the 1950s that just because a person goes to college does not mean he is getting an education. Ironically, the statement is even more salient today than six decades ago. As a matter of fact, if Bill Gates or Steve Jobs had ever finished their college degrees, we probably would not have either Windows or Apple operating systems today. Nor do we have to worry about using the Internet for educational purposes. But now, in this fast disappearing present, we worry about how to utilize technology to enhance students learning as the standing of higher education as the depository of knowledge is being questioned. The future of many higher education institutions is uncertain. Of all the colleges and universities in the United States surveyed by the Sloan Consortium on distance education over the last ten years, the proportion of chief academic leaders that reported online education was critical to their long-term strategy has changed from less than 50\% in 2002 to close to $70 \%$ in 2011 . Likewise, a historical low of $11.2 \%$ of institutions reported

\footnotetext{
${ }^{1}$ The sample universe contains 4,527 institutions with a total of 2,820 responses included in the analysis, representing $62.3 \%$ of the sample universe and $83.3 \%$ of higher education enrollments. (Allen \& Seaman, 2013, p.32)
} 
that online education is not critical to their long-term strategy (Allen \& Seaman, 2013).

\section{The Problem}

Organizational expert Jerry Harvey once said: "the theory is the intervention.” For centuries, scholars and inquiring minds in higher learning institutions were coached to understand the theoretical framework before actually practicing in a field. However, many technologies we utilize in day-to-day living and learning are not developed on academic theories but rather are based on practice. What happens when there are only a handful of best practices and scarcely any leading theory about a particular problem the whole industry is facing? In this case, the problem is integrating distance learning in the education delivery modes of postsecondary institutions. Distance learning is not a new concept. However, until less than a decade ago, distance learning was never “front and center” in any institutional discussions compared with the traditional brick and mortar model we are familiar with in our own educational experiences.

Teaching online may sound exciting to some. However, for the majority of faculty members in higher learning institutions, teaching in cyberspace promotes a high level of anxiety. Ever since I was a little girl, I wondered how it would be to learn new things without the limitations of time and space. Speaking from personal experience, teaching and learning in cyberspace did not just transcend the limitations of time and space. It obliterated our traditional sense of bearings on class schedules and physical classroom space that served us religiously so well for so long. For the 
trained professionals in the teaching profession, teaching students in this powerful realm of cyberspace requires not only a strong heart, but also a heart that's willing to interrogate old beliefs and alter its practices along the way, no matter how painful it may be, in the absence of theories. When Allen and Seaman (2013) asked the question of whether faculty acceptance of online education increased in their Sloan Consortium annual report, only 30.2\% of chief academic officers believe their faculty accept the value and legitimacy of online education. This rate is even lower than the rate recorded in 2004.

In the recent $10^{\text {th }}$ Sloan Consortium (2013) annual report on distance education, the paper "Changing Course: ten years of tracking online education in the United States” provided clues that the leading consortium on online education is perhaps pondering ideas about ways to conceptually map "the road ahead" for the higher education industry. Peter Vaill stated: "change projects will indeed fade away if organization members have not learned to think fundamentally differently about the system...” (cited in Olson \& Eoyang, 2001, p. xxvi). Although one may be tempted to consider the higher education industry as a large system with all elements facing the same problem, the self-governing nature of postsecondary institutions will easily prevent such an attempt to think differently. While a majority of academic leaders increasingly believe online education is critical to their long-term strategy, the rate of faculty acceptance decreased over the same period of time (Allen \& Seaman, 2013). Thus, while we live in a world where time and space boundaries are shattered in many ways, in which leaders of institutions of higher education see the necessity for faculty members to adapt to a new way of working, faculty members themselves in 
large part have not adapted to new ways of working. But, some have. It is the stories of those few who have adapted and done so effectively with which this paper concerns itself.

This study aims to unveil the journeys of those few faculty members who pioneered and continue to teach online in a traditional private university. By understanding their experiences, it intends to provide considerations for others to conceptually map their road ahead in teaching online.

\section{Significance of the Study}

Colbeck (2002) stated institutionalization requires changes in rules, values, norms, beliefs, and behaviors, thus encouraging institutions to use multiple indicators to assess and provide evidence of lasting change. Each institution is a vessel carrying its crew (faculty members) and passengers (students) in need of some degree of reengineering while traveling in cyberspace. With an apparently widening gap between institutional strategy and faculty acceptance, each organization is in essence left to its own devices to figure out how to conceptually map its road ahead. However, only an institution as a whole can decide for itself what kind of change is needed and define what constitutes evidence of lasting change. This implies a unique transformation of institutional philosophy, culture, strategy, and reward systems for faculty members. This transformation would likely be led by the institution's administration, not by the faculty members who do not control the institution’s mission. In efforts to integrate teaching online into the main stream, each organization will need to not only invest in online faculty development in part, but also change the organizational philosophy as a 
whole. This change will require commitment from all members of the organization.

After all, the institution of higher learning, in whole and in part, exists for the purpose of enriching students learning. Faculty members are the connection between administrations and students and therefore the major driving force of each higher education institution in meeting its institutional vision. Without buy-in from the traditional faculty body, it will be difficult for the institution to move forward in this endeavor, especially if online courses were previously offered as ad-hoc projects heavily staffed by adjunct faculty.

Within this institutional context, the individual instructor does have control of his/her course content, pedagogy, and technology. What motivates instructors to offer courses online, how they develop, design, and conduct their courses, and whether they continue to digitally integrate their teaching are just some of the missing pieces in configuring the institutional vision of integrating technology in teaching and learning. However, Pina (2008) echoed Surrey and Brennan (1998) who stated that organizations, when using models of organizational change, should be cautious of “a deterministic bias-it assumes that once an innovation has been adopted, it will continue to be used" (p. 2). How and when would we know if an innovation becomes part of the long-term institutional reality in online teaching and learning? Complex adoptive systems (CAS) theory argues that it is at this micro level where "day-to-day" institutional behaviors and values patterns begin to develop (Olsen \& Eoyang, 2001).

Faculty development is a never-ending process. Teaching online has certainly added more variables and complexity to this process. Online faculty development 
programs are here to stay as long as we have Internet capability. The question is no longer whether higher education institutions should provide online faculty development programs but rather how to create cohesiveness for all people involved in the process. Therefore, higher education administrations need to know if there is any lasting impact once the grant money is gone or if the training changed faculty acceptance toward online (or blended) teaching. If so, what kind of institutional adjustment may help faculty members' who were not recipients of pilot project funding transition to teaching online?

Some faculty admitted that it was "by decree" rather than "by choice" that they got involved in the teaching online faculty development efforts offered by their institutions (Pina, 2008). Whether the faculty members' motivational level changes when "by decree" is part of the reward structure is beyond the scope of this study. However, while some online courses later became online programs, others remained ad-hoc projects or were discontinued once the funding was depleted (Boyd-Barrett, 2000.) What differentiated continuation from abandonment of online teaching? We can continue to contemplate integrating technology in teaching as a necessary yet inconvenient part of the teaching profession or perhaps we can find ways to systematically sift out the essential elements of thriving in this digital age and thus allow fellow professors to model successes. Will those innovative risk takers be recognized as “change agents” or “troublemakers' on this path less traveled by fellow professors? 
This study is aimed to reveal the paths of those individuals who have taken the journey to become pioneers in their institutional context. The researcher hopes that this study will help to bridge the understanding of the transformation process to teaching online from the instructors' point of view within the institutional context. And by doing so promote discussions about institutional online faculty development programs among the following stakeholders: (1) institutional administrators, (2) faculty members interested in offering online courses, (3) online faculty program developers, and (4) fellow researchers interested in understanding the genesis of online faculty development programs.

\section{Purpose of the Study}

Instead of focusing on the macro level, in this case, the institutional strategies, complex adoptive systems (CAS) theory suggests that the most powerful change processes occur at the micro level, in this case, the professors who transform themselves to teach online regularly. Complexity theory suggests that it is at the micro level, where relationships, interactions, and simple rules generate structures and patterns of behavior that "emerge" as a result (Olsen \& Eoyang, 2001). Although complexity theory argues there is no single source of change, over time the emergent patterns are influenced by three factors:

- The environment--for example, institutional culture, mission, and resources;

- Significant differences between individuals - for example, competency, 
expertise, and educational background; and

- Transforming exchanges - for example, meetings, educational events, and faculty development efforts

Complex adoptive systems (CAS) theory also makes distinctions between “competence” and “capability” (Olsen \& Eoyang, 2001). Competence is defined as the individuals' knowledge and skills, e.g., the technology competence and content knowledge when teaching the particular course online. Capability is defined as the extent to which individuals can adapt to change, generate new knowledge, and continue to improve their performance when taking both individual capacity and context capacity into account.

This study aims to illustrate several tenured faculty members' transformation from teaching in a traditional setting to teaching online in a private (not-for-profit) residential university. By studying the "change agents" in a changing organization in a changing industry, this study is not an exercise to identify the best practices, but rather an attempt to conceptually map the issues facing online higher education in general, from the instructors' point of view.

The basic research questions were:

1. Why did faculty members decide to teach online and why do they continue to do so?

2. What characterizes the journey taken by faculty members in learning to teach online? 


\section{Organization of the Study}

This study followed the case study framework (Stake, 1995; Yin, 2009) by using multiple sources of data including additional industry and historic data to triangulate interview data. The researcher then analyzed and summarized the interviews in an attempt to conceptually map the faculty members' experiences of their journey to teaching online.

To further understand the implications of this study, the history and progress of the university online faculty development program was incorporated to illustrate the dynamic context in which the research subjects reside. This single-case with multiple embedded units of analysis (see Table 1) approach is coherent with the complex adoptive systems theory’s environmental, individual, transforming exchanges factors by demonstrating the institutional context (single-case) where the individual instructors (i.e., the embedded multiple units of analysis) perform their job function.

The researcher conducted in-depth interviews with 4 tenured faculty members (2 females and 2 males) at the University of Denver with regard to their experiences in their personal and professional journeys to teaching online. Tenured faculty members teaching online regularly were chosen as the population for this study since job security is not an issue with this group and they enjoy more freedom in the format in which their courses are delivered. In addition, tenured faculty members are likely to be more experienced in the courses they teach. Faculty gender was not part of the consideration for this study since there is little research available on gender effects in 
teaching online, but to gain potential variability in perspectives both males and females views were elicited. It should be noted that the researcher did not participate in the online faculty development programs nor did she observe the actual online and traditional courses. In its place, this study focused on reporting these instructors' experiences of their journey to teaching online, following the case study method format detailed in Table 2.

Table 1. Basic Types of Design for Case Studies, from Case Study Research: Designs \& Methods (Yin, 2009, p. 46)

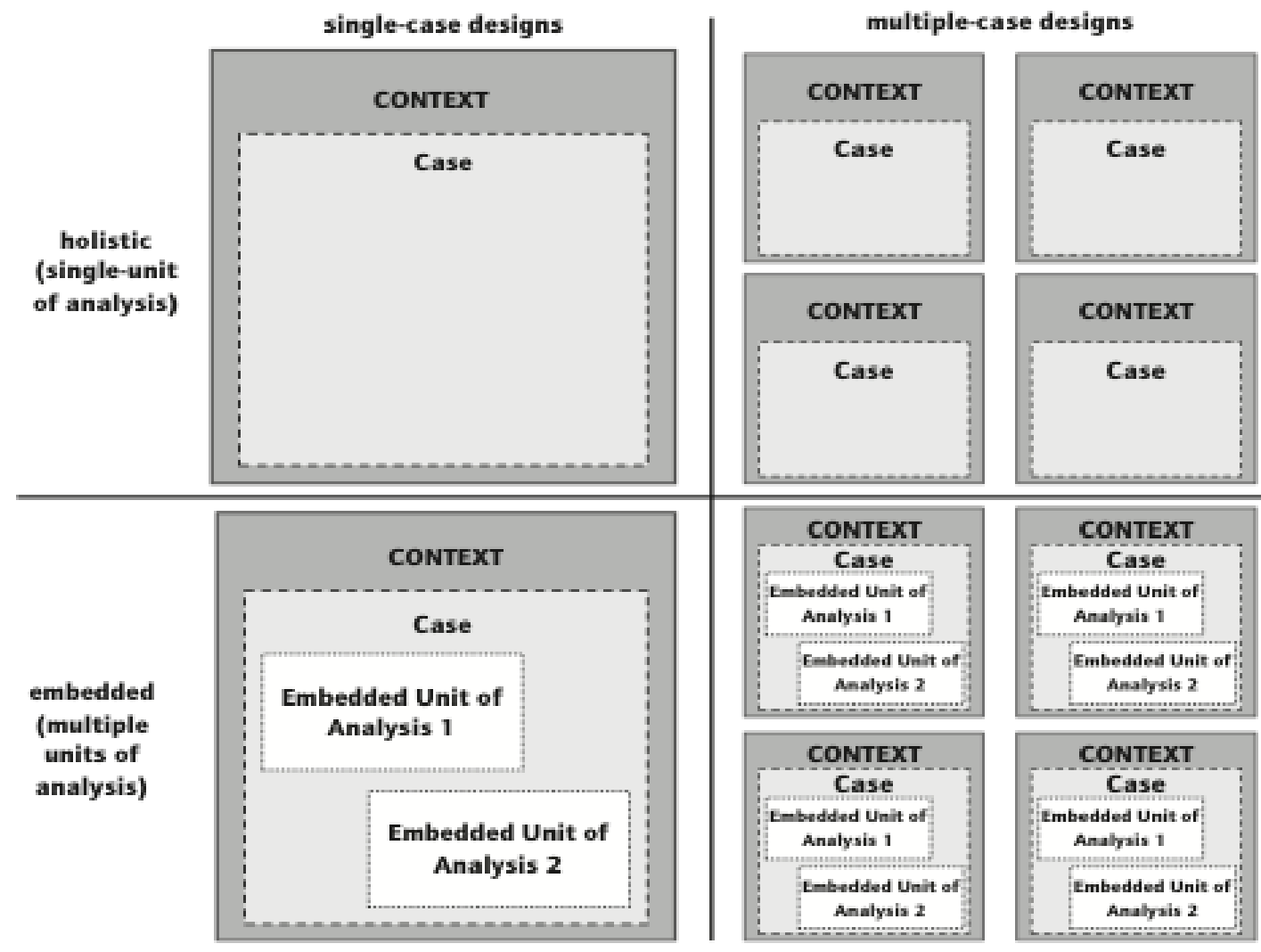

Figure 2.4 Basic Types of Designs for Case Studies SOURCE: COSMOS Corporation. 
Table 2. Case Study Method, from Case Study Research: Designs \& Methods (Yin, 2009, p. 57)

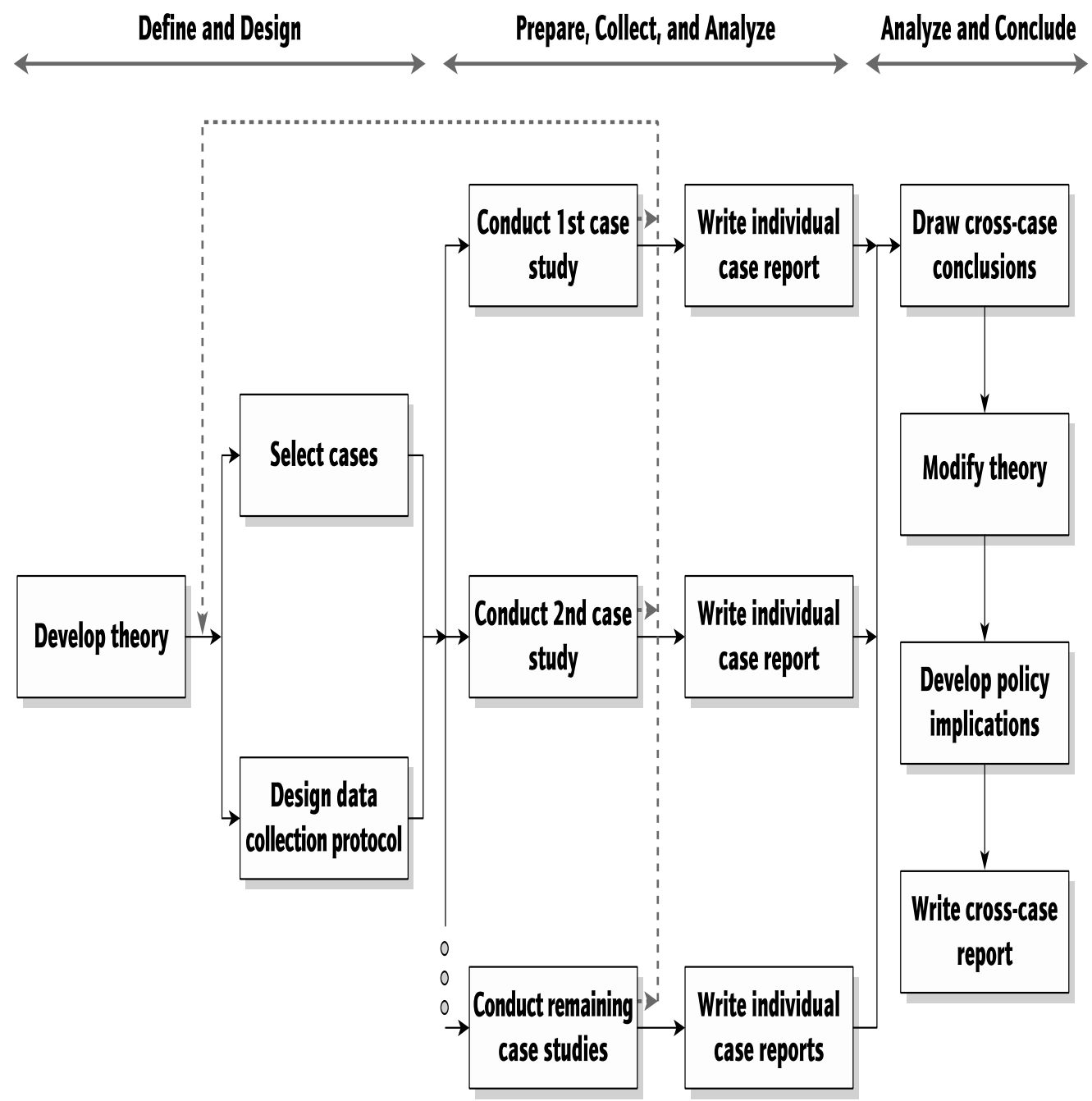

Figure 2.5 Case Study Method

un

SOURCE: COSMOS Corporation. 


\section{Background of the Researcher}

The researcher is a $\mathrm{PhD}$ candidate in curriculum and instruction development who holds a master's degree in business administration and a bachelor's degree in mathematics, both from the University of Denver. I am currently halfway toward finishing a Master's degree in research methods and statistics. I am a Chinese female who grew up in Taipei, Taiwan, R.O.C. and came to United States 30 years ago to pursuit postsecondary education. I have worked in investment management, international business consulting, and media production for over twenty years. My professional demands and family background have also taken me to 16 countries and about 200 cities over the last 30 years.

In the spring of 2008, the beginning of the global financial meltdown, I was teaching college classes on capital markets and financial institutions. Many textbooks became outdated overnight, I was forced to rewrite our curriculum pending daily events as the quarter progressed. In response to the subsequent global financial institutions’ crises and increasing international student enrollment, I designed and completed with three other faculty members four grants using multimedia and technology to integrate real-world cases in curricula for the Reiman School of Finance at the University of Denver. Both personally and professionally, it has been extremely important for me to be able to communicate real-time events and share knowledge by transcending the limitations of time and space.

Both of my parents are teachers. My father was a music professor who was very knowledgeable about world history and my mother was a high school history teacher who is a great vocalist and sings the national anthem at baseball opening 
days. I learned early in life that we can always learn more and do better with ourselves for the finite amount of time we have on earth. It is with this personal philosophy that I have been an advocate for utilizing technology effectively and efficiently to enrich learning, for not only students in school, but also students in life.

My husband, a seasoned professor in law, accounting and business ethics, has always been an early adopter (Fetters \& Duby, 2012) of technology throughout his professional practice and in his day-to-day teaching. As a movie buff, he utilizes movie clips when training lawyers and accountants on how to identify questionable professional practices. He inspires me to think beyond the confines of traditional academia and look for ways to share our professional knowledge from "knowing what" to "knowing how" (Margetson, 1991) with our audience.

I recently completed an evaluation of its online faculty development program for the Office of Teaching and Learning (OTL) at the University of Denver. The evaluation report was posted on the OTL portfolio site as a resource for the university online teaching community. During the course of evaluating the online faculty development program, I became aware of the many obstacles on the road to teaching online, for both the faculty developers conducting the training and the faculty members participated in the training programs. While teaching online does not present the same level of difficulty as climbing Mount Everest, for the majority of the faculty members who completed the teaching online workshops (TOW), knowing what road to take to teach online still does not translate directly into knowing how to actually teach online. For the rest of the faculty body, there is no urgency or motivation to transition into teaching online, since it is not a job requirement nor does 
the current appointment, promotion, and tenure structure take efforts in teaching online into consideration. The challenge for the institution is to know how to encourage more faculty members to teach online in the increasingly technology enabled future.

\section{University of Denver}

The University of Denver (DU) is the oldest and largest private university in the Rocky Mountain region. Current enrollment consists of approximately 11,600 students with about 5,000 undergraduate students and 6,600 graduate students. The Carnegie Foundation classifies DU as a doctoral/research University with high research activity. With the exception of University College (one of the colleges within DU) that has been offering online degree programs for non-traditional students for the last decade, DU is primarily a brick and mortar residential university with primarily traditional and a small number of blended courses.

\section{The Office of Teaching and Learning (OTL)}

Formerly Center of Teaching and Learning (CTL) is the in-house university faculty development center. The OTL supports the faculty learning management system (LMS, primarily Blackboard) training and support. In recent years, discussions of technology utilization in teaching and learning have become more prevalent in university meetings. Most of those discussions are coordinated and led by the OTL. 
With regard to online course development, the OTL works closely with the university's Distance Learning Council (DLC). According to the OTL website link to the DLC, the general understanding of online courses is that "Individual courses need not be formally reviewed by the Distance Learning Council, but should be approved by the appropriate person in the department, division, school, or college and include consultation with the online learning team in the Office of Teaching \& Learning. Online instructors must complete the OTL's Teaching Online Workshop before teaching an online course.“ However, no formal procedure is currently in place to ensure all online instructors have completed the Teaching Online Workshop (TOW) prior to offering online courses.

The institutional purpose of the online faculty development program is to identify and train faculty members in order to offer online courses, with an initial emphasis on increasing the availability of undergraduate online courses during summer quarters. In addition, the university intends to increase technology utilization for all courses during regular academic year. The stakeholders for the online faculty development program include the OTL, faculty participants, students, and program/college/university administrators.

Based on interviews with the OTL staff, about $49 \%$ of undergraduate students are out-of-state students, and so providing online courses will ensure consistency of the quality of their curriculum when they are not on campus. The OTL has established its online faculty development program partly based on the Sloan-C 5 
pillars $^{2}$ quality framework (Table 3), with goal, process/practice, sample metric, and progress indices along each pillar listed here:

1. Learning effectiveness

2. Scale (cost effectiveness and commitment)

3. Access

4. Faculty satisfaction

5. Student satisfaction

There is no emphasis on particular academic disciplines, nor is scale part of the university administrative consideration for the number of online courses offered at the early stages of online faculty development. The remaining three pillars: learning effectiveness, faculty satisfaction, and student satisfaction are concerns that are the same as with traditional face-to-face courses. Therefore, DU, through the OTL, intends to provide training to help existing traditional course faculty members to design, develop, transform, and teach online courses.

\section{Definition of Terms Used}

\section{The Sloan Consortium}

Sloan Consortium (Sloan-C hereafter) is the leading organization on online learning currently. Sloan-C offers online faculty development courses for instructors, faculty training developers, and administrators in higher education. Since 2002, Sloan-C has conducted annual surveys in the state of online education in higher

\footnotetext{
${ }^{2}$ http://sloanconsortium.org/5pillars
} 
education in the United States. Sloan-C subsequently developed the five-pillar quality framework as a rubric for institutional online concerns. The five pillars are listed below (in Table 3).

Table 3. The 5 Pillars.

SLOAN-C QUALITY FRAMEWORK

\begin{tabular}{|c|c|c|c|}
\hline Goal & Process/Practice & Sample Metric & $\begin{array}{l}\text { Progress } \\
\text { Indices }\end{array}$ \\
\hline \multicolumn{4}{|c|}{ LEARNING EFFECTIVENESS } \\
\hline $\begin{array}{l}\text { The provider } \\
\text { demonstrates that } \\
\text { online learning } \\
\text { outcomes meet or } \\
\text { exceed institutional, } \\
\text { industry, and/or } \\
\text { community } \\
\text { standards }\end{array}$ & $\begin{array}{l}\text { Academic integrity } \\
\text { and control reside } \\
\text { with faculty in the } \\
\text { same way as in } \\
\text { traditional program } \\
\mathrm{s} \text { at the provider } \\
\text { institution or } \\
\text { organization }\end{array}$ & $\begin{array}{l}\text { Faculty perception surveys } \\
\text { or sampled interviews } \\
\text { compare learning } \\
\text { effectiveness in delivery } \\
\text { modes } \\
\text { Learner/graduate/employer } \\
\text { focus groups or interviews } \\
\text { measure learning gains }\end{array}$ & $\begin{array}{l}\text { Faculty } \\
\text { report } \\
\text { online } \\
\text { learning is } \\
\text { equivalent } \\
\text { or better } \\
\text { Direct } \\
\text { assessment } \\
\text { of student } \\
\text { learning is } \\
\text { equivalent } \\
\text { or better }\end{array}$ \\
\hline \multicolumn{4}{|c|}{ SCALE (COST EFFECTIVENESS AND COMMITMENT) } \\
\hline $\begin{array}{l}\text { The provider } \\
\text { continuously } \\
\text { improves services } \\
\text { while reducing } \\
\text { costs }\end{array}$ & $\begin{array}{l}\text { The provider } \\
\text { demonstrates } \\
\text { financial and } \\
\text { technical } \\
\text { commitment to its } \\
\text { online programs } \\
\text { Tuition rates } \\
\text { provide a fair return } \\
\text { to the provider and } \\
\text { best value to } \\
\text { learners at the same }\end{array}$ & $\begin{array}{l}\text { Institutional and } \\
\text { organizational } \\
\text { stakeholders show support } \\
\text { for participation in online } \\
\text { education } \\
\text { Effective practices are } \\
\text { identified and } \\
\text { implemented }\end{array}$ & $\begin{array}{l}\text { The } \\
\text { provider } \\
\text { sustains the } \\
\text { program, } \\
\text { expands and } \\
\text { scales } \\
\text { upward as } \\
\text { desired, } \\
\text { strengthens } \\
\text { and } \\
\text { disseminate } \\
\text { s its mission }\end{array}$ \\
\hline
\end{tabular}




\begin{tabular}{|c|c|c|c|}
\hline & $\begin{array}{l}\text { time } \\
\text { Tuition rates are } \\
\text { equivalent or less } \\
\text { than on-campus } \\
\text { tuition }\end{array}$ & & $\begin{array}{l}\text { and core } \\
\text { values throu } \\
\text { gh online } \\
\text { education }\end{array}$ \\
\hline \multicolumn{4}{|c|}{ ACCESS } \\
\hline $\begin{array}{l}\text { All learners who } \\
\text { wish to learn online } \\
\text { can access learning } \\
\text { in a wide array of } \\
\text { programs \& courses }\end{array}$ & $\begin{array}{l}\text { Program entry } \\
\text { processes inform } \\
\text { learners of } \\
\text { opportunities, and } \\
\text { ensure that } \\
\text { qualified, motivated } \\
\text { learners have } \\
\text { reliable access } \\
\text { Integrated support } \\
\text { services are } \\
\text { available online to } \\
\text { learners }\end{array}$ & $\begin{array}{l}\text { Administrative and } \\
\text { technical infrastructure } \\
\text { provides access to all } \\
\text { prospective and enrolled } \\
\text { learners } \\
\text { Quality metrics for } \\
\text { information dissemination; } \\
\text { learning resources } \\
\text { delivery; } \\
\text { and tutoring services }\end{array}$ & $\begin{array}{l}\text { Qualitative } \\
\text { indicators } \\
\text { show } \\
\text { continuous } \\
\text { improveme } \\
\text { nt in growth } \\
\text { and } \\
\text { effectivenes } \\
\text { s rates }\end{array}$ \\
\hline \multicolumn{4}{|c|}{ FACULTY SATISFACTION } \\
\hline $\begin{array}{l}\text { Faculty are pleased } \\
\text { with teaching } \\
\text { online, citing } \\
\text { appreciation and } \\
\text { happiness }\end{array}$ & $\begin{array}{l}\text { Process to ensure } \\
\text { faculty participation } \\
\text { in matters particular } \\
\text { to online education } \\
\text { (e.g. governance, } \\
\text { intellectual } \\
\text { property, and } \\
\text { royalty sharing) } \\
\text { Process to ensure } \\
\text { adequate support } \\
\text { for faculty in course } \\
\text { preparation and } \\
\text { course delivery }\end{array}$ & 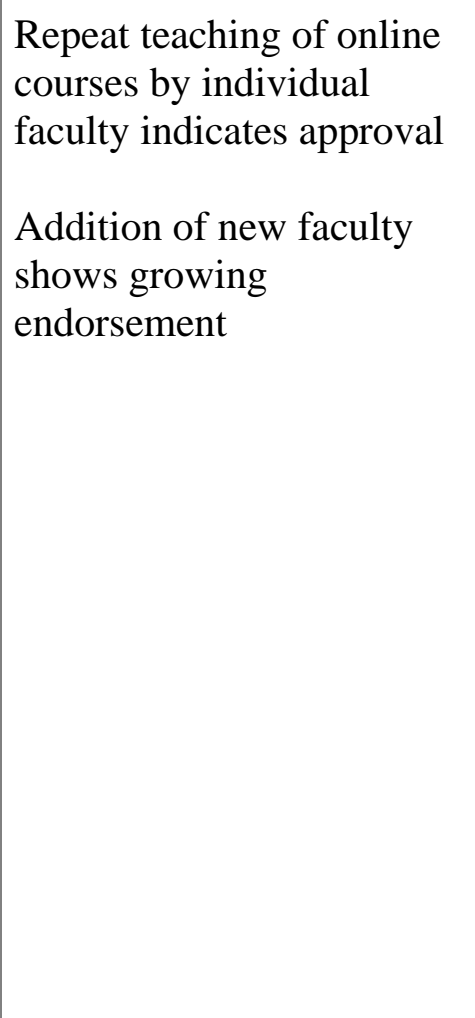 & $\begin{array}{l}\text { Data from } \\
\text { post-course } \\
\text { surveys } \\
\text { show } \\
\text { continuous } \\
\text { improveme } \\
\text { nt: } \\
\text { At least } \\
\text { 90\% of } \\
\text { faculty } \\
\text { believe the } \\
\text { overall } \\
\text { online } \\
\text { teaching/lea } \\
\text { rning } \\
\text { experience } \\
\text { is positive } \\
\text { Willingness } \\
\text { /desire to }\end{array}$ \\
\hline
\end{tabular}




\begin{tabular}{|c|c|c|c|}
\hline & & & $\begin{array}{l}\text { teach } \\
\text { additional } \\
\text { courses in } \\
\text { the } \\
\text { program: } 8 \\
\text { 0\% positive }\end{array}$ \\
\hline \multicolumn{4}{|c|}{ STUDENT SATISFACTION } \\
\hline $\begin{array}{l}\text { Students are } \\
\text { pleased with their } \\
\text { experiences in } \\
\text { learning online, } \\
\text { including } \\
\text { interaction with } \\
\text { instructors and } \\
\text { peers, learning } \\
\text { outcomes that } \\
\text { match expectations, } \\
\text { services, and } \\
\text { orientation }\end{array}$ & $\begin{array}{l}\text { Faculty/learner } \\
\text { interaction is timely } \\
\text { and substantive } \\
\text { Adequate and fair } \\
\text { systems assess } \\
\text { course learning } \\
\text { objectives; results } \\
\text { are used for } \\
\text { improving learning }\end{array}$ & $\begin{array}{l}\text { Metrics show growing } \\
\text { satisfaction: } \\
\text { Surveys (see above) and/or } \\
\text { interviews } \\
\text { Alumni surveys, referrals, } \\
\text { testimonials } \\
\text { Outcomes measures } \\
\text { Focus groups } \\
\text { Faculty/Mentor/Advisor } \\
\text { perceptions }\end{array}$ & $\begin{array}{l}\text { Satisfaction } \\
\text { measures } \\
\text { show } \\
\text { continuousl } \\
\text { y increasing } \\
\text { improveme } \\
\text { nt } \\
\text { Provider } \\
\text { surveys, } \\
\text { interviews, } \\
\text { or other } \\
\text { metrics sho } \\
\text { w } \\
\text { satisfaction } \\
\text { levels are } \\
\text { equivalent } \\
\text { to or better } \\
\text { than those } \\
\text { of other } \\
\text { delivery } \\
\text { modes for } \\
\text { the provider }\end{array}$ \\
\hline
\end{tabular}

(C) 2012, The Sloan Consortium

\section{Distance Education}

Distance education is a method of teaching where the students and the instructors are separated by time or space, or both. When it comes to defining online learning, multiple iterations evolved from E-learning, distance learning, computer 
assisted learning (CAL), information communication technology (ICT) enabled classroom, computer-supported collaborated learning (CSCL), hybrid/blended learning, to name a few. According to Sloan-C definition, the type of course is classified by the proportion of content delivered online.

Table 4. Sloan-C Definitions of Types of Courses

\section{Definitions*}

\begin{tabular}{|c|l|l|}
\hline $\begin{array}{c}\text { Proportion of } \\
\text { Content } \\
\text { Delivered } \\
\text { Online }\end{array}$ & \multicolumn{1}{|c|}{ Types of Courses } & \multicolumn{1}{c|}{ Typical Description } \\
\hline $0 \%$ & Traditional & $\begin{array}{l}\text { No online technology used, } \\
\text { content delivered in writing } \\
\text { or orally }\end{array}$ \\
\hline $1-29 \%$ & Web Facilitated & $\begin{array}{l}\text { Web-based technology } \\
\text { facilitates f-2-f course } \\
\text { Substantial proportion of } \\
\text { content delivered online } \\
\text { (online discussions, reduced } \\
\text { f-2-f meetings) }\end{array}$ \\
\hline $30-79 \%$ & Blended/Hybrid & $\begin{array}{l}\text { Most or all of the content is } \\
\text { delivered online, few or no } \\
\text { f-2-f meetings }\end{array}$ \\
\hline $80+\%$ & Online &
\end{tabular}

From: http://sloanconsortium.org/publications/survey/pdf/learningondemand.pdf

For the purposes of the University of Denver Distance Learning Council,

"Distance learning is further defined as a formal educational process in which more than half (51\%) of the contact hours occur when student and instructor are not in the same place. Instruction may be synchronous or asynchronous. 
Distance learning may employ any combination of correspondence study, audio, video, or computer and other online technologies.” ${ }^{3}$

However, as part of the study, the researcher asked the individual instructors to clarify their understanding of the definitions of distance learning.

${ }^{3}$ https://portfolio.du.edu/pc/port.detail?id=113516 


\section{Chapter Two: Literature Review}

"Ideals are like stars: You will not succeed in touching them. But like the seafaring man on the desert of waters, you choose them as your guides, and following them you will reach your destiny.” -- Carl Shurz

\section{The Evolution of Distance Education}

Distance education is not a novel concept. The basic concept of distance education is to bring education to students who are not physically able to attend the traditional campus classes due to individual circumstances. During the industrial revolution in the late $19^{\text {th }}$ century, correspondence courses provided access for adult students who would not have had opportunities to receive further education otherwise. In the mid $20^{\text {th }}$ century, with the development of radio, $\mathrm{TV}$, and recording devices, many distance learners were able to see and hear the instructors in their own residences with minimal interruptions to their work or personal lives. With the advancement of information communication technology and the Internet in the late

$20^{\text {th }}$ century and the new millennium, distance education has grown by leaps and bounds as evident in National Center of Educational Statistics (NCES) and Sloan Consortium data showing exponential growth in student enrollment and institutional investment (Allen \& Seaman, 2002-2013; Epper \& Bates, 2001). Distance education 
has and will continue to be an excellent alternative for non-traditional students who are interested in advancing their education without being physically on "campus."

In the recent decade, distance education has come of age. Instead of merely being a device for accommodating non-traditional students, more students in traditional not-for- profit public and private universities are enrolling in online classes both during the academic year and the summer months (Allen \& Seaman, 20022013). On the other hand, academic research on distance education has not shown the same level of progress and development during the same period of time. In other words, there are limited examples in building a theoretical framework in modeling new online courses and programs for traditional not-for-profit universities. Although many postsecondary institutions have a long history of offering online courses and programs, most online programs are typically ad-hoc projects primarily staffed by adjunct and non-tenured instructors and therefore not prominent in the institutional long-term strategies. Frankly, the idea of offering distance (online) education to traditional students throughout the calendar year is quite foreign to the traditional ivory tower mentality. Discussions on why and how traditional faculty members will adjust to this new way of functioning in their profession create fear and excitement in looking into the future of higher education. However, when more than $30 \%$ of students in postsecondary institutions in US (Allen \& Seaman, 2013) have taken at least one course online, the topic of distance education is no longer avoidable in institutional discussions. Many faculty members are finding themselves at the crossroads of either taking the risk by jumping into the cyber frontier or playing safe by shying away from the digital current. 
In addition, the widening gap between institutional expectation and faculty acceptance (Allen \& Seaman, 2013) raises serious concerns about what many postsecondary institutions' futures will look like in the digital age, especially when distance education may dilute the campus experiences so many universities tried so hard to maintain for their students. The usual tendency for academic research is to measure our institutions' programs in comparison to macro trends on distance education or grasp onto the latest online faculty development model in dealing with this industry-wide phenomena. However, I propose we resist those temptations, pause, and first, reflect on the relationship of education and society in the past and now in the digital age; second, examine the concept of living and learning in this new digital age, and finally, contemplate ideas in transforming thinking for postsecondary institutions in institutionalizing their distance education efforts.

\section{The Relationship of Educators, Learners, and Society}

Beyers (2009) argues the Net Generation, born between roughly 1980 and 1994, grew up in an environment very different from their parents and teachers. With the exception of a small percentage of non-traditional students, the Net Generation students have dominated the college campuses since late 1990s. The Net Generation presents different characteristics and values (Prensky, 2001) concerning knowledge in this digital media environment (Tapscott, 1988). Most authors write about the disconnections ${ }^{4}$ between addressing the needs of society versus the needs of learners

\footnotetext{
${ }^{4}$ Wall Street Journal article by Alison Seiffer, October 21, 2008, “The 'Trophy Kids' Go to Work”. “...With Wall Street in turmoil and a financial system in crisis mode, companies are facing another
} 
(Gardener, 2004; Gee, 2011; Halverson, 2008; Trilling \& Fadel, 2009). Few have proposed actual models bridging concerns of all members of society in transforming educational thinking ${ }^{5}$. Beyers, a scientist and scholar from Meraka Institute in South Africa, a young democratic nation motivated to understand the meaning of education in society, articulates the whole human ecology in three simple figures relating to:

(1) the education system, society and the curriculum (Figure 1); (2) a five

dimensional model of education (Figure 2); and (3) moving from a teacher-centered to a learner-centered approach (Figure 3).

Figure 1: The Education System, Society and the Curriculum

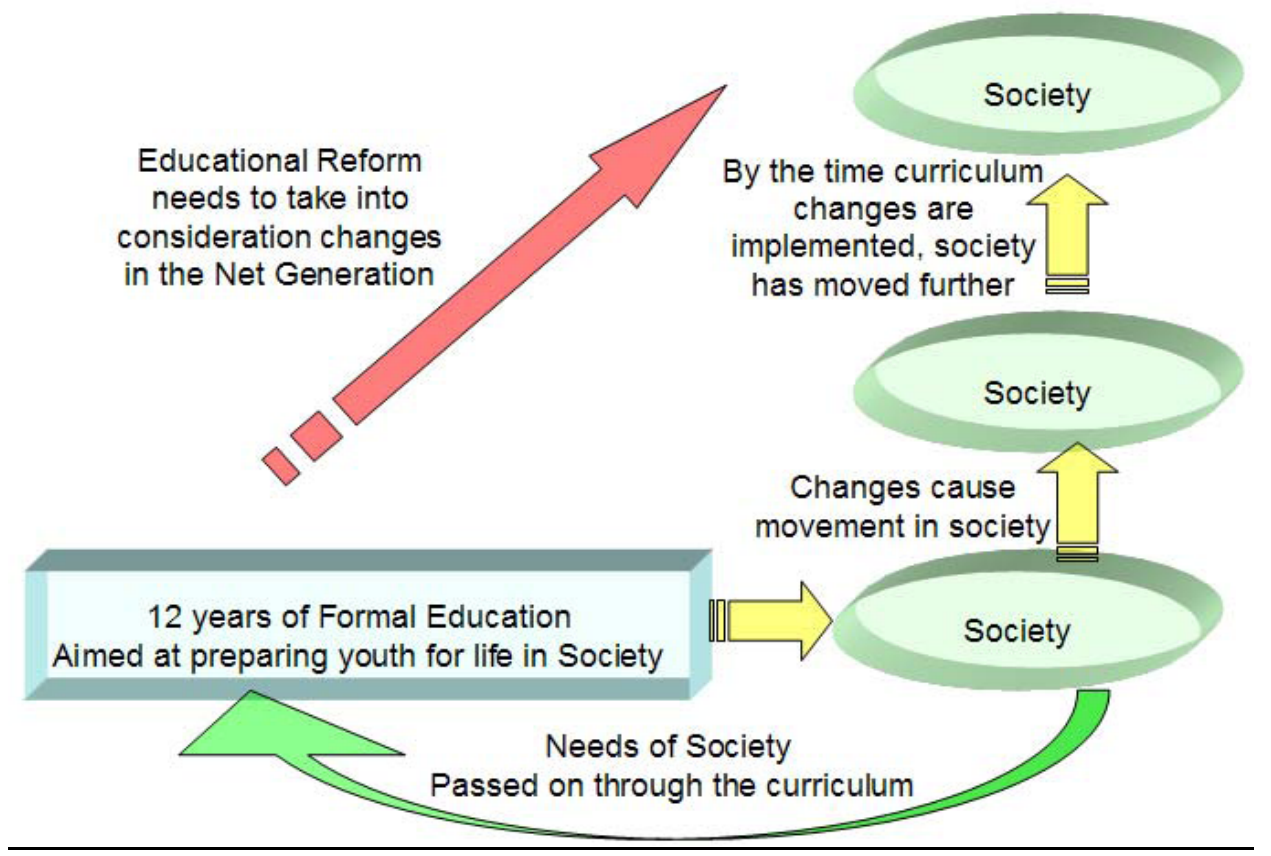

major challenge: figuring out how to manage a new crop of young people in the work force -- the millennial generation. Born between 1980 and 2001, the Millennials were coddled by their parents and nurtured with a strong sense of entitlement...”

${ }^{5}$ In Educational Week article by Stephen Sawchuk, March 2, 2009 article: "Backers of '21 $11^{\text {st }}$-Century Skills' Take Flak.” Diane Ravitch stated: “The same ideas were iterated and reiterated by pedagogues across the $20^{\text {th }}$ century." In the same article, Linda Darling-Hammond from Stanford University said, "We are stuck. ... We've been having this curriculum war for years." 
Figure 2: Five Dimensional Model of Education

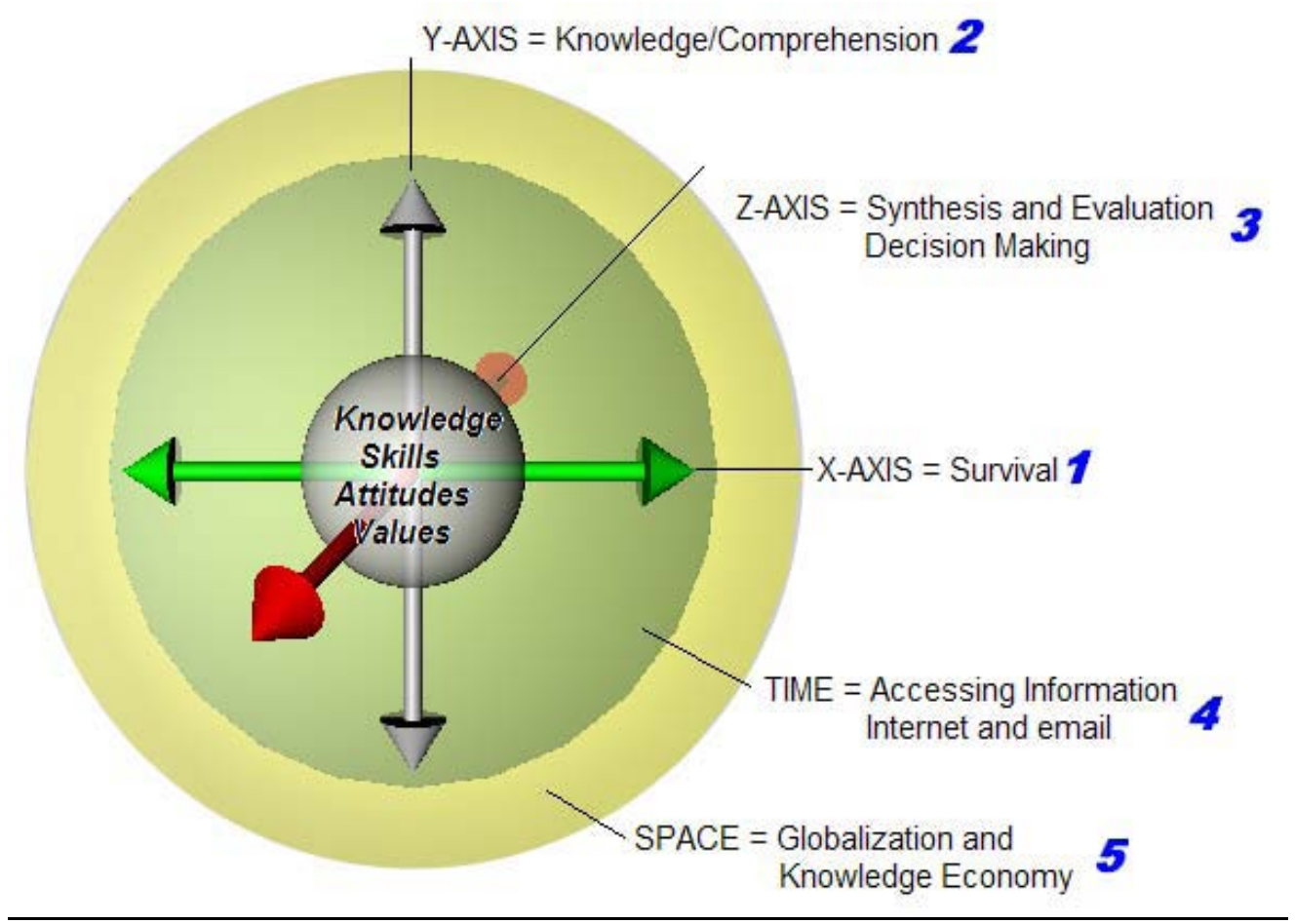

Figure 3: Moving from a Teacher-Centered to a Learner-Centered Approach

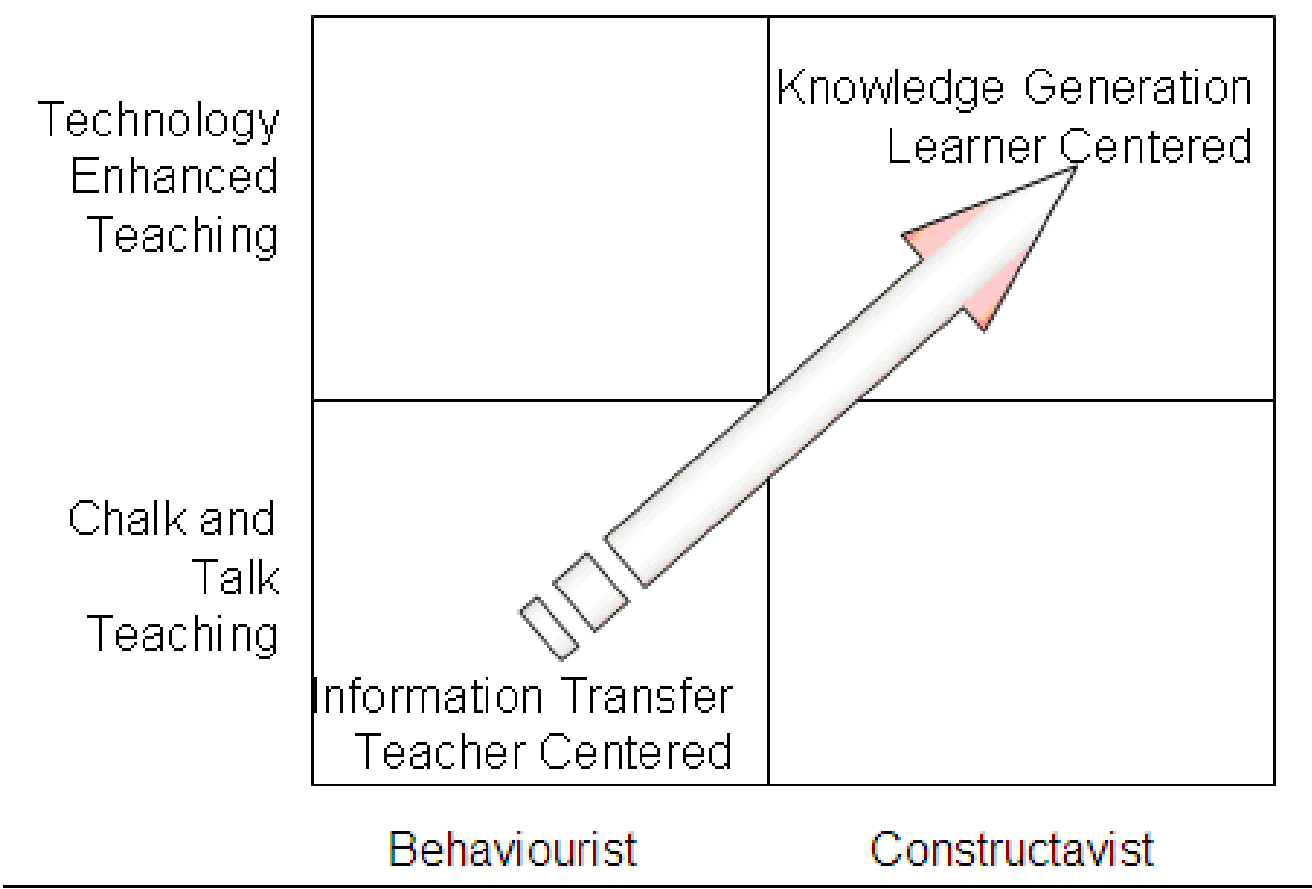


Beyers first addressed the issues facing educators, learners, and society (Bransford, Brown, \& Cocking, 1999). He then proposed a five-dimensional model for the Net Generation (Carlson, 2005) as a conceptual framework with theoretical grounding in constructivism related to knowledge building (Bhattacharya \& Han, 2001). Although not comprehensive in addressing all human needs, Beyers’ five-dimensional model illustrates the contingent concept of knowledge relating to time and space. By elaborating on each dimension and the interdependency among all the dimensions, he broadens the dynamic scope for conceptualizing where we are, where we have been, and where we are going. Beyer's student- centered constructivist learning environment accentuates the essence of learning in the digital age, for both learners and educators.

\section{Living and Learning in The Digital Age}

\section{$\underline{\text { Digital Impacts }}$}

Although the first commercial Internet browser "Netscape” was not available till 1994, Walter B. Wriston in his 1992 book "the Twilight of Sovereignty," predicted that traditional national boundaries become increasingly irrelevant in the information age. When Tom Friedman named his book "the World is Flat" in 2005 to make the point of our inter-connectedness and interdependency, he would never have imagined that "Facebook", a relatively unknown experimental social networking site at the time, would develop into a global social networking community of 1.3 billion 
users as of the beginning of 2013. ${ }^{6}$ Technology has become an integral part of our daily lives.

Dewey (1910) articulated the human interest for "self-realization” is sympathetic, socially and aesthetically sympathetic, rather than cognitive. "This sympathetic interest provides the medium for carrying and binding together what would otherwise be a multitude of items, diverse, disconnected, and of no intellectual use (p.189, Dewey, 1910). As citizens in modern society, we need the ability to process information intelligently, think critically, make informed decisions, and adjust in a timely manner to technological advancement to better our daily functions. Some scholars have argued for " $21^{\text {st }}$ century skills"7 (Trilling \& Fadel, 2009) well before we entered this millennium. Those skills, however they are labeled, are reflections of contemporary societal needs for its members whether those skills are obtained through schooling or not. Maslow's hierarchy of needs further details the human motivation and personal development's intricate interplay within the societal context (1943 \& 1954). It is a fundamental human right ${ }^{8}$ to live one's life to maximize one's potential in any period of time. No one can reach one's full potential without the necessary tools, skills, and knowledge, including the utilization of timely information through the technologies that are available in our daily functions. The impact of information communication technologies (ICT) has and will continue to permeate every aspect of our lives: physically, emotionally, psychologically,

\footnotetext{
${ }^{6}$ Source: WSJ.com

${ }^{7}$ dido note 5

${ }^{8}$ See the UN Declaration of Human Rights Section 22 (right to free development of one's personality) and Section 26 (right to an education).
} 
socially, legally and politically, as Figure 4 illustrates. Learning is not merely an educational issue. It is an issue of survival in the modern society (Carr, 1998). Figure 4. Digital Impacts on Our Lives

\section{Digital Impacts on Our Lives}

physically

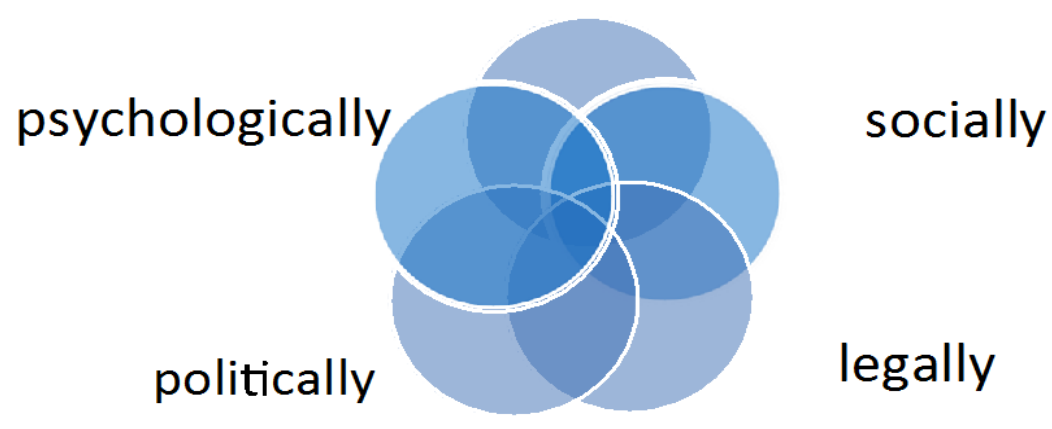

\section{Ubiquitous Learning}

A Chinese proverb said: "we live to old ages and we learn till old ages." However the traditional wisdom of living carries a new meaning in these modern days. As we grow older, we have more demands in our lives. Professors, like students, are no exception in this case. While trying to advance research in their academic disciplines, professors are facing increasing demands of learning to teach online while student demographics are becoming increasingly diverse. We are overwhelmed by new technology and practices but often lack the knowledge or the expertise on how to utilize those technologies and practices in actually teaching and 
learning online in the global context. With the Internet bubbles, the global financial crises, Facebook, and Arab Spring, technologies have created unprecedented chaos but also helped global citizens expose social injustices and greatly promoted our understanding of the world. Learning is no longer confined in an academic environment with the traditional lecture format with the printed textbooks. Learning is ubiquitous (Figure 5).

Figure 5. Ubiquitous Learning

\section{Ubiquitous Learning}

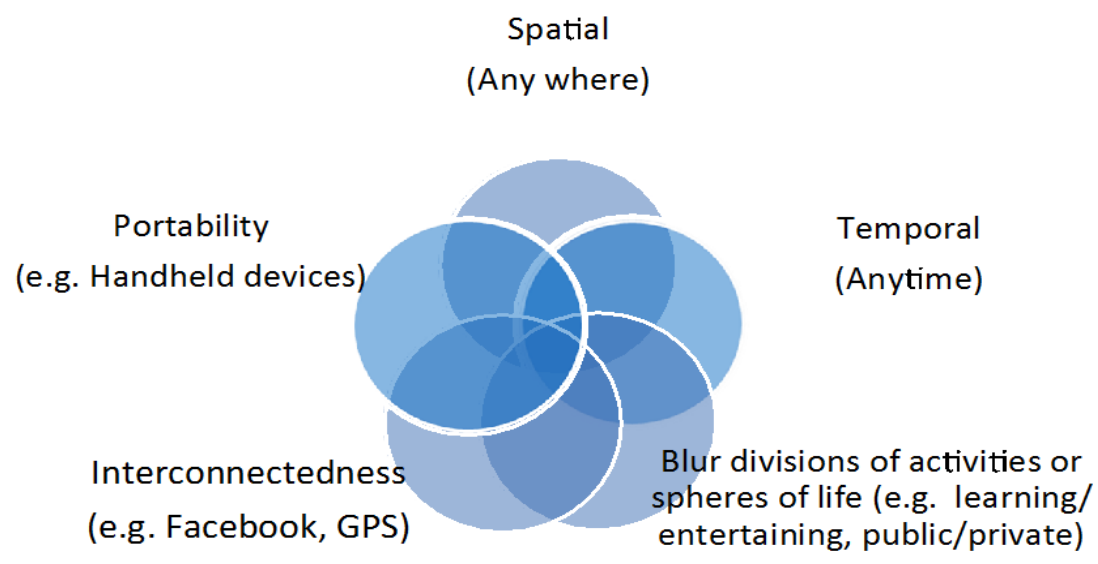

With the newfound power of technology, it also becomes increasingly difficult to distinguish profound truths from pure nuisances. Teachers are expected not only to deliver relevant content, but also act as experienced coaches who can inspire confidence in developing skills and working with others, not only when learners are in school but also throughout their lives. John Dewey (1938) cautioned 
"perhaps the greatest of all pedagogical fallacies is the notion that a person learns only that particular thing he is studying at the time. Collateral learning in the way of formation of enduring attitudes, of likes and dislikes, may be and often is much more important than the spelling lesson in geography or history that is learned. For these attitudes are fundamentally what count in the future” (p. 48).

The ultimate goal of utilizing technology for online and hybrid classes is and should be to enhance students' educational experiences. With the global economy we live in, what are the most effective ways to stimulate changes in our postsecondary institutions so that technology will aid both the educators and the learners in fulfilling their potential? How do educators transcend the limitation of time and space of traditional classrooms by integrating teaching and learning digitally? Dewey (1938) believed that educators could not teach students what they learn. We can only provide the conditions in which they learn through their own experience. Further research is much needed on ways of improving student learning through multimodal literacies afforded by technology. Further literature review and comparisons across disciplines in ICT-enabled learning could provide inspiration in future research designs and shed some light on other implications.

\section{New Literacy}

Eisner states that "meaning is not simply found; it is constructed" (1994, p.x). Eisner argues that cognition and curriculum are dynamically interactive on a continuous cycle for the learner and that "the ability to 'encode' and 'decode' the 
meanings construed from different forms of representation requires a form of literacy. Not literacy in the literal sense, but literacy in the metaphorical sense” (1994, p.x).

In our daily lives we are bombarded by new multiple interpretations in multiple media formats through multiple delivery methods. Content and delivery methods not only change how we receive information, but also how we process, interpret, and utilize that information. The continuous transactions and negotiations between the learners and the environment enable the learners to construct new (and/or deconstruct old) meanings of oneself and the relationships with one's environment. In addition, modern learning enabled by multimedia technology represents a fundamental change of curriculum development from $20^{\text {th }}$ century teaching from a book and corresponding lecture in class, to a $21^{\text {st }}$ century approach involving active and cooperative learning (Dede, 2008). Steven Johnson, a popular science author and a Distinguished Writer in Residence in New York University, in his book "Everything Bad is Good for You” (2005) articulated the differences between traditional medium and other media. (Table 5)

Johnson states (2005) that purposefully enriching students' learning by utilizing those new media and delivery formats will not only enhance learner outcomes, but also further the value of their education in their professional lives. Johnson's list is not necessarily consistent or comprehensive from the educational literacy experts' point of view. However, the comparisons between traditional print medium and other media do provide inspiration for future research in multi-modal 
learning, multiple-intelligence (Gardener, 2006) and multiple-sensory e-learning environment.

Table 5. Traditional Medium vs. Other Media

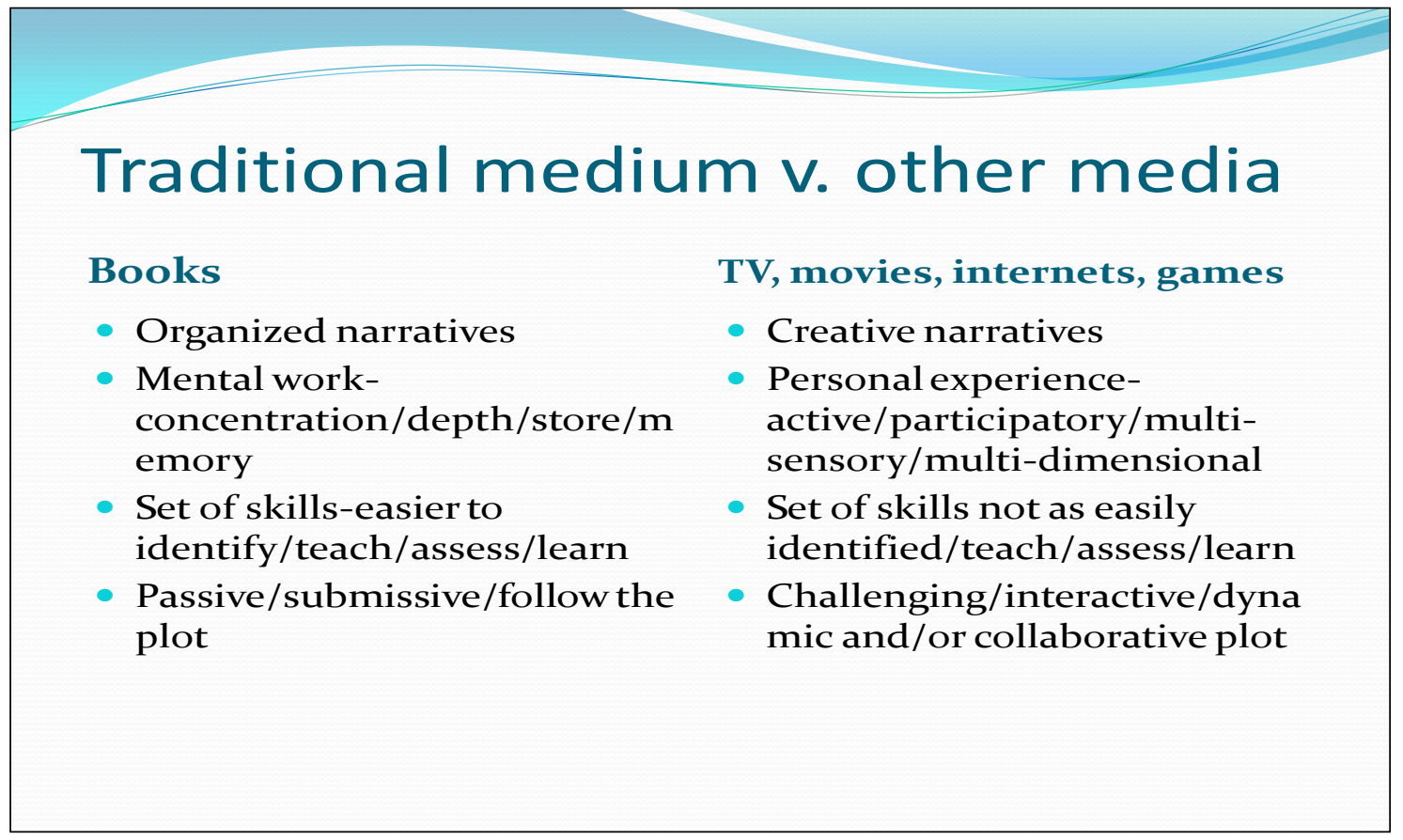

Curtis Bonk, a former CPA and now an educational scholar has published over 225 articles and books on using technologies for learning. In his book "The World Is Open,” Bonk (2009) suggested ten key trends that make up the "WE-ALLLEARN" framework for understanding the impact of technology on learning in the $21^{\text {st }}$ century. Collins and Halverson suggest the seeds for a new system of education with new "learner-oriented understanding of knowledge acquisition (2010, p.24.)" Leu, Kinzer, Coire, and Cammack (2004) state:

"The new literacies of the Internet and other ICTs, include the skills, strategies, and dispositions necessary to successfully use and adapt to the rapidly changing information and communication technologies and contexts 
that continuously emerge in our world and influence all areas of our personal and professional lives...(p.1572)”

further illustrate the interconnectivity of new literacy to our day-to-day learning. Technology has and is changing how we interact, socialize, and function locally and globally. It is a reality, not an assumption. Postsecondary institutions are not immune to this global social transformation.

\section{Promise and Perils in Reconceptualizing Education in The Digital Age}

In reviewing recent educational history in our societal context, traditional schools rose from the need for skilled workers stemming from the industrial revolution. A post-modern economy is based on the efficiency and effectiveness of services that compete for resources and logistics on a real-time basis on a global scale. Peter Drucker coined the term "knowledge worker” in 1959, envisioning a society in which ordinary people "do not earn their daily bread by the sweat of their brow," and "honest work does not mean a callused hand.” Modern society demands that its workers can functionally synthesize and apply information in this ICT (Information Communication Technologies) enabled global environment (Cogburn, 1998).

For centuries, postsecondary institutions have been the depository of knowledge. It was a sanctuary where scholars shared their knowledge with an elite audience within the boundaries of academe. The difference now is that instead of going to college to get education, the education can come to you through utilization of technology with or without academic endorsement, as evidenced by the popularity

of MOOCs (Massive Online Open Courses.) A recent news article reported Coursera, 
the California company that offers free college classes online, is forming partnerships with 10 large public university systems and public flagship universities to create courses that students can take for credit, either fully online or with classroom sessions. ${ }^{9}$ The new knowledge-based economy promotes unprecedented social mobility but has also continued to distort the traditional boundary marking formal education and informal education. While traditional education is primarily based on knowledge comprehension for the acquisition of basic skills during the formal education years in a sheltered academic setting, modern society members need to continually direct, develop, and apply their own lifelong learning in an open virtual environment (Miller 2000). Formal and informal education, both parts of one's successful lifelong knowledge acquisition process increasingly depend on the effective utilization of technologies.

In addition, college degrees are no longer the terminal degree for the average "knowledge workers" while they advance in their careers. College degrees do not necessarily equate to professional expertise when people change professions either. Postsecondary institutions are not only preparing students entering the workplace, but also serving as refueling stations for professionals to renew and fulfill their needs for knowledge throughout their careers. Increasing costs of college tuition also means fewer and fewer students can afford their education without working either part-time or even full-time while pursuing their education. Both the tangible and intangible

\footnotetext{
9 “Universities Team With Online Course Provider”, New York Times, May 30 2013. http://www.nytimes.com/2013/05/30/education/universities-team-with-online-courseprovider.html?emc $=$ eta1
} 
boundaries of ivory towers have analogously become as increasingly irrelevant as Wriston’s (1992) prediction for national boundaries. Postsecondary education institutions need to ask themselves whether their programs are preparing their students in making the transition into and continuing to excel in their professional lives in this new digital world. As the Millennials ${ }^{10}$ go to college (Carlson, 2005) and go on with their careers including the teaching profession, two notable considerations comes to mind in reconstructing the future of higher education in this age of social transformation: first, the rate of change is unprecedented; second, this transformation is no longer containable within the United States anymore--it demands engagement on a global scale.

While education and technology become increasingly interdependent in our modern existence and despite of all the ensuing challenges and concerns, the majority of faculty members in postsecondary institutions have been steadfast in maintaining the traditional way of teaching (Allen \& Seaman, 2002-2013). As I review those Sloan annual reports again, I can’t help but recognize the resemblance of our present day circumstances as described in Spencer Johnson’s (1998) book “Who moved my cheese?” In Johnson's (1998) parable, four main characters depicted the different reactions and subsequent behavioral patterns when dealing with change - the disappearance of "the cheese" in their maze. Two little mice named "Sniff," who sniffs out change early, and "Scurry," who scurries into action; along with two miniature humans named "Hem," who denies and resists change as he fears it will lead to something worse, and "Haw," who learns to adapt in time when he sees

${ }^{10}$ Dido, note 4 
changing leads to something better. "Teaching and learning," the bread and butter in higher education, is analogously "the cheese" in Johnson's story. Especially for the people working in the higher learning institutions, I though it would be worthwhile to share "the handwriting on the wall" (p.74) in Johnson's book:

1. Change Happens --- They Keep Moving The Cheese

2. Anticipate Change --- Get Ready For The Cheese To Move

3. Monitor Change --- Smell The Cheese Often So You Know When It Is Getting Old

4. Adapt To Change Quickly --- The Quicker You Let Go Of Old Cheese, The Sooner You Can Enjoy New Cheese

5. Change --- Move With The Cheese

6. Enjoy Change! --- Savor The Adventure And Enjoy The Taste Of New Cheese!

7. Be Ready To Change Quickly And Enjoy It Again \& Again--- They Keep Moving The Cheese.

Complex adoptive systems theory (CAS) (Olsen \& Eoyang, 2001) provides the theoretical framework for examining the organizational transformation at the micro level by categorizing the influences resulting in individual changes in three areas: organizational environment, individual differences, and transformation exchanges. And thus conceptualizes how organizations transform themselves through emerging behavioral patterns and shared values of those "change agents." On the other hand, Spencer Johnson’s (1998) book lends a different lens in looking at the different behavioral patterns of its members within the organization when describing the organization as a whole in its larger macro societal context. Johnson (1998) implies 
that the individuals and the organizations with members most ready to adapt to larger macro changes will survive and thrive in the future.

Further, Herda (1999) describes the concept of transformative social change, when she credits language with a "generative role in enabling us to create and acknowledge meaning as we engage in discourse and fulfill social obligations... (that) are characterized as moral activities” (p.24). Campbell and her colleagues (Campbell, Schwier, \& Kenny, 2009) propose a multivariate agentic model (in Figure 6) as a way to understand the narratives of instructional designers in higher education. This multivariate model (Campbell, et. al, 2009) incorporates four types of agency: interpersonal, professional, institutional, and societal agency, interacting with the fundamental "zone of moral coherence" on the small (micro), intermediate (meso), and large (macro) levels. Similarly, complex adoptive systems theory argues that there is no single source of change causing the emergences of changed behaviors and shared values at the individual (micro) level. This emerging model, like complex adoptive system, is also dynamic and fluid. It also incorporates the intentional dimensions and operational dimensions at the center of the zone of moral coherence, which implies individual intrinsic and extrinsic motivations in actualizing intentions into operations. By adding societal agency in this emerging model, Campbell and her colleagues complement both CAS and Johnson's concept of change. Although this emerging model was constructed as a way to analyze the narratives of instructional designers in higher education, by incorporating the societal agency consideration into the discourse around online learning in higher education, it helps to facilitate discussions for all members of society. 
Figure 6. An Emerging Model of Change Agency in Instructional Design

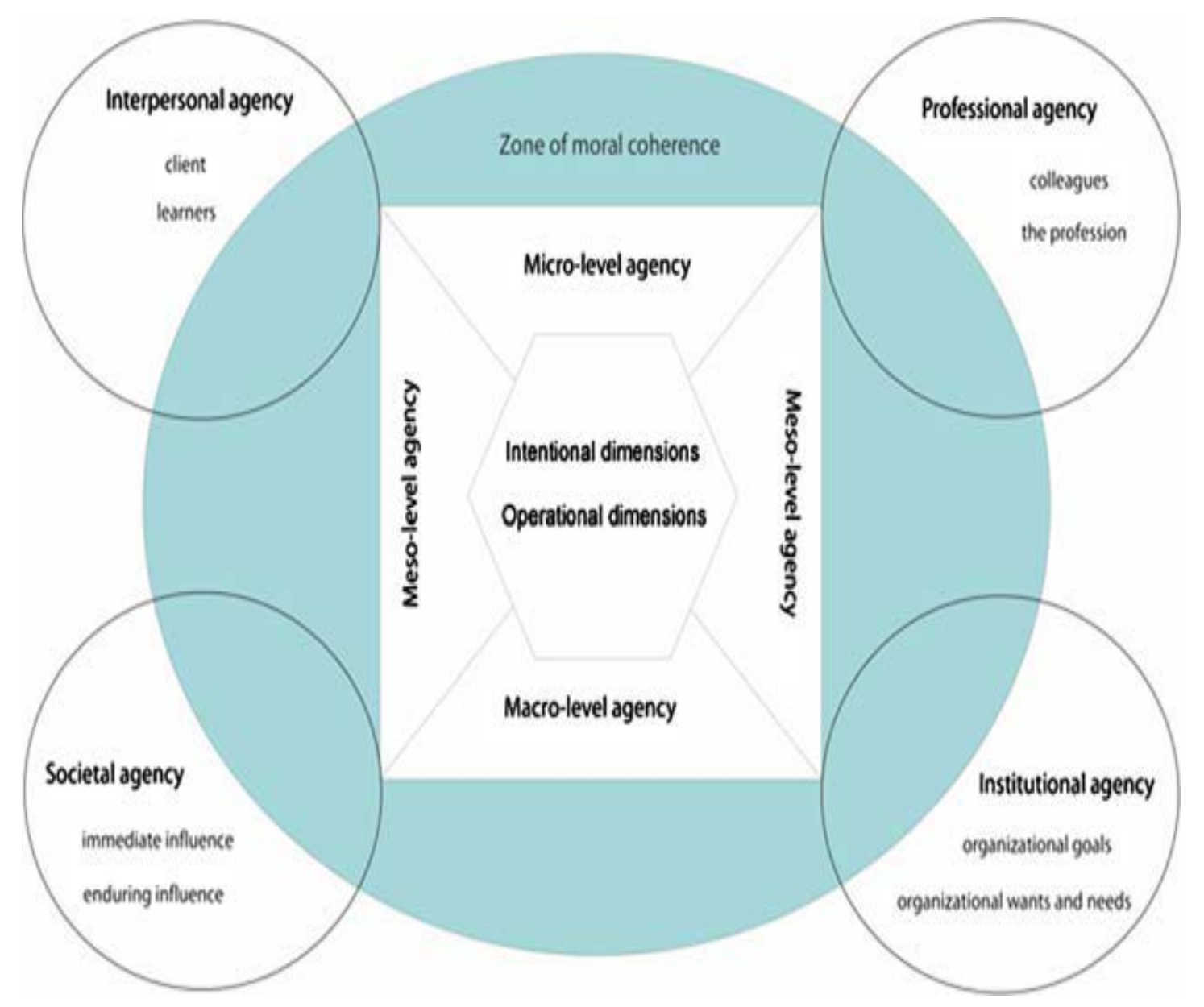

(Adopted from p.649, Campbell, et al., 2009).

Collins and Halverson (2010) in "The Second Educational Revolution: rethinking education in the age of technology” highlight and elaborate the incompatibilities between traditional education and information technologies. Christensen and Eyring (2011) suggest that innovative universities will come about only by changing the DNA of higher education from the inside out through nothing short of genetic reengineering. Let's put aside for a moment the debate between 
“schooling” and “education” (Dewey, 1938; Gardner, 1994, 2004; Gee, 2008;

Johnson, 2005). Technology is a means to the end not the end in itself in achieving our goals. Thus, technology is a means to the end to help learners in developing their skills and knowledge in making a difference in their lives. Before we can tackle those issues within the educational system, we as educators must reexamine our own understanding of fundamental changes in the digital age in the broader concept of human lives. The traditional ivory tower model of lecturing in an auditorium full of students using printed textbooks is simply not how we learn, live, and work today. Since it is unlikely we will ever go back to the old way of learning, the question is what are postsecondary institutions doing today to prepare for tomorrow?

Many experts are eager to dive into debates on issues involving: "What are the considerations for thinking about learning in this digital age? What will be our roles as educators in this learning environment? If technology is changing the definition of "classroom," shall we as educators freshly examine our own ways of teaching and learning? How has and will ICT-enabled curricula and pedagogies change our postsecondary institutions?” I believe before we leap yet again to tackle those issues within our specialized disciplines, we need to take a step back and consider the broader perspective on not only how technology impacts how we learn within the formal education setting, but also how we utilize technology in our lives to achieve lifelong learning. These current conversations primarily deal with existing policies, practices, and issues within the postsecondary educational system. Rather than consider the promise of technologies in fulfilling human potential through our lives, 
the peril is to accept and engage in the conventional way of thinking about using technologies in the classroom.

Technologically, there is no limit on what we can offer as the interactive, collaborative and learner-centered learning environment to improve lifelong learning. As a society, how we leverage our efforts to overcome the aforementioned systemic issues will determine how technology fulfills its promise not only in education, but also in our lives.

\section{Issues in Distance Education Research}

\section{Challenges}

While utilizing information communication technologies (ICT) in education brings promise to enhance student learning (Burbules, 2008; Dede, 2008), there are several challenges in reviewing the current academic literature. (Although I personally believe the typical lag time between research and publication in academic journals is a gesture of defiance in the digital age, I was able to use technology to locate most publications online.)

Regarding the first challenge, there are no set "academic" definitions in the use of terms in distance education. For example, the terms may include: web-based instruction, online teaching/learning, ICT enabled instructions, distance education, instructional technology, cyber space learning, E-learning, virtual learning, computer assisted learning (CAL), computer supported collaborated learning (CSCL), multimedia literacy, multi modality instruction, distributed learning, instructional design, educational technologies, and etc. The problem of a lack of definition was 
summarized in the review of research on teaching courses online (Tallent-Runnels et al, 2006.) Among postsecondary institutions, there is inconsistency in defining what qualifies as an "online" course. Although the Sloan Consortium defines types of courses based on the proportion of content delivered online (see Table 4, p.23 in chapter 1), not all faculty members can clearly define what percentage of their courses are truly considered online.

Second, there is a shortage of research dealing with teaching online or student outcomes especially in the higher education environment. In the limited available literature, additional issues arise involving student learning (Dey et al, 2009), student motivation (ChanLin, 2009), student experiences (Endres, 2009), multimedia learning (Mayer, 2001), factors influencing end users acceptance of knowledge management systems (Xu \& Quaddus, 2007), the relationship of key aspects of e-learning and student learning experiences (Ellis, Ginns \& Piggott, 2009), using self-direction, metacognition, and collaborative in transforming learning in online settings (Boyer, Maher \& Kirkman, 2006), changes in teacher-student relationship by technology (McGrath, 1998), the relationship of online course assessment practice and cognitive learning strategies (Arend, 2006), content knowledge versus pedagogical knowledge (Halverson \& Clifford, 2006), faculty motivation (Hall \& Elliot, 2003; Wolcott, 2003), teachers' attitudes toward information and communication technology (Albirini, 2006), management and assessment issues (Khan, 2005), and the role of instructional designers in transforming the learning system (Campbell, Schwier, \& Kenny, 2009). The use of technology (e.g., the Internet) as a research tool has also brought on more questions with regards to the perception of computers and the World 
Wide Web (Liaw, 2002). The lack of a coherent theoretical framework in this (cyber) space further execrates difficulties in conceptualizing research design.

Third, research using qualitative or mixed-methods on curriculum development using multimedia and online Web 2.0 tools is in short supply. Of the existing literature, the research scope tends to focus quantitatively on a narrow set of learning outcomes using specific technologies (e.g. Blackboard, Wiki, Blogs) in specific academic disciplines within a specified course or (virtual or hybrid) classroom, or a specific pilot project. The inconsistences in identifying the unit of analysis has not helped facilitate research in online teaching within or beyond the particular academic discipline or the specific (virtual or hybrid) classroom or project.

Fourth, distance education was never the focus for the traditional higher educational system. The explosive social transformation enabled by ICT in recent years has really caught many higher learning institutions and its faculty members by surprise. At the same time, postsecondary institutions have been facing increasing competition from both traditional not-for-profit universities with better online offerings and for-profit universities focusing on online degrees (Farrington \& Yoshida, 2000). The uncertainty of online learning, as part of a traditional institution's mission within each postsecondary institution certainly does not make research in this new (cyber) space a priority in the traditional mode of scholarship at many institutions. In addition, although the job description of what constitutes the professorate has evolved over the last few decades, the academic reward structure for appointment, tenure, and promotion has not. This possibly could also explain the lack 
of advocacy and scant contribution from the faculty point of view in the existing literature.

Fifth, most literature and faculty development models in the online space are conducted either from students' point of view or the institutions' point of view. Rarely are from the faculty members’ point of view.

Implications

Additional questions come to mind during the literature review, some of which may have further implications in future research including:

- Whether positive learner experience increased from text-lecture driven classroom to virtual classroom?

- What are learners’ perceptions on whether online learning environment enhance their learning?

- Whether online student learning outcomes differ from face-to-face classroom students?

- How do postsecondary institutions measure online learning outcomes?

- How do postsecondary institutions evaluate online teaching?

Online teaching and learning has and will increasingly challenge the limitations of traditional modes of scholarship. In short, the societal demand for distance education has evolved while the research on distance education remains diverse and unwieldy. New conceptual frameworks and research methodologies are needed for research in this erratically charted frontier. Wider adoption of a working 
definition will certainly help to ease the struggle and inject some momentum in streamlining research in the area. With all the intellectual powers in academe, the institutions that are able to successfully develop research and apply technology in online teaching and learning to further the institutional mission will likely ensure the institution's survival in the digital age.

\section{Examples of Current Practice}

Pragmatists John Dewey and C.S. Peirce first introduced the community of inquiry (C of I) concept concerning the nature of knowledge formation and the process of scientific inquiry describing when a group of individuals involved in a process of empirical or conceptual inquiry into problematic situations. Studies suggest that in an excellent computer-mediated learning environment, students experience rich transactions in cognitive presence, teaching presence, and social presence (Figure 7, adopted from Garrison, Anderson \& Archer, 2000). Garrison and Anderson (2003) also suggest using a community of inquiry (C of I) framework for E-learning research and practice. However, most researches use C of I framework for measuring learning outcome rather than for online faculty development purpose. Some postsecondary institutions and consortiums such as Colorado Community Colleges Systems (CCCOnline) utilize surveys designed based on community of inquiry (C of I) model to assess online student learning (Arend, 2006).

Students in some of the online courses at University of Denver also participated in surveys designed partly based on the community of inquiry model. The survey questions are rated and tabulated on agreement/disagreement with 
statements relating to those social, cognitive, and teaching presences. Here are some of the reported reasons for students enrolling online courses:

- attracted by the use of digital technology

- convenience due to work schedule

- convenience due to extracurricular activities schedule

- convenience due to athletic travel schedule

- needed to add more credit hours beyond what is available on campus

- convenience due to summer travel, and

- some students simple stated they want to take online courses.

Figure 7. Community of Inquiry

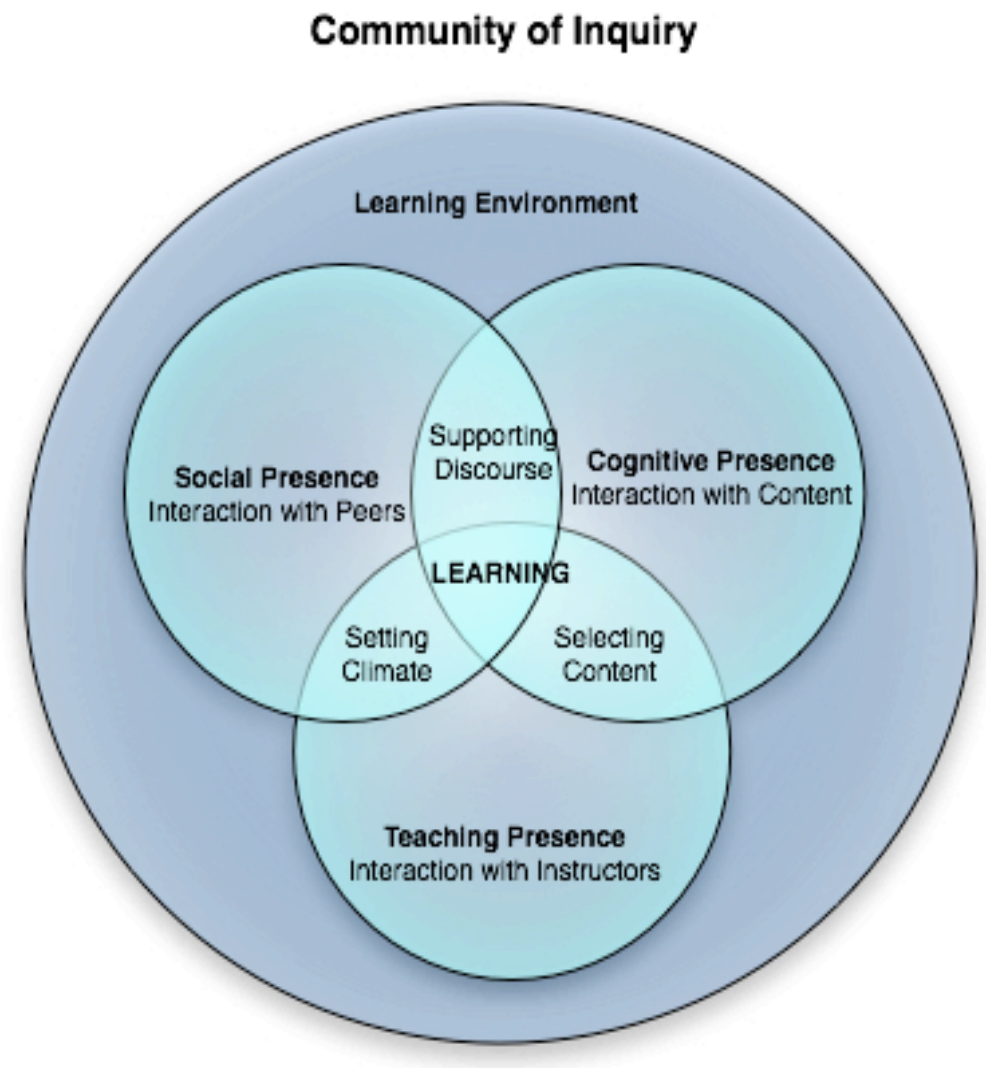

Figure adapted trom R. Garrison, T. Anderson, L. Rourke et al Community of Inquiry Model [2007] 
Over two-thirds of students expressed willingness to enroll in additional online courses. Over two-thirds of online students also reported similar or better learning outcomes when compared to f2f classes. Students were asked to comment on their online course experience at the end of the survey, here are some of the perceived strengths and weaknesses of online courses based on students' comments:

\section{$\underline{\text { Strengths }}$}

- "Ease of doing work, participating, and submitting coursework from any location at any time, I travelled quite a bit during this class, but was still able to participate and do well.”

- "The ability to engage during lecture, in class I never feel like I can reflect on what the teacher is saying since I'm so busy taking notes, it makes it so I miss a lot of what I should be learning in favor of recording info to regurgitate during tests. I also enjoy the self-paced format. “

- "We learned a lot of interesting things from both our text and a number of outside sources-and all the communication an online class allowed really helped me to understand this information, construct an opinion of it, and read differing views of other students.”

- "Everything I needed was available to me via online tools. The instructor was also available to me via email and phone so it made it easy for me to communicate with her and address my needs.”

- “ I really liked how much you had to interact with each other. There was no possibility to have a few class members who completely led the 
discussion and left the rest of the class sitting and falling asleep. Each person's input was equally important.”

“ I could work when it was convenient for me. With my schedule this was extremely important. Because we had weekly deadlines, I was forced to do my work instead of putting it off until the end of the quarter.”

- "Flexible schedule, learning at my own pace."

\section{$\underline{\text { Weakness }}$}

- "Whenever I worked on the class material it was later at night, therefore I was never able to go to office hours or get help on assignments because it was so late at night. It's hard to remember to go online multiple times a week."

- "It's a lot harder to relate to other students. In a regular classroom environment, I would be able to better understand where other students are coming from and anticipate their answers because I can associate a thought or an opinion with a face and a voice.”

- "I had to motivate myself to complete assignments on time without prompting from the teacher.”

- "Not getting to interact with the teacher and other students as much as I would have wanted. I am a social person, so this course was definitely a challenge in that regard. I like networking and talking face to face.”

- "It was a double-edged sword. I like not going to classes for lectures, but not hearing lectures every day made things harder to understand.” 
"Not being able to explain myself to the teacher when I was struggling, email wasn’t as successful as I wish it was to help me with online course difficulties.”

Although those surveys do not provide the contextual, complex, and situational account of the actual virtual learning environment, they present some perceived strengths and weaknesses amongst the participants in those online courses.

\section{Issues in Institutionalizing Distance Education}

Most studies of online learning focus on the efficacy of utilizing web-based tools for curriculum and pedagogy in a defined virtual learning environment within particular academic units. Though higher learning institutions wrestle with how (or whether) to integrate online learning into their mission, only a few studies have been conducted at an institutional level with regard to online faculty development or student satisfaction (Bishop \& White, 2007; Bolliger \& Wasilik, 2009; Campbell et. al, 2009; Dewar, 2010; Farmer, 2004; Pina, 2008). However, those studies have not shown how faculty or student feedback impacted institutional strategies and cultures with regard to online teaching and learning. As stated by Ellsworth (2000), "the successful transition from implementation to institutionalization is rarely mentioned in the literature" (p.43). The question remaining for many academic leaders is not if students will demand online courses, but how fast and how well can they train their faculty members to teach online.

Douglas Reeves (2010) identified the educational reform "initiative fatigue” symptom caused by a variety of good ideas competing for a "finite amount of 
resources, time and leadership attention” (p.30). Although Reeves’ observations are for K-12 educational systems, they apply to online faculty development efforts in postsecondary institutions. Reeves suggested that having more data does not translate into more useful information for administrators and teachers. Reeves stated that looking at the measurement of school performance once a year is similar to a doctor weighing students once a year to assess their health. In either case, it doesn't help the school or the students. From 2002 to 2013, while the Sloan C annual report on the status of distance learning in US higher education provided encouraging long-term industry trends, they rarely offer ideas on how to promote distance learning in the context of postsecondary institutional technology integration.

Further, although what we learn and how we learn have changed in $21^{\text {st }}$ century, the teacher in Tan \& Guo’s (2009) study stated she would hesitate in incorporating new literacy pedagogy due to the concerns of traditional assessment on student achievement. This study underscores the weak alignment between new pedagogical approach and old mode of assessment (O’Brien \& Bauer, 2005).

\section{$\underline{\text { Issues in Online Faculty Development }}$}

The exponential growth in demands in recent years for online instructors has prompted the development of various models of online faculty development programs (Epper \& Bates, 2001, Ko \& Rossen 2010; Palloff \& Pratt, 2011; Simonson et. al 2009), most of which were developed primarily based on best practices rather than for academic research purposes. In addition, the faculty teaching online efforts often ended after grant funding cycles concluded (Boyd-Barrett, 2000). Although faculty 
satisfaction is one of the five pillars of the Sloan-C quality framework, existing literature rarely discussed why and how faculty members make the transition to teaching online. The self-governing nature of each postsecondary institution and its distinctive administrative structure also present challenges for research design when study online faculty development.

In addition, when reviewing literature in online faculty development, it was found that most institutions develop online courses as a reaction to enrollment concerns (Oakley, 2004), faculty and/or student demands, or competition from competing institutions (Olson, 2002; Picciano, 2001). In more cases than institutions are willing to admit, online courses started out as "the result of random acts of innovation initiated by risk-taking individual academics” (Taylor, 2001, p.7). Consequently, the question of how higher education institutions design, develop, implement, and evaluate their online faculty development programs has not been addressed. Furthermore, institutional online faculty development programs require commitment of resources from not only administration but also faculty and students who participate in those online courses. Questions remain about how the institution and the faculty members participating in those online faculty development programs determine the values of their efforts.

Educational technology experts argue successful institutionalization of online faculty development depends on the design, implementation, and adaptation of those programs (Campbell, et. al, 2007; Surry \& Brennan, 1998.) There are a few quantitative studies on factors affecting faculty satisfaction with online teaching as 
one of the indicators in institutionalization of distance learning (Bolliger \& Wasilik, 2009; Tallent-Runnels, et. al, 2006). These studies mainly focus on the macro institutional point of view using a top down approach in the adoption process (Ellis, Ginns, \& Piggott, 2009; Pina, 2008; Surrey \& Brennan, 1998) and technologyfocused training (Feist, 2003; Palloff \& Pratt, 2011), rather than the individual instructor's point of view. Models of organizational change have cautioned us about the transitory nature of leadership in institutions. Complex adoptive systems theory also points out the assumptions of traditional models of organizational change, where changes trickle down the command chain and groups follow predicable stages of development, will no longer hold true for the complex adaptive systems today (Olson \& Eoyang, 2001).

Faculty is the driving force of an institution and the connection between the institution and the students. In the studies cited by Guzman and Nussbaumt (2009), educators expressed the lack of competency they felt after a training involving technology. With this sense of "lack of competency," they felt it would be better to deliver a lesson in the manner that they always taught, instead of using technology for technology’s sake. In order to integrate technology in student’s learning, technology proficiency trainings should be “relevant and recurring” (Corcoran, 1999). In most cases, assessment and accountability of technology use in classrooms is administered by groups multiple steps away from the classroom itself. There exists little incentive, other than the acquisition of the technology itself, for professors, administrators, and institutions to properly utilize the technology at their disposal. Current perspectives regarding incentives follow certain passive-aggressive lines: paid training, 
mentoring, or even job security. Referring to Tenbusch's example of training preservice and in-service K-12 teachers where incentives related to job security can include adding technological competence to the teacher evaluation instrument, requiring teachers to earn a specified number of technology-related in-service credits to ensure continued employment (1998) or requiring technology in-service training for recertification (Corcoran, 1995).

However, in the higher learning institutions, tenured faculty members do not have to worry about job security. Neither does the existing reward structure offer incentives or recognitions for online teaching efforts. Pina’s (2008) study indicates, "Faculty by and large are not rewarded or credited professionally for engaging in distance education activities” (p.436). The macro digital world demands more excellent online instructors yet the postsecondary institutional structure has been slow to supply an online faculty development pipeline.

\section{$\underline{\text { Online Faculty Development Models }}$}

Sloan Consortium developed the 5-pillar quality framework (see Table 1, p. 20 in Chapter 1) in guiding institutions in designing, implementing, and evaluating their online faculty development efforts. In Babson College’s example (Fetters \& Duby, 2011), its ten-year faculty development efforts for blended learning were characterized in three stages/phases: Stage1. Early Adopters are risk takers who are willing to experiment with new technology and comfortable with curriculum design and teaching experience from which to explore new methods and ways to improve student learning. Stage 2. Early Majority people require on-going training and 
support in adopting technology in their curriculum development and pedagogy from the institutions. And Stage 3. Late Majority group require faculty incentives for curriculum innovation, a well-designed faculty development with open enrollment, and a coordinated collection of online learning modules, advanced workshops, and discussion groups focused on curriculum innovation training and seminars (Figure 8). A fourth group “Laggards” (Rogers, 2003) represent faculty who will never embrace technology and were not included in the maturation cycle. However, the Sloan C quality framework does not take institutional culture and reward structure into consideration.

Figure 8. Stages of Blended Learning Faculty Development

\section{Babson College: \\ Stages of Blended Learning Faculty Development}

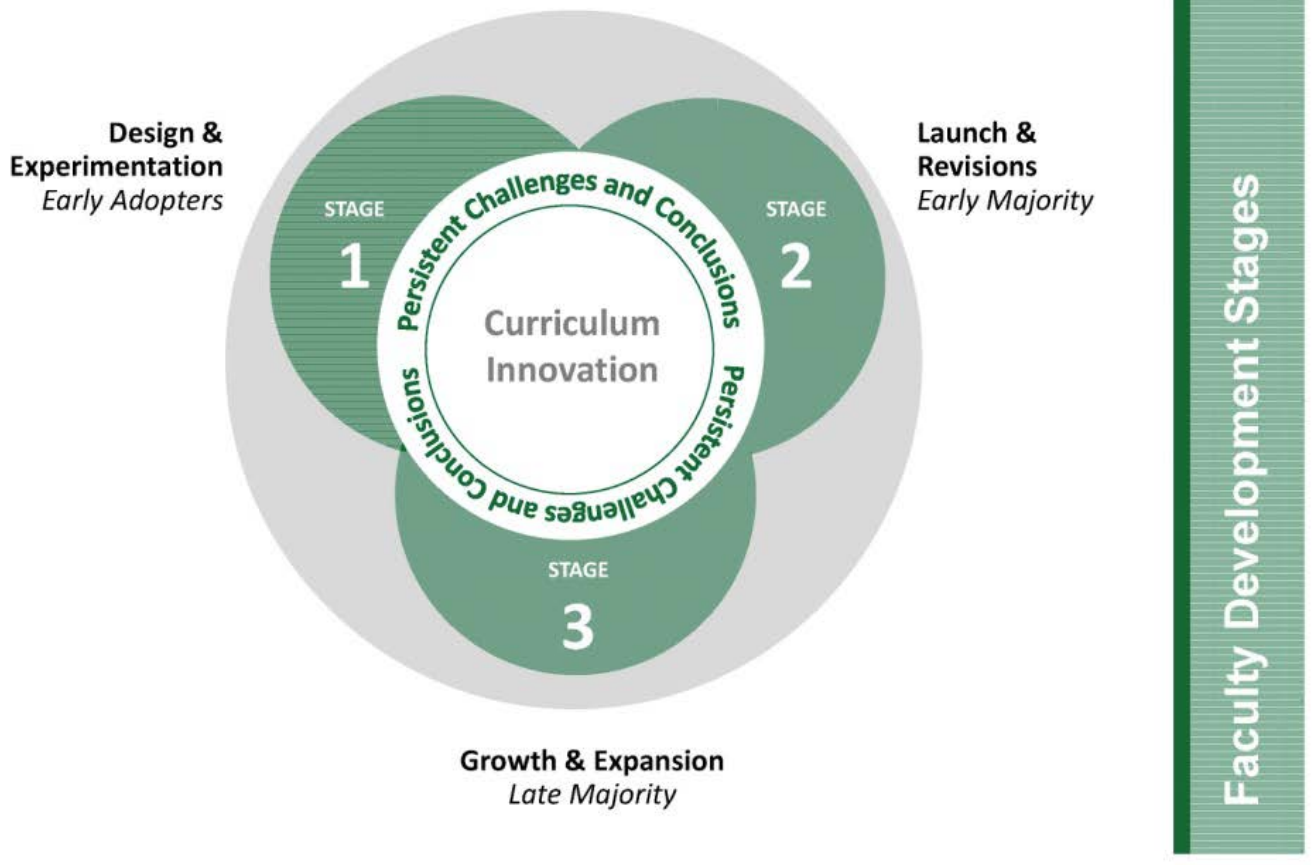


Similarly, Rogers $(1962,1995)$ suggested that the adoption of an innovation is not a single act, but a process that occurs over time. Rogers proposed adopters go through five stages of innovation-decision process model when interacting with innovations: knowledge $\rightarrow$ persuasion $\rightarrow$ decision $\rightarrow$ implementation $\rightarrow$ confirmation. Rogers (1995) also suggested that there is usually a normal distribution of the various adopter categories that forms a bell curve. Surrey and Ely suggest that "Innovators", those who readily adopted an innovation, make up about $2.5 \%$ of any population, “Early Adopters” make up approximately 13.5\% of the population, most people will fall into either the "Early Majority" (34\%) or the "Late Majority" (34\%) categories, and "Laggard" (16\%) are people who will resist an innovation until the bitter end.

Surrey and Ely argue this concept is important because it shows all innovations go through a natural, predictable process before wide adoption within a population. However, as Allen and Seaman pointed out (2013) that faculty acceptance has not shown any significant change since 2003. As a matter of fact, the level of faculty acceptance in 2013 is actually lower than the level recorded in 2004. In addition, the exponential growth of Facebook users from few hundreds (2005) to 1.3 billion (2013) probable defies any theory of technology adoption across different demographics.

In “The Excellent Online Instructor,” Palloff and Pratt (2011) ask and try to answer the following questions: (1) what makes a successful online instructor, (2) how can excellent instructors be trained and developed, and (3) how can faculty become their own trainers-developers (to achieve a goal of excellence in online 
teaching)? Palloff and Pratt labeled the five levels of faculty development based on faculty experiences and level of proficiency with personal pedagogy, technology, and content uses of online teaching environment (Figure 8, adopted from p.22, Palloff \& Pratt, 2011). The book also provides a self-assessment questionnaire for faculty members to determine which phase of development is more appropriate for their needs. Although Palloff and Pratt offered an excellent model detailing the phases of and strategies for online faculty development, the book did not discuss the institutional structure (extrinsic) or the individual (intrinsic) motivation for faculty participation in online professional development.

All those online faculty development models are helpful in training people becoming better online instructors. However, none of them touched on why faculty wish to be involved in the online teaching process to begin with. Nor have those online faculty development models address issues in: (1) the changing job requirement of a modern day professorate in the unchanged ivory tower reward structure, and (2) how to contribute to scholarship in their academic disciplines in the digital space. 
Figure 9. Phases of Online Faculty Development

\section{Phases of online faculty development: Palloff \& Pratt}

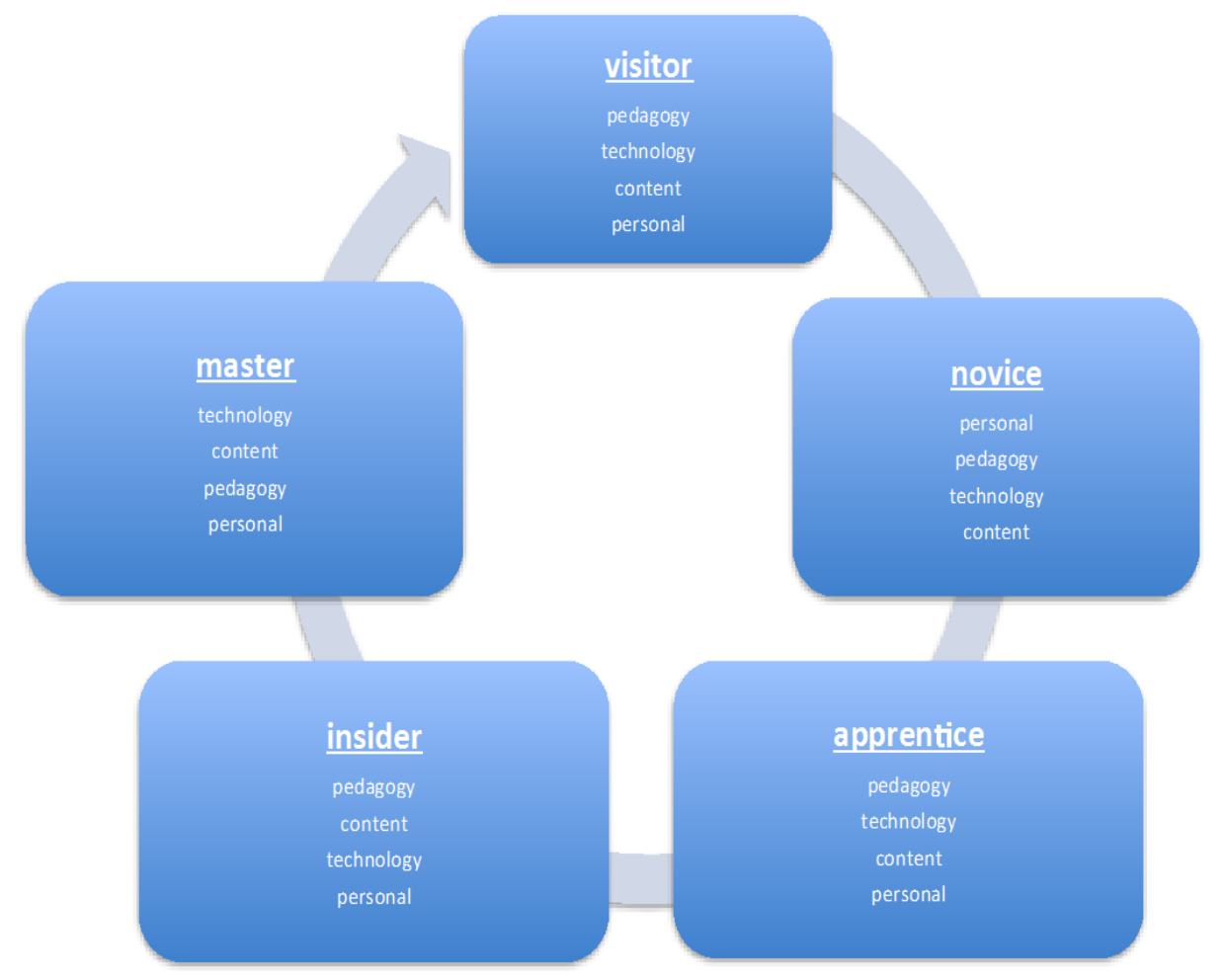




\section{Chapter Three: Methodology}

"Hope cannot be said to exist, nor can it be said not to exist. It is just like roads across the earth. For actually the earth has no roads to begin with ... but when many people pass one way, a road is made.” Lu Xun, My Old Home, 1921

Although faculty satisfaction is one of the five pillars of the Sloan-C quality framework, existing literature rarely discussed why and how faculty members make the transition to teaching online. In addition, the self-governing nature of each postsecondary institution and its distinctive administrative structure also present challenges for research design when study online faculty development. Olson \& Eoyang (2001) argue that organization change emerges from evolution of individuals and small groups. Those changes, like biological evolution, are not always incremental (Gersick, 1991). Complex adoptive system (CAS) theory (Olson \& Eoyang, 2001), suggests that the most powerful organizational transformations occurs not at the macro level but rather at the micro level where behaviors and changes began to emerge. These changes are not caused by a single source of influence. The agents in these self-organizing complex systems, based on their individual differences, will respond differently depending on their institutional context and their transformational exchanges with the institutional and macro environment. 
Thus, instead of trying to measure, evaluate, or categorize which faculty member fits into which stage of online faculty development under which framework, this study aims to explore, document, and share the stories of those instructors through their journeys to teaching online. In this study, the researcher asked tenured faculty members to reconstruct their experiences (Dewey, 1938) on why they teach online, how they learn to teach online, and what factors influences their journeys to teaching online. This study intends to empower participants as Siedman (2006) prescribes through "the process of selecting constitutive details of experience, reflecting on them, give them order, and thereby making sense of them that makes telling stories a meaning-making experience (p.7).” Through those stories, this study hopes to inspire readers through the process of retrospective generalization (Eisner, 1998), "born by examining our prior experience, also perform an anticipatory function. Like a guidebook, the generalization sensitizes readers to what is likely to be found, if they know where and how to look” (p.207).

\section{Research Design}

Robert Yin (2009) argues that case studies are appropriate when (1) the researcher is interested in contemporary events over which they have little or no control and (2) cases may be used to generate theory or describe and critique program processes. Yin stated: “A case study is an empirical inquiry that investigates a contemporary phenomenon in depth and within its real life context, especially when boundaries between phenomenon and context are not clearly evident” (2009, p.18). The U.S. Government Accountability Office (1990) defines a case study as "a method 
for learning about a complex instance, based on a comprehensive understanding of that instance obtained by extensive description and analysis of that instance taken as a whole and in its context.” Thus, the analysis of individual cases allows researchers to make sense of complex situations, identify thematic variables, and facilitate the process of developing theory (Creswell, 2007; Merriam, 1998; Stake, 1995.)

In addition, no two stories are exactly alike. It is through other people's experiences that we learn how to compare and interpret ours. In-depth interviews afford us the opportunities to understand participants' experiences from their point of view. Those different stories provide us the windows in seeing "how their individual experience interacts with the powerful social and organizational forces that pervade the context in which they live and work, and we can discover the interconnections among people who live and work in a shared context” (Siedman, 2006, p. 130). Dewey (1910) articulated the human interest for "self-realization” is sympathetic, socially and aesthetically sympathetic, rather than cognitive. "This sympathetic interest provides the medium for carrying and bringing together what would otherwise be a multitude of items, diverse, disconnected, and of no intellectual use” (p.189, Dewey, 1910).

This study aimed to unveil the individual experiences of a small group of pioneers who made the journey to teaching online in a not-for-profit traditional private university. The participants' narratives in reconstructing their experiences provide the institutional context where they learned to teach online and their interactions with that context. This study also borrows ideas from case study where a single case with multiple embedded units of analysis approach (see Table 1 in chapter 
1). Thus by combining techniques from Siedman's interview methodology within the Yin's case study framework provide the operational guide for this study. This mixed qualitative method approach is coherent with the complex adoptive systems theory's lens in examining behavior changes experienced by our participants in environmental, individual, and transforming exchanges areas in the institutional context (single-case) where the individual instructors (i.e., the embedded multiple units of analysis) perform their job functions.

\section{Research Questions}

The purpose of this study is to describe the institutional environment, illustrate the characteristics of these faculty' experiences of their individual transition from teaching traditionally to teaching online, and enlighten their transformational exchanges with the institutional environment. As complex adoptive system theory (Olsen \& Eoyang, 2001) suggested, there is no single source of change. By studying the "change agents" in a changing organization in a changing industry, this study intends to conceptually map the issues facing online higher education in general, from the instructors' point of view.

The basic research questions are:

1. Why did faculty members decide to teach online and why do they continue to do so?

2. What characterizes the journey taken by faculty members in learning to teach online? 


\section{Environment and Sample}

The University of Denver (DU, the case) started online faculty training in 2005 via Office of Teaching and Learning (OTL). The Teaching Online Workshop (TOW) grant initiative started in 2009 and focused on offering training to teach online courses. Faculty members apply for grants, which include online faculty development training and support. OTL's current phase III of its faculty development program has shifted its emphasis from online to more blended learning. To date more than 120 faculty members have completed the TOW program. With help from OTL staff and background research by the researcher, the researcher identified 40 tenured faculty members who teach online regularly in various academic programs in the university. After receiving IRB approval, the researcher sent email invitations to the above 40 identified tenured faculty members and asked if they were willing to participate in this study. The study's intent was to recruit 2-3 female faculty members and 2-3 male faculty members as in-depth interview candidates (embedded units of analysis.) Race and gender of the faculty members were not part of the consideration for this study due to lack of research on racial differences or gender effects in the teaching online area, however an attempt was made to balance the research sample by gender. After email exchanges, the following participants are confirmed. They are all tenured professors working at University of Denver (DU). Their positions and academic disciplines are listed in Table 6 in Chapter 4. 


\section{Procedure}

This study focused on instructors’ (multiple embedded units of analysis)

personal recollections, reflections, and retrospections of their experiences in transiting from teaching traditionally to teaching online within the University of Denver (the case.) The researcher first sought approval for this study from the DU Institutional Review Board. After approval was granted, the researcher interviewed the participants in the university environment where the participants choose to be interviewed, which was their offices, library conference rooms, or nearby coffee shops. The interviewees signed consent forms at the beginning of the interviews and those interviews were recorded via audio recording device. The participant could choose to stop the interview anytime if they were not comfortable in continuing the interview. The researcher offered a \$20 Starbucks gift card for each participant for his or her time for participating in the study. All the participants felt they have answered all the questions to the best they can so we did not schedule additional meetings for them. In addition, they indicated that they like to see this study when it's done and would love to continue further discussions on ways to improve their online practices. Each interviewee spent approximately 1-3 hours with the researcher. The interviews were conducted over a 2-month period of time, from May to June 2013. 


\section{Interview Questions}

The researcher first asked the instructors a series of demographic questions as background information for each embedded unit of analysis, i.e. the individual instructor. The interview questions for instructors are as follows:

Demographic questions:

1. Tell me about yourself.

2. When did you start teaching and why?

3. How many years have you worked at DU?

4. What is your current rank, i.e. lecture/assistant/associate/full professor?

5. Do you also handle administrative duties?

6. What's your definition of "teaching online”?

Why do you teach online and why do you continue to teach online questions:

7. When did you start teaching online and why?

8. Do you develop the curriculum for the online courses you teach?

9. How many online courses have you taught?

10. Do you continue to teach online? Why?

11. Do you still teach face-to-face courses? Why?

12. How many online courses do you plan to teach in the coming academic year?

13. Does your department offer online certificate or degree programs? 
What characterizes your journey in learning to teach online:

14. How did you learn to teach online?

15. What are the incentives to teach online?

16. Do you consider yourself a good online instructor?

17. How have you changed as a teacher after you start teaching online?

18. What adjustment do you make for your online classes or face-to-face classes since you start teaching online?

19. Any changes in online student learning outcomes comparing with traditional class?

20. Do you feel teaching online help you become a better instructor for your traditional classes?

21. What challenges and highlights have you encountered personally and professionally in your journey to teach online? e.g. institutional support, peer recognition, time management, technology competency, professional development, personal preferences, student feedbacks.

Other remarks on teaching online:

22. What insights can you share with other faculty members who are considering the transition from teaching traditionally to teaching online?

23. Any comments with regards to teaching online? 


\section{Data Analysis}

Although university faculty members enjoy quasi-autonomous freedom in their work, they are employees of bureaucracies and need to work within the institutional framework with the infrastructure that is provided to them. Furthermore, complex adoptive systems (CAS) theory makes distinctions between "competence” and “capability” (Olsen \&Eoyang, 2001). Competence is defined as the individuals' knowledge and skills, e.g., technology competence and content knowledge when teaching the particular course online. Capability is defined as the extent to which individuals can adapt to change, generate new knowledge, and continue to improve their performance when taking both individual capacity and institutional capacity into account.

Siedman’s (2006) states: “how their individual experiences interact with the powerful social and organizational forces that pervade the context in which they live and work, and we can discover the interconnections among people who live and work in a shared context” (p.130). Yin (2009) suggests case study inquiry “copes with the technically distinctive situation in which there will be many more variables of interest than data points, and as one result relies on multiple sources of evidence, and as another result benefits from the prior development of theoretical propositions to guide data collection and analysis” (p.18.)

When we read stories in newspaper articles, our interpretations do not happen only after we finish reading the whole story. Similarly, interpretations occur along the process of qualitative research. Interpretations guide us in the interviews (by 
following up on interesting or contradicting responses), facilitate the analysis, and help to format the structure in informing the readers of the thematic patterns presented in the interview data (Siedman, 2006; Wolcott, 1994). Eisner (1994) suggests that it is through the continuous "coding" and "decoding” with our environment that we are able to construct meanings. The continuous interactions between the participant and the environment enable the participant to construct new meanings of oneself and the relationship with one’s environment. Dewey (1938) stated: "The two principles of continuity and interaction are not separate from each other. They intercept and unite. They are, so to speak, the longitudinal and lateral aspects of experience" (p.44).

The researcher combined the case study framework (Stake, 1995; Yin, 2009) and Siedman's (2006) interview method. I first shared the interview data, profiling each professor (embedded unit of analysis), and then thematically analyze and summarize the group characteristics. The study aims to conceptually map the faculty members' experiences of their journey to teaching online within the institution (case) where they operate.

\section{Reporting}

Lyons (2009) prescribes using the case study method for publishing development in the ICT-facilitated (Information Communication Technology) learning in higher education environment. Lyons further summarized Burns’ (2000) characterization of case study as "a portmanteau approach that addresses bounded 
systems such as an organization where the content of a case study is defined by the opportunities for analysis and recommendations that it provides” (2009, p.31). Their narratives (Siedman, 2006; Wolcott, 2004) and their individual summaries inform the readers the reasons why they teach online, why they continue to teach online and what characterized their journey for each professor. The final chapter the researcher summarized the study and themetized the group data according to the three areas outlined by complex adoptive system theoretical framework: the environment, individual differences, and transformational exchanges, to facilitate further discussions. 


\section{Chapter Four: Findings}

"What sets the world in motion is the interplay of differences, their attraction and repulsion. Life is plurality, death is uniformity."-- Octavio Paz

The intention of the study was to identify the participants' individual experiences reconstructed and interpreted through the complex adoptive systems theory lens. According to complex adoptive systems theory, it is in this micro level where their subsequent behaviors changes and shared values may be categorized in three areas: environmental (e.g. institutional culture and resources), significant individual differences (competency, expertise, and educational background), and transformational exchanges (meetings, educational events, and faculty development efforts). However, most participants' responses were contemporaneously interrelated to one, two or all three areas, and in some cases the conversations extended beyond the institutional boundary. The informants' experiences are dynamic, not linear, and not unadulterated by their background or personal beliefs. When I met them, they seemed anxious yet pleasant, concerned yet prophetic, persuasive yet calm, contemplative yet practical, professorial yet commonsensical. For the most part, they were delighted to engage the opportunity to reflect on their experiences, and to partake in an outlet to share their stories with their peers. All those ranges of emotions projected through their "public voices" and "private voices" have intricately 
interweaved into every fiber of their being. Through our conversations, their private stream of consciousness surfaced and morphed into manifesto of their public persona. That's why their stories are so fascinating and worth sharing. In addition, as they reflected on their experiences, they discovered deeper understanding of their own journeys. They all said they would love to continue the conversations down the road.

Therefore, in order to truthfully portray their experiences, instead of mechanically taking our conversations apart by forcing different parts of their stories into strict thematic groupings, I felt it is important to share their stories in the style in which they were told. At the conclusion of each interview, I offer a brief profile of each professor's experience of his or her journey to teaching online. I then thematically interpret and summarize the group's experiences as a whole. Further, although more than half the participants expressed consent in using their real names in this study, in order to protect all participants equally, I have changed their names for this report. All participants were tenured professors working at University of Denver (DU). Their positions and academic disciplines are listed in Table 6.

Table 6. List of Teaching Online Study Participants

$\begin{array}{lllccc}\text { Professors } & \text { Rank } & \underline{\text { Academic }} & \underline{\text { Years of }} & \underline{\text { Years }} & \underline{\text { Administrator }} \\ & & \underline{\underline{\text { Teaching }}} & \underline{\underline{\text { At }}} & \\ \text { Holly } & \text { Associate } & \text { Sociology } & >20 & >9 & \text { No } \\ \text { John } & \text { Associate } & \text { Media } & >17 & >8 & \text { No } \\ \text { Bill } & \text { Full } & \text { Management } & >20 & >14 & \text { Yes } \\ \text { Mary } & \text { Associate } & \text { Marketing } & >22 & >17 & \text { Yes }\end{array}$


Three interviews took place in their offices. One interview was conducted in a nearby Starbucks coffee shop. Since I have many years of experiences as a radio and TV show host, I know how to interview people and find out information without interfering with their thought processes. Keep in mind though, they are all tenured professors, so talking is very comfortable for them too. In order to solicit responses without my influence as a data collector, I did not disclose my personal or professional background prior to our interviews. In most cases, I also refrained from commenting on their responses during the interviews, unless it helped to clarify or deepen the conversations. After we exchanged pleasantries, signed the IRB consent forms, we started the interviews. I asked them questions (Q) and they answered (A) those questions in any way they wanted to. The following pages are a synopsis of our

conversations about their journeys to teaching online. At the end of each interview, I offer a profile of the participant highlighting their responses on why they teach online, why they continue to teach online, and what characterizes their journey in learning to teach online. In the final chapter, I then summarize the characteristics of their journeys to teaching online as a group to facilitate further discussions.

\section{Participant 1 -- Holly, the sociologist}

Interview with Holly

Q: How long have you been a teacher?

A: I feel like I have always been a teacher. I started teaching when I was in high school as part of the teacher-training program to support the pipeline for k-12 
teachers. I did a lot of teaching when I was in graduate school and taught English abroad for a while. I have been fulltime at DU for 9 years.

\section{Q: When did you start teaching online?}

A: I completed the Teaching Online Workshop (TOW) spring last year (2012) and started teaching online last summer (2012) for the first time. I am teaching the same course online again this summer. Last summer the class was capped at 15 but only 8 students enrolled. The (undergraduate) course will meet an elective or general common curriculum requirement for juniors and sophomores or can fulfill the requirement for major in sociology. This summer the class is capped at 15 and it's full.

\section{Q: How did you learn to teach online?}

A: Last spring (2012), the OTL was doing the teaching online preparedness program (TOW). I was very critical of the inventories online. Realizing I had never taken any courses online or taught one, I decided I would try it and see how it was. I did the entire training program and taught one class online (last summer.) I thought I would try (teaching online) one more time this summer.

Since then, I tried to integrate more online tools in my in-person classes like discussions and virtual meetings. For example, for a different course with a larger class (30 students), during the week of the Presidential debate last November, because students could not park on campus, we had virtual meetings that week. I made some changes to the pedagogy but did not change the content. Some (f2f) students commented that they really did not like the (online) format for that week. 


\section{Q: Did you design the curriculum for this (online) course?}

A: Most courses I teach require heavy reading and robust discussions, which don't lend them into bite sizes well. I chose this one class, which is more skill-based by learning to take controversies apart, so I can see the way each piece is more selfcontained and more appropriate for the online format. I taught this course 6-7 times in person before and felt it would translate the best (for an online format). It is one of the few classes I actually use a core textbook, which I thought was important. Other courses I usually give the concept in class and students read articles and discuss those concepts. Since I have a lot of experience teaching it, I felt comfortable with the transition. I have not taught in person again (for the same online course) so I have not tested how it's like to go back and forth.

\section{Q: Why do you teach online?}

A: I was curious and feel that teaching online is part of national conversation of where higher education is going, mostly on MOOCs. I am very critical of the forces driving online education, mostly economics. I decided to try it and learn it to see if I would change my opinion of it. Demographically there are fewer college students today. Some colleges downsize the programs to the right amount of applicants. Other institutions become increasingly tuition dependent and believe they will add revenue by capturing students they did not capture before through online teaching. Watching the controversy around MOOCs in San Jose State, and University of Colorado signed on last week; I think a lot of values in higher education will get lost in translation. It will depend on the discipline, of course. In sociology, a lot of what 
we teach relating to "legality,” which involves conceptual understanding through a lot of discussions around power structures and experiences, and are not necessarily content driven, so I wasn't sure how well those would translate into online environment. Moving more towards online what I fear is students will lose the value of higher education, where you encounter people who are different than you, feeling uncomfortable and figuring out how to navigate through those situations, and learn to collaborate with people who are different than you.

\section{Q: How do you define teaching online?}

A: My definition of online courses is that students and teachers don't meet and all content and instructions are delivered asynchronously. Faculty and students do not interact in person at all.

I am more interested in hybrid courses than online. After last summer, I realized my teaching online experiences magnified my least favorite part of teaching which are grading and emailing; and took away my most favorite part of teaching like meeting students, finding out where they are from, what their experiences are, get to know them as a person, and engaging in constructive interactions in their learning.

My definition of hybrid is when parts of the course are in person and parts online, for example, for my f2f research method classes students can go into the community to do field research (40\%) and when we meet in class we engage in discussion and group activities (60\%.) That's why I decided to teach another online course this summer so I don't base my decision (whether to continue teaching online) on (after) just one class. 


\section{Q: Do you feel you have adequate support in teaching online?}

A: Last summer I went to OTL a few times when I could not figure out some technological issues. But I didn’t feel like I am getting appropriate help in answering the type of pedagogical questions I was interested in. Although I attended a lot of faculty workshops on campus since I've been at DU, my impression is that the pedagogical approaches (e.g., modulization of topics) in natural science don't quite mesh with our subject matters or style of learning in (arts and humanities) social science. I couldn’t visualize how to do some pretty controversial topics online like race, religion, or sexuality, where students may have the potential of harming each other in discussions if unsupervised. In f2f class I know when to intervene or interject when I see the discussion going down the dark path (in real time through both tone and nonverbal cues.) I think some courses content are easier to modulize (put into the week by week format). For courses with complex topics that require intense real time discussions, I would not feel comfortable in teaching those courses online.

Also, I have not figured out pedagogically how to engage online students in the same level of rich spontaneous discussions we have in $\mathrm{f} 2 \mathrm{f}$ class. I would hesitate to translate a lot of my courses online. Last summer I only had 8 students. I don’t know what the ideal size of class is but I know 8 were too small for meaningful discussions.

I talk with friends and colleagues from other universities about our experiences (teaching online.) They teach much larger classes but in the same subject 
area. We compare notes often. I attend sessions in professional conferences on teaching online topics.

Q: Do you assess students the same way (for f2f and online courses)?

A: I do not grade students the same way because online course requires more bookkeeping on my end for their participation (discussion board.) Students have to be accountable to me because I grade their work but it’s hard to make students accountable with each other in their participation. The best learning experience usually occurs when people feel that they are part of the whole.

This summer teaching the same course $2^{\text {nd }}$ time I will be able to spend less time on modifying content and more time on working out the mechanics in the virtual learning environment. I did not allow students to call me last summer but may allow that this summer.

One colleague at a different university advised me that in online environment even if you think you are clear, you are never clear enough for students. That was helpful for me to think through. Which means I have to be more meticulous with keeping track of their discussions. Sometimes in $\mathrm{f} 2 \mathrm{f}$ you can clear up certain points with a ten-minute conversation but online it may turn into a series of long emails. The self-paced structure accommodates different learning styles better because students can watch the same video clip again and again if they did not get it the first time. Some students think online is easy but were surprised by the level of intensity, so online students require more monitoring (from me on their progress.) The student learning outcomes are good but different. 
After teaching last summer’s online course, I stop counting f2f attendance as part of their grade this academic year. I did not offer online participation as an option because the Presidential debate week experience wasn’t good. I found out because attendance was not part of their grades, it did not affect the A students but affected the borderline B or C students since there is no incentive to come to class anymore. Some students may need the physical time and space structure to give them the extra push for their grades.

Q: Do online students fill out the same teaching evaluation as regular classes?

A: They do. Mine did not suffer too much even though it did not meet my expectation, but students may have different expectations for a summer courses in general (shorter time, online.) OTL has a separate survey for students but I did not get feedback from them.

\section{Q: Do you consider yourself a good online teacher?}

A: I don't, but definitely like to be better. I still find challenges in adopting pedagogy in the online environment. For example, f2f allows more room for spontaneity, e.g. students brought up DU mascot protests and debates of which I can direct them to the relevant course content on race and white privileges, etc.

While in online courses I have to spend more time preparing ahead and less time to anticipate what's coming. Although last summer, I did use the Aurora theater shooting example for online course, but I brought in the example. I would prefer students bringing in the examples for class. How do I create expectation for students that there is room for them to be spontaneous in the online environment as well? I 
don't think it's because it's an intensive course (4 instead 10 weeks) because I taught the same course $\mathrm{f} 2 \mathrm{f}$ in (2 weeks) intensive format before. I think students feel less sense of ownership for the (online) content. Students were not as confident going forward on their own) in the virtual environment. Both teachers and students need more experience online. How do I communicate with online students there are room for participation and ownership of content?

In one of my f2f, when discussing childhood extending or shortening, one student brought up an article she saw on the Internet: “21things you can’t do after you graduate from college.” I was able to share with students who have not seen the article and brought them into the discussion in the same session. I am still trying to figure out when and how much I should interject in online courses or let them go on for a while. F2f is easier to identify and interject.

\section{Q: How have you changed as a teacher after you start teaching online?}

A: After I start teaching online courses, I feel I have more tools and skills for my f2f classes too. I am less fearful of technology, not that I was resisting it before but I have never been an early adopter in any technology. I sense that I am more relaxed about creating teacher-student boundary in the online environment (as opposed to the f2f environment.)

I am more cognitively aware of the quiet students in f2f class because they need more time to reflect and respond. The quiet students felt alleviated from the pressure to speak in class but still able to actively participate. One quiet student told me she loves online course in general and signed up for her $3^{\text {rd }}$ one this summer. People learn differently. 
In any format, there are students who will participate and students who won't. I found it hard to pull in (online) students who won’t participate. One (online) student expressed she needed more structure (time and space) than online course can provide. For international students the language barrier could be a challenge for textbased online courses if reading is not their strong suit. Online magnifies their challenge. I wonder how to keep them engaged. I wonder how to create more of a sense of community early.

I feel online courses are mis-marketed to students. It feels like the university is trying to capture summer tuition dollars without explaining (to students) the (level of) commitment required for online courses. Some students have this perception that because there is flexibility in online courses so they are easy and found out they actually take more time and require active engagement.

\section{Q: Do you feel you are recognized for your teaching online efforts?}

A: Not really. The bigger question is what is the larger pedagogical goal (for the institution.) The university wants to have more summer courses online. My division (AHS-Arts, Humanities, and Social Science) is happy if the summer online courses fill because it means extra revenue. Online courses usually fill before f2f courses because students can do them from home. In the mean time, students are graduating earlier so we are losing the backend of tuition. Some students come in with AP credits. Some students register for 19 or 20 hours (instead of average 15 hrs. per quarter, and because 12-18 hrs. are the same rate so they only pay additional credit hours above 18). Financially, it makes sense to offer students an online option that 
they would otherwise take those courses somewhere else when they go home for the summer. But pedagogically it is not a very compelling reason for me.

My department is very supportive of me teaching online summer courses, although I am the only one in my department doing it. My colleagues seem to be very relaxed about whether I am doing it online or not. It is not part of the discussion in our tenure review process. I prefer f2f classes. After this summer, my second time teaching this course online, I will know if I want to continue teaching online.

\section{Q: Any other incentives?}

A: I like the flexibility for travel, being there for my kids in the summer, and taking care of family commitment. It (teaching online) facilitates other parts of my life while I work. It provides extra income (additional teaching load) for the summer. Last year summer online courses' income made up for cancelled courses during the year.

Our current dean is leaving. We had a lot of deans over the years. It is not clear to me what the institutional agenda is by offering more courses online. I have not thought about teaching online during the regular academic year. I suppose if I teach online during the academic year, it would allow more flexibility to be away from campus to do ethnographic research but (I think) it contradicts with the institutional demands wanting faculty being on campus more.

Professionally, It was a good experience to be an online student in the online training program (TOW.) It's good to have the experiences to be a student and a 
teacher online. I learn more ways to get to know my students and be aware of their different learning styles. But not all workshops or feedback were useful.

\section{Q: Has your teaching philosophy changed?}

A: No. I am concerned that we (our institution) may loose our focus and our strength by diverting resources in online programs. We need a stronger identity of what we want to be. Right now is a little bit of everything. We have some strong graduate programs in law, business, international relationship, social work, and education. In undergraduate we have Arts and humanities (and social science) division, (it’s) the largest division for undergraduates. However, I am still very critical of online teaching in general.

I can't image all courses offered online during the whole calendar year. However, I think the online format during the 10 -week regular quarter will provide more flexibility for colleague who teach internship or for my research method course needing fieldwork. One colleague uses Facebook for her class. Students have sociology club on Facebook so I try to meet students where they are by posting some materials there too. Pedagogically that makes more sense to me because that's the best way to deliver the course. (For me,) I still keep on thinking if I want students to leave my class with 4 things, what's the best way to do that? (The 4 things change depending on courses.) In f2f class where we may spend the whole 2 hours on intensive debates, it would be hard to duplicate the same experiences online. So I constantly still feel like not trying to duplicate f2f, and (instead) try to re-imagine what online would look like. It is a continuous evolving process for me. 
Q: What advice do you have for tenure-track faculty who are interested in teaching online?

A: At DU, we are suppose to be very good teachers. But teaching is the smaller part (compared with scholarship) of the total reward structure. They should do so only if their department supports it and they need to make sure they get evaluation that's at least around (or better than) the department average. But if your teaching is just okay, you better publish a lot and not worry about teaching online.

\section{Q: Any other comments about online teaching in general?}

A: We (our institution) need to ask (ourselves) why do we invest in online courses? Ongoing challenges will be to know what the larger pedagogical goals for the institution are. Is it better learning outcome? Or is it to enhance students' universal adoptivity (in life)? Where are we trying to go? I don't know what the end goal is since no one has communicated it to me. My sense is we are doing it because everybody is doing it so we better do it too.

When we ask people about their best college experiences, they rarely mention content but rather the experience meeting the most diverse environment (racial and socio-economical), being uncomfortable and overcoming that. Our job is to help students grow up. I have students come back years after they took my courses for advice on job placement, internship, mentorship, and support. One (f2f) student who has done well before did poorly this quarter; he came to see me and explained that he is in the middle of a custody battle. I fear that I will miss those relationships (in the online environment.) 
My final concern is with MOOCS, which has created a lot of financial concerns for higher education. If our end goal is to enroll 1000 online students who would otherwise go somewhere else, they may have the same degree but not the same quality of education. It may cost us our brand (which is small classes where students and teachers know each other well) because we will be creating a 2-tiered educational system. Or maybe that's the future (of higher education) whether we (DU) do online or not? If there is some kind of national agreement (like the accrediting body for law schools allowing only 16 hours online credit), then we probably won't see the same kind of craze we see right now with institutions chasing this small piece of pie they think it's out there.

\section{Q: Do you feel like you have a voice?}

A: I see a lot of things needing to change but don't know who to talk to about those issues. It would be helpful as an institution to know what our goal is now we created this different path. Then we can work toward it together. It is not clear to me what all the academic discussions are about without the subtext. Personally, I like having the tools because I think that's where the future is. Learning to do new things also makes me happy. It is not teaching online makes me uncomfortable. But rather not knowing what we try to accomplish is making me uncomfortable with online teaching.

\section{Summary for Holly}

Holly, a sociology professor, is very aware of social changes and demographic changes in higher education. She has never considered herself as being 
technologically savvy but does not consider technology an issue for her in teaching online. She was very critical of online education but realized she never learned or taught online, so she signed up for the TOW training in spring 2012 when her department chair was asking people to participate. In addition, she was motivated to teach online because it is important for her to be part of the national conversation on online education. She is also motivated intrinsically as a learner to learn new ways of doing things. Learning to teach online has been an ongoing, evolving, and challenging process for her. Extrinsic incentives such as flexibility and recognition are helpful but not her main motivation, although last summer the online course made up income for cancelled classes during the regular academic year. Holistically she is pleased that teaching online enabled her to facilitate other areas of her personal life while teaching.

She taught one online course last summer (2012) and will teach another one this summer so she may decide if she wishes to continue. She made some adjustment for her f2f courses after her teaching online experience. She felt her TOW experience as an online student has helped her in recognizing the different learning styles in her f2f students as well. However, she felt not all trainings offered were helpful in her subject areas or pedagogically agree with her teaching philosophy. She believes online format may be better utilized in blended courses where the flexibility would allow field research opportunities for students and the faculty. However, she feels staggered on how to reimage, redesign, and actual implement more online courses. She continues to converse with colleagues in other universities and professional 
organizations on how online education impacting their academic discipline and higher learning institutions.

She teaches only undergraduate courses. She believes students come to college, probably the most diverse environment before they enter society, to meet people who are different from them, feeling uncomfortable, learn to overcome and work with people who are different. Therefore she is concerned whether this alternative path (online education) may distract the focus of institutional vision.

She has been and continues to be very critical of online education. Her concerns are primarily pedagogically whether the new platform is the best way to deliver the best educational experiences for her students. More globally, she is concerned the craze around MOOCs will forever change the landscape in higher education and cheapen the institutional values for both the faculty and students. As an agent in the institution, she is eager yet perplexed on how to anticipate and participate in the organizational change except by personally learning and teaching online. Without knowing what the institutional motivation for creating the online path is continues to make her uneasy in going forward with teaching online.

\section{Participant 2 - John, the international journalist}

Interview with John

Q: How long have you been a teacher?

A: I am in my $8^{\text {th }}$ year at DU. I was an adjunct faculty member at Colorado State and the University of Northern Colorado during my graduate school years. I have been a teacher since 1996, so about 17 years? 
Q: When did you start teaching online?

A: I started summer 2010 on this course “America through foreign eyes” where we critically look at foreign media coverage of the US. I teach this course for the $4^{\text {th }}$ time (online) this summer. I attended CTL’s course (TOW) in spring 2010 and start teaching (online) that summer.

Q: Why do you teach online?

A: I like to teach in the summer because it's a good source of income I really need right now. And if I have to teach in the summer, I would rather do it online. I like the flexibility of not having to be here 3 hours a day every day for 4 weeks in the summer while teaching. I guess that how it got started and I got into a routine. It's a habit (teaching online in summer.)

I also teach the (f2f version) same class once a year during the school year but it's different format (and it's over 10 weeks.) During the regular school year I only teach f2f classes. I guess I never asked whether I could teach online during the regular (academic) year. Never really thought much about it. I taught the same class $\mathrm{f} 2 \mathrm{f}$ in the summer before over 5 weeks so I will need to reformat it. But it wouldn't be that hard.

\section{Q: How do you define teaching online?}

A: Online, in this case, let's make it case specific means doing everything online, chat rooms, discussions, readings, and assignments. Never really see students during the course. Unless I've met the students before (or after) in other classes, my only way to get to know them is through the Internet. All the instructions and interactions are 
exclusively via the Internet or computer. Besides real time office hours with chat window which students rarely used in the last three years, everything else is asynchronous. I have a lot of discussion board interactions but it's generally not realtime.

\section{Q: Do you assess students the same way (for f2f and online courses)?}

A: I have 1000 points for the course: “America through foreign eyes.” Readings are clustered around views of the US from different regions of the world: Europe, Asia, Middle East, Africa, and Latin America. In that sense a lot of the readings are the same, some of the assignments are the same. The big difference is that in the f2f class has a big group project at the end with group paper and group presentation. I was a little bit intimidated in terms of figuring out how to do that in terms of technology. So I decided to structure it differently. So instead of a big group project at the end, they have a lot of 1-page analysis papers. Every week they do 2 1-page analysis papers and 3 discussion board posts. And they have a big paper at the end. In terms of discussion boards they also have to reply to their classmates. The main component that is different is I did not do any group work (for the online class.) It's an (undergraduate) advanced seminar and it's a writing intensive class. They write lots of 500-700 word pieces. The class is typically $12-15$ and it's capped at 15 students.

Each individual online post, discussions, and/or reply I grade them based on a rubric that I distributed to them. I gave them feedback publicly through my reply and individually based on the rubrics through emails. The goal for both f2f and online format is to teach students how to put forward an informed, knowledgeable, 
persuasive argument position and be able to argue it persuasively. The other goal is to get them to look at US from outside US perspectives. They don't always have to go to CNN, New York Times, or BBC. With the Internet, it is easy to go to other sources to see what people are thinking and saying about the United States.

I started teaching this course f2f since 2007, tried using online discussions (in f2f) but got a lot of push back, students thought it was just busy work. Now I use informal group-lead discussions; the group posts two readings focused on US from news source in their assigned region for their fellow students. I use pop quizzes (with materials from the student-posted readings) to hold students accountable to their classmates. If they have not done the readings (posted online by fellow students), they won't do well on the quizzes.

I used to organize 4-5 times international online discussions board using Blackboard for f2f students with students in University of Queensland in Australia and University of Marlboro in Slovenia with help from Kathy from CTL. Those were really interesting and dynamic discussions. But it always seemed to fall on me to take the initiative (instead of the foreign universities) so after a while I got tired of doing that. I tried to do Skype but the time difference was difficult. I actually wrote a couple journal articles about my experience doing that. I haven't used that with the online class.

Q: Do online students fill out the same teaching evaluation as regular classes?

A: It's the same required evaluation form but OTL has a separate supplementary form for online class. The teaching evaluations are pretty similar for me. "America through foreign eyes" and "International communication" are my two most favorite 
undergraduate classes to teach and I generally got my best evaluations in those classes. I get very good teaching evaluations for both online and face-to-face (averaging around 5.5 out of 6). Which is nice to know I've done it right in both (ways.)

I know from colleagues that they were frustrated when they didn't do as well for online courses. This one colleague is funny and dynamic in f2f classes and usually gets close to a 6 (top) in teaching scale. Obliviously it's hard to get all that across in the online format. So he actually quit (teaching online.) And another colleague (you interviewed) also quit (teaching online), so now it’s just me. I continue to do it because I've done okay. I enjoy it and the extra income is real important (my kids go to private language immersion school and that's expensive.)

\section{Q: Any other reasons for you to teach online?}

A: When my department chair came to me in 2010 (when DU was pushing online courses, she went around the department), I also thought it was good to learn to switch teaching in dual platforms. I have always been technologically savvy and I taught myself HTML, CMS ${ }^{11}$, I've done web sites. So professionally it's important to me to stay current. The flexibility part did not hit me till later. I am not aware of any other financial incentives besides the initial grant money for the 10-week training (TOW is marketed as 3 weeks but actually extends over 10 weeks). I don't know if the department has money for (developing) online course. If it does, I don’t know about it.

\footnotetext{
${ }^{11}$ CMS stands for content management system
} 
Q: Do you feel you have adequate support in teaching online?

A: I didn't feel any specific administrative support or special recognition other than I write in my annual review. I don't remember any other financial reward like a bigger raise or anything as a result of teaching the (online) course. I think generally it would be nice to see more recognition. I know that's what DU is really pushing (summer courses) especially online summer courses so it couldn’t hurt to do something (to encourage people to teach online.)

\section{Q: What kind of recognition?}

A: I don't know (mumbling.) I guess it can be some sort of attempt to bring summer online teachers together, maybe a picnic with opportunity like a drawing of moderate financial reward, I am thinking sort of on the fly here. I know there is a big push for it and I see in my own department that some of us are falling away and I am still there teaching the class (sigh!) So it seems like if DU really want summer online class to stick, it better get in there and figure out why people are falling away especially and see if there is anything they can do.

Q: Do you feel you are recognized for your teaching online efforts in the tenure process?

A: I don’t get to see my own review. I don’t remember any specific mentioning of it. I went up for tenure last year and I just chaired someone else's tenure review. It's your colleagues who write the report. You write your own portion of it and in the portion I wrote I did point out that I was teaching online for three years as part of the 
mandate of the university. But I don’t think it has really helped me that much. I can't see any specific promotion, reward or recognition I can point to as a result of me teaching online. I think being a good online teacher consistently for 3 now going on 4 years in a row without recognition is disappointing to me.

In terms of hurting me, not in a direct way, it does reduce the amount of time I can spend devoted to scholarship. It took a lot of time initially to reformat the curriculum and teach the class online. Any extra teaching you take on reduces the amount of time you can devote to scholarship, which is generally what get you promoted and raises, unless you are the top 5 percent teaching people. Summer is usually a block of time I can write. Winter break I usually have to do other things like reviewing other people’s tenure package.

\section{Q: Does it take you more time teaching online?}

A: I have not done a log but my sense is pretty similar. Hard to compare summer classes because it's a compressed version. If I extend the 4 weeks across 10, I am probably spending less time teaching online because I don’t have to be in front of students. It takes a lot of energy to keep students engaged for 3 hours everyday for 20 days. I guess people teaching (summer) online can select the 9-week option but then you will feel like you are spending the whole summer online.

\section{Q: Has your teaching style changed?}

A: Hard to know for sure. I always respond to students' emails promptly for my f2f class too. I view myself as pretty customer oriented. I don’t have a textbook for the f2f course. All the articles are online. My presentations are online. I posted some 
short audio clips of my lectures online. I used Blackboard pretty extensively for f2f classes before I ever taught online.

The summer courses are compressed in 4 weeks and I emphasize my expectation early usually a few days before class that there is writing assignment due everyday. I use more short video clips for online courses. At the beginning of the class they post pictures and a short bio and introduce themselves to each other. I have high percentage of athletes in my online course. I had one student who did not like her last online experience but took this class and liked it. I wish for the discussion board (in Blackboard), whenever people post, their pictures and bio would pop up. For me it is actually easier to keep track of online students. Maybe because of the compressed nature so they know they can't screw around. I have fewer problems with online students. Maybe it is a self-selecting process. I don't know. There are lots of variables.

\section{Q: Any other comments about online teaching in general?}

A: Next summer may be the first time I won't teach online. I am getting ready to go on one year sabbatical with a Fulbright scholarship after this (online) class. I like to devote next summer for scholarship since I couldn’t last few summers. When I come back, I probably won’t teach online during the regular school year since I have to be here anyway.

My perception of my colleagues' perception is they feel probably online courses seem not as good (quality) during the regular school year. Some colleagues quit because they miss the f2f human elements. Another tenure-track person in my department is teaching (online) for the first time this summer. For me, in certain 
cases I actually develop better relationships with students than in f2f class. Last summer I had a student who is a single Mom and I probably would not have that personal understanding if she were in the f2f class. I don't feel online is impersonal necessarily. Because of the compressed format, I interact with online students everyday, which is more than the f2f classes. That's probably not just online but also the compressed nature of class.

It would be nice to bring online instructors in, say, for free lunch and bring us up to date with what's going on. But that takes organization. The academic reward structure is so heavily weighted by publications. I am not against scholarship. If the university wants to encourage more people to teach online, it would be nice to know that it's not going to hurt us but actually help us in tenure and promotion. But that's hard to change because there is such a long history of academic culture.

In DU the teaching load is higher, although we are on a quarter system (rather than semester system), that's still 2 more (6 v. 4) courses. More visible incentives like perks or retreats from higher up would help. I am hoping it’s not a stick but a carrot. They should try to find out what percentage of faculty is teaching online and what percentage is sticking with it. I don't even know if the university knows how many online courses are offered by which school and what's the number of enrollment, if it's that important.

I feel kind of alone and doing my thing. It's hard for me to participate in subsequent OTL workshops because I am busy. If I am offered more incentives, more time, and more recognition at the front end to develop them (online courses) and on the back end to continue to teach them, I can see myself being more involved. 
Q: What's been rewarding?

A: It's rewarding in the sense that I get to know (online) students well that defies the conventional wisdom of teaching online. But I would not want to teach all my classes online. The challenge is to know people well in the online environment. I use the tools that are available to me pretty well. Maybe more real time stuff will create more a collective sense for the students. I think students miss out the collective social component. They are not going to have the sense they are in a class with a bunch of people. College in general is about learning with life, living on their own, and dealing with other people. Not sure what higher education will look like in 10-15 years.

Q: What advise do you have for tenure-track faculty who are interested in teaching online?

A: Try it. Take the risk. Open to the possibility of teaching online. Try to put your preconceptions aside. Enjoy the flexibility and other positive components. Maybe hybrid works better for some people. If it's still not for you, at least you know. 


\section{$\underline{\text { Summary for John }}$}

John, a professional in media, film, and journalism, is soft-spoken and quite thoughtful before responding to each question, although he claims he can be very lively in f2f classes too. He has always been technically savvy. He is self-taught and used many interactive tools and many functions in Blackboard well before he ever taught online. He also published journal articles on his experiences in using ICT tools for international communications in his (f2f) classes before he taught online.

He signed up for TOW training in spring 2010 when his department chair was soliciting participations. He has taught online every summer since 2010 after his initial training. However, he was a bit intimidated initially on technologically how to transfer the f2f content online. He made some adjustment in content as well as assessment method in his online course. He teaches only undergraduate courses and has excellent teaching evaluations for both $\mathrm{f} 2 \mathrm{f}$ and online classes. He teaches in the summer for the extra income and prefers online format because it offers more flexibility for him and the students. In addition, for condensed summer classes, he prefers online format so he does not feel as tired when trying to keep students’ attention for 4 hours every day for 4 weeks in f2f classes. He feels it take him less time to teach online and he can provide students with more individual attention of which probably would not be available in $\mathrm{f} 2 \mathrm{f}$ format. He has utilized most tools available to know online students well but would not want to teach all his classes online. He believes students come to college not just for education but also to learn how to live, learn, and deal with people on their own. He feels that students will miss out on those social learning opportunities online. 
Although he self-reported his online teaching effort in tenure review package last year, he is not sure if any special consideration was ever given for his online teaching effort. He wonders how the university will take the online teaching efforts into consideration in the APT process, especially if the university really wants more people to teach online. Some of his colleagues taught online but decide not to continue. He is still doing it but feeling isolated. He also feels more incentives and recognition would help to keep the momentum going in moving faculty online.

\section{Participant 3 -- Bill, the organizational management consultant}

\section{Interview with Bill}

Q: How long have you been a teacher?

A: Oh my God, way too many years, about 60 (big laughs). Let’s say 25. 20 plus will be the correct answer. I've been here (DU) 14 years now.

\section{Q: When did you start teaching online?}

A: I incorporated an online business or strategy simulation game into my classes probably 12 or 13 years ago, after the second year I came here. Students could create and run the company (and everything else) all online as part of the class. Then I took that simulation game and put it as a part of a hybrid class without any training, maybe 6 or 7 years ago. At that time, CTL was also not that involved in training or certifying people, so I did it myself. So we would have some class sections, not too many, on Blackboard and online, plus the simulation game they can play without my interference. Of course I would look at the results and give them feedback. So I was 
probably one of the few did all this without training. I figured I have the simulation game and Blackboard as a medium for instruction and exchange information with students, so why couldn’t I put it together (for the students)? So I did it all by myself.

\section{Q: Why did you do that?}

A: Why did I do that? I thought it was just an extension of what I was doing in class. Part of it because it was interterm, it was a good medium of instructions. I still could create a good learning environment, very rich. If I wasn’t here, they could still learn. It was 5 weeks (the entire winter interterm.) There wasn't any regulation on how it could be or how long it should be. So I thought I could do my traveling being anywhere in the world and still interact with my students. Feedback from students was very positive. More and more it became entirely online (the last couple times.) I went through the certification (TOW) later. I started doing it without even knowing what I was doing exactly but I learned as I went on.

\section{Q: How did you learn?}

A: How did I learn? I was one of those people who've never been afraid of technology. I learn things all on my own, whether it's a statistical package I never used, I would ask colleague if they could do certain things, if they don't use it, I would get couple books, read it, stumble a few times, and implement it. Technology is one of those things that never bother me. Whether it's for research, I learn something from you today about recording, an app., just learning by doing. Part of it was that I used that simulation game for a number of years. So I have the tools to 
integrate into online class. I was already using that for my (business strategies) hybrid class. Students’ responses have been very good.

Q: Do you and students meet in person for online class?

A: Students would make presentation to a venture capitalist and to me, either through Skype, or etc. Last summer some students were not here, one was in Telluride, two were in Kuwait, and two were in Beijing. We used "Oovoo" (an app) so 12 people can simultaneously (real time) talk and see each other. One student in Beijing did not have a good connection so I put her on Skype on a separate (second) computer so other students can see her too. I used Adobe Connect for audio for another student in Beijing who did not have the bandwidth for video conferencing. We do this 2-3 times for the course, usually at the beginning, the middle and the final presentation. The rest of communications are online (asynchronously.)

Q: Is this an undergraduate or graduate course? How big is the class?

A: It's cross-listed for undergraduate senior and graduate students. The class is usually 12-14 people and capped at 15 .

Q: Has your teaching style changed?

A: I don't use the simulation game or discussion board for f2f classes anymore. I use them (the game and discussion board) for online class now. The learning outcomes are similar. 
Q: Do students fill out the same teaching evaluation form?

A: Yes. The interterm students fill out another form for the special program office (for all interterm courses both $\mathrm{f} 2 \mathrm{f}$ and online) regarding student satisfaction but I don't get the results for that one.

Q: Will you teach more online course this year?

A: Last year we started requiring all incoming freshmen and transfer students take the Gateway class (BUSI 1000-f2f.) In 10 weeks they learn 10 different topics. And they develop an app for iPhone. Last fall we had 12 teams in front of "Angel investors" who then wrote them a check to develop the app. I tried to put this course online this summer but the class did not fill.

I have a business negotiation (course) idea I can probably do it online. I will probably have to change some of my other $\mathrm{f} 2 \mathrm{f}$ courses (for online) if I want to teach more online courses. But I would probably do it only in winter interterm or summer because during the year I am already here.

I used to schedule department classes. I went around the department to see if anyone wants to teach online but did not get much response. Now just me and one other professor (in my department) are doing online classes.

Q: Why do you teach online?

A: In a way it is the future. Students are incredibly tech savvy and I don’t want to fall behind. Even f2f classes they want to be online. I put all the contents online. Even when I use a text, I put it online, they can purchase it from Harvard Business Publishing if they want. Every piece of information they need is online. All the texts 
for all the courses from last year, this year and going forward will be open source (free of charge.) We are not using a textbook. When I do use parts of a textbook, they are always online for purchase or free. The readings they can access from Penrose library online. I hardly ever use a textbook like this anymore (hold up a paper textbook.) (As he pointed toward the books on his book shelf,) they are obsolete. Students can get a hard copy but they don't. They like to read it on their iPad or phones. Chapters from my own books now I make a PDF of it and make it available to students free of charge. These (books) are all going to go away. Myself, I try not to have (paper) books anymore. I use my iPad to read. I don’t have a Kindle or Nook. I stopped using paper a while back. I read newspapers online. My wife (also a professor) still likes (paper) books so she goes to library or buys them. Every once in a while I will have a book but the rest of the stuff (pointing to all the books on the shelves in his office again) should just go into the recycling bin.

\section{Q: Maybe a barn fire?}

A: I always tell my students at the end of the quarter you should sell your books so you can have beer money. You are going to have a barn fire with your notes and jump over it while you are drunk. The only things you have is in here (pointing to his head.) I totally agree with you. Those are the exact words I use (barn fire.)

\section{Q: What other incentives for you to teach online?}

A: I see some demands for it. Not every student feels comfortable with it and not every faculty feels comfortable with it either. Some students hate it. Some students 
think it's easy but it's not. Every once in while I get one of those. It gives them a lot of flexibilities in some way. It's not just for me but also for students.

And I see when you got 140,000 people signed up for a MOOC class, since when did any one of us ever taught a class for 140,000 people? Even if a lot of them drop out it is still a lot of people. If there is such a demand for it, so maybe when I first taught online I was swimming against the crowd, now I am swimming with the crowd. Back then if you tell people (you are teaching) online, they say yeah-yeah (facetiously.) Online is not easy. I am not satisfied with the rigor. I am not expecting everything I expect in an online class. And the students who are motivated learn a lot, like this game they have to play on their own and there is no team to hide behind. It is a lot of fun. In f2f classes, often if there are 5 in a team, 2 of them are working and 3 of them are floating along.

When you are online there is no place to hide. They learn a whole lot from each other and on their own. Most (f2f) classes are usually just division of labor, one does a little bit here and another one does a little bit there and at the end of class they staple it together. It’s (online) not easier. I am not lowering my standards. Student learning is my incentive. If they need to go somewhere else for internship while they learn, that's fine. Its kind of like hitting multiple targets with this (online.)

\section{Q: Did you mention it takes more time?}

A: It takes more time (for students.) But it's hard to argue with yourself and you don't have to try to figure out meeting time with other students or disagree with them. They learn on their own. In many ways I see positive (learning) outcomes, not negative outcomes. 
Q: Any support from the administration?

A: No administrative support. No course release. No matter whether you teach it the first time or the $5^{\text {th }}$ time. With regards to technical support, I don't seek it. I am pretty good at figuring out how things work. Daniels (College of Business) does not have good technical support. There is neither encouragement nor restrictions from the administration.

Q: Did you develop the (online) curriculum yourself?

A: Yes.

Q: Do you feel you are recognized for your (online) efforts?

A: No. No recognition. No support. No resistance.

Q: What advise would you give other tenure-track faculty who are interested in teaching online?

A: Definitely take the class (TOW.) Not only is it required also it's a good thing to do. Don’t be afraid. Learn as you go. Perhaps when I started hardly anyone was doing it. I incorporated things along the way. Now there are so many things online. (Back then) I wanted to teach online and nobody said no so I did it (big laugh.)

Q: Support groups?

A: If there was one back then, I didn't know about it. Part of it was I already had the online simulation game in my (f2f) class; it was kind of easy for me to transit (online.) Now there are so many people doing it, so many books about it, so much 
stuff online. Back then if you say online people will say, "gee, that's an easy class." It's not an easy class. Now it's information overload.

\section{Q: Any other plans for online courses?}

A: I'll eventually probably take some f2f classes during the year and put them online. I got to talk with couple other people see what they think. We already have registration for fall (quarter) so I can’t change those. For the future is doable. Technology is not an issue. It's (technology) so much easier, so much smoother and so much more available.

\section{Q: Any other issues?}

A: For the Gateway class it's a group of us teaching. We have to come to consensus on who will try their class first. It’s a very unique class.

\section{Q: Any other insights?}

A: People need to understand that online is not easy nor lack of rigor. The perception is if you teach online you won't do it right or do it the way you want. Nobody mentions it but it's there. They might think because someone is teaching online that person does not have to do as much work, when in fact it is more work.

Q: Do you feel teaching online can interfere with people's tenure process?

A: I am on the APT committee (one of six.) I haven't seen it. My gut feeling is APT doesn't distinguish whether courses are online or not. They just look at whether the person is a good teacher (same teaching evaluation form for both formats.) Now we 
(the administration) are thinking about allocating more (teaching) points to online courses but hasn’t trickled down to APT yet.

Q: If it takes more work and I am already short on time, why do it then?

A: I guess if your department chair is pushing it. There is no job requirement says you have to teach your class online. I only got one response when I asked my department people about teaching online the last two years. I don’t see anyone prodding or recognizing or supporting it. But at the same time the Provost is talking about teaching more online and there is a task force at Daniels (College of Business) is looking at it. So let's see what happens in the next 2-3 years. We are far behind than a lot of other schools.

Q: What's the (Daniels) task force looking at?

A: I am not on the task force. I asked twice to be on the task force. They are looking at more use of technology for teaching online and hybrid classes. I don't know the specifics.

Q: Do you consider yourself a better teacher after you start teaching online? A: Students are changing. Their expectations are changing. Hard to tell. I don't know if I am a better teacher or not. I am just using a different medium for instruction. The problem is when you use more and more technology, you don't know in the f2f classes they (students) are on their computer, if they are doing their (personal) thing or actually paying attention to class. There is no guarantee that f2f is 
the better learning environment either. I am torn. A lot of it comes from selfmotivation whether it's f2f or online, undergrad or graduate (students.) You taught both so you know what I mean.

For the first time for a (f2f) class, I created a Facebook page for our class and held our first meeting there (on Facebook.) One thing I have not done in the past for f2f class is to put my voice/video over the power point slides (on Blackboard,) which I am considering, which means more work. It doesn’t come easy.

I use technology wherever I can. I use a lot of video clips from CNBC, CNN, WSJ, etc. for both (f2f and online.) I am one of the few people can download almost any video clips on the Internet (and put into my LMS ${ }^{12}$.) I download the videos and put on my computer so when I go to my f2f class I don't have to rely on the Internet connection. I know I will never catch up with students. I just don’t want to fall too far behind. Sometimes I have to call my 18-year old son to come help me with something. Most of time I prefer not to call tech support. I spent hours trying to solve my problems before I go to tech support.

Q: Why?

A: That's how I learn. If I go to someone and they show me real quick (clicking his fingers), I am clueless what they did. If I have to go to someone I will ask them to show me (step-by-step) what they did but that's my usually last resort. I learn by going through the process, which may take longer but I learn new tricks.

\footnotetext{
${ }^{12}$ LMS stands for Learning Management System
} 
Q: You mentioned students are changing, how?

A: Many of them are more technology savvy. Some are not (know less than I do). I learn from them and I teach them so it goes both ways. I told you my app (for recording) so now I am going to go home and spend \$1.99 to download yours. I am a fairly early adopter in many things. One thing I regret is I should have switched (from Blackberry) to iPhone years ago. I am constantly looking for new things. I hear something and I'll try it.

\section{Q: Do you go to professional conferences?}

A: I have not gone to other professional development (teaching online) conferences in person. I attend many webinars. I only have $\$ 2000$ travel budget so I use it for our “Academy of Management” conference. But they (Academy of Management) don’t talk about online teaching much.

Q: Anything you like to say to your colleagues about teaching online?

A: I think my colleagues need to JUMP! Not if, but how high and how fast.

\section{Q: How do you propose they do that?}

A: The same way I learn how to swim. For years I didn’t know how to float when I learned to swim. So I have this fear of drowning. I wore a nose clip, swam from the shallow end of the pool to the deeper end of pool, got out and walked to the shallow end of the pool, jump in again and do the same thing. One time the nose clip came loose when I was jumping in the water, water came right into my nose, so I quit. My 
friend was the lifeguard. I asked why he did not come save me. He said you were on the shallow end and you could have walked, you wouldn't drown. He said the next time you can either jump in or we will throw you in. I asked them how they're going to throw me in. (Then) I said I will jump (in myself) and I (subsequently) learned how to swim.

Sometimes you just have to take the plunge. People who are not are going to get left behind. There is no way we can compete with others (schools) who are doing it. I don’t know if students are willing to pay $\$ 40,000$ a year or $\$ 100,000$ a year in a few years to listen to us bore them to death. They (students) are changing. I've been teaching for 20 plus years but I am not ready to retire. I better do something.

I have videos of myself from years ago on VHS. I didn’t put them online. I review my own videos so I can improve. I used it for myself but I may use some for my class now. I will have to break down the video piece by piece because people's attention span is not that long. In f2f class at least I can jump up and hit them in the head if they are not paying attention. I do a lot of animation in (f2f) class. Online they can pause, go drink a beer and come back (to the video.) They are in the driver's seat. I have to make it (video of my teaching) more user-friendly. It's work.

We got to have more incentives, more recognition. For some people it needs to be extrinsic like a carrot. For some people it’s risky because they've never done it.

\section{Q: What kind of risks?}

A: They may not get good teaching eval(uation)s which hurt personally and professionally, the fear of the unknown. Some of them still use a lot of (printed) 
handouts. Some of them will never teach online. Some of them are older and getting toward the end of their career.

Q: Any way to make people feel more competent about technology?

A: Maybe team teaching. Have a younger (more technology competent) professor team teach with an older (more teaching experience) professor.

Q: Do you mean mentorship?

A: No. Don’t ever call it mentoring or coaching because no full professors want to be mentored by assistant professors on anything. You can say the full professor is mentoring the assistant professor on teaching, but you can never say the assistant professor is mentoring the full professor on technology.

\section{Q: What would you call it?}

A: Team teaching. The older professor learns technology from the young professor and the young professor learns teaching experience from the old professor. It's a two-way street. We used to have team teaching but were discontinued. You know we are on a (teaching) point system, right? When you teach a class by yourself is 40 points but the team-taught class is usually 50 or 60 points allocated to the team. It was expensive and financially it was not sustainable, so we went back to solo teaching, very few team teaching classes now.

But I think the team teaching concept would work where people learn from each other. If you want to bring the old people into the technology realm, then team teaching with assistant professors, give them more points or some other rewards. 
Maybe even tweak the ATP considerations. It's a two-way street. Somehow it has to be appealing for full professors to want to learn technology from assistant professors. And make it appealing for the assistant professors to take the time (to teach older professors) and take the risk of somebody else (full professor) watching them (for a full quarter.) There should be financial, recognition, and some points for tenure promotion (considerations) for both parties. Team teaching will take the fear out of the old timers who've never done it (teaching online.)

\section{Q: How do you continue to encourage people to do it?}

A: Financially it's always an issue. But if you (the administration) really want to do it; you need to put some money aside. The OTL grant is only $\$ 4000$ one time; it’s ok but not sufficient to drive a lot of people to want to do it or not to do it. I did it before there was $\$ 4000$. For me I'll do it with or without the money. Some people need more than that. They (the administration) really need a number of paradigm shifts to create that cultural change. The OTL training is good but not sufficient. It needs to come deeper into the trenches to colleges and departments. Not just one department or one program.

Q: How do you change the culture?

A: Getting rid of the fear some people have. Make it easier for them to take the plunge. And give them incentives and support to do it at the department level. 
Q: How do you take away the fear of being punished (for trying something new)?

A: Colleges and departments have to accept the fact that sometimes when someone does something totally new to them, they should be exempt, meaning they would not be frowned upon by the outcome for say the first 2-3 times. You want to teach online, at the end of the quarter you get to decide whether you want that teaching evaluation counted or not counted in your review. So the faculty can decide for themselves. Take the risk out of it for a while.

Q: Students don't want to be guinea pigs, do they?

A: You have to start somewhere. If you (the administration) want faculty to do it, you have to take some risk. Not all professors have good f2f eval(uation)s all the time. It's not because it's online. The risk is there anyway (in either format.) The downside (risk) is really manageable.

You have to improve the "buy-in" from faculty. With the new hires you can make it part of the job requirement. They are the easiest ones to bring them into the system. Just add one more line to the job (description) posting as a requirement. It's the end of story, very easy to solve. Just tell me how much new blood you need and I can hire as many as you want. With the old timers it's hard. If you (the administration) really want to speed up the adoption process, then it’s teaming, supporting, acknowledging, and rewarding. You (the administration) got to do something, otherwise they (tenured faculty) won't. For some people even if you give them everything they still won't. But at least you take a few people who wouldn't do it on their own and bring them to the table. 
I did not have a mentor for teaching f2f. Most graduate schools don’t teach people how to teach. I didn’t have a mentor for online teaching either. I learn as I go. My teaching evaluations did not suffer. It certainly has been an evolving process for me too. I learn new things everyday. If I don't learn one new thing a day, that's one day wasted in my life. For me, learning (has been and) is my motivation. OTL does good training but it's not sufficient. We need cultural change and paradigm shift. Faculties are not dumb, they can learn. It comes down to motivation.

\section{Q: What motivates the institution?}

A: Competition! I don't see the traditional (ivory tower) model beyond the next 1015 years. The model has not changed for a few hundred years. When universities can make their courses available free of charge. I remember using the mainframe in graduate school. What the next generation will use? What's their expectation? I may be retired by then.

\section{Q: Some institutions are doing it.}

A: They do a better job at it but they don't have all the answers either. My son is 18 and he usually has the answers for my questions. I ask him where he learned it, he will say the Internet, the TV, and he is usually right. He knows a lot but I would not say he has a lot of wisdom of what is right and what is wrong. They (students) have a lot of information but whether they know how to apply it is a different question. Some of them think they know it all. How do higher education institutions reach those who know a lot and those who think they know a lot? People need to learn how to learn! I have a lot of questions on my mind. 
For many years I thought books are obsolete. I have written a few myself. One day, will universities become obsolete? Lots to think about. I do my share but I don't know if I will be around to see what happens. The one thing universities offer is the social environment. Students get together, getting into mischief, drinking beer, getting drunk, and living with roommates, those experiences you cannot duplicate online. So in some ways universities have their role. F2f is still good but needs to tweak and change to some degree, how much? I don't know. I don't think it'll be gone. It has to change. It has to provide more options. It has to think about the learning styles of more people. Can we blend those attractions (of f2f and online) together? How to make those marriages work? I don’t know. But don't reinvent the wheel if you don't have to. There is no time for that.

Technologies are tools. We (as professors) evolved over the years too. We are not totally obsolete yet but we have to change. I would love to see what you write. It's (this study) very timely.

\section{$\underline{\text { Summary for Bill }}$}

Bill is someone who never stops learning. He learns new things from almost anyone he encounters in his professional and personal lives every day. He is extremely tech savvy and loves to figure out how new things work on his own. He started teaching online more than a decade ago well before distance learning was ever mentioned in any institutional or academic conversations. Therefore when the university started to promote online courses in 2009, he chose one of his courses 
where students already using online simulation game as his first online course. In addition, the online format offers flexibility for him and his students to travel, work on internship, and learn during the interterms. He teaches both undergraduate and graduate courses. He thinks students are very comfortable with technology and have a lot of information available to them. However, he feels that students don't necessary know how to build wisdom with those information. He feels students come to college not just for content knowledge but also need to learn how to learn, how to distinguish useful information and able to apply those knowledge in real world. It is important that students know how to utilize the tools and sources for their professional and personal lives. He believes textbooks are going to be obsolete and uses mainly open source (free online) materials for all his courses, both f2f and online.

The TOW workshop was helpful but was not his primary source in learning how to teach online, although he believes it would be a great starting point for others. In addition, he suggests that the faculty should be prepared to continue to update their craft and improve their courses in the digital realm. He did not have mentors for teaching f2f or online but has done well in both. He is very personable and can be quite persuasive as a teacher. He is multilingual, taught and lived abroad in different continents. He teaches international management and business strategies. Dealing with an increasingly diverse international student base, he believes his colleagues need to take the plunge and harness the digital power beyond the academic boundaries. Spoken like a true management consultant, he offers invaluable advice 
on how higher learning administrators may reduce the risks and suggests ways to engage faculty in the transformational process to teach online.

He is concerned the perceptions of online education have been hindering the online faculty adaptation process. Without the much needed paradigm shifts and cultural changes in dealing with the increasingly diverse student base, he believes many traditional institutions would not survive beyond the next 10-15 years. He believes institutions need to be fully committed in online education in order to stay competitive in the industry. Since he is not ready to retire yet, he figures he better do something to try to keep up with his students' generation. He worries about the future of higher education in general but is optimistic in using technology in enriching lifelong learning for everyone. 


\section{Participant 4 - Mary, the marketing guru and online expert}

Interview with Mary

Q: How long have you been a teacher?

A: I finished my PhD in 1995 so I have been a teacher here for 18 years. When I was in graduate school, I taught 4 out of the 5 years. So total 22 years.

\section{Q: When did you start teaching online?}

A: Well, very recently. I took the $3^{\text {rd }}$ teaching online workshop (TOW) they offered at OTL in 2010. I taught that summer 2 courses online, “brand management” and “public service marketing” in 2010. We had a client, a local government we worked with (for the public service marketing course.) Since then, I have not taught any online classes.

However, now the environment is changing such that in the department here that we are launching more and more online classes. In my department here I have 67 faculty members who are certified (by OTL) to teach online. As an administrator, it has been very useful to me to understand thoroughly through the Sloan- $\mathrm{C}^{13}$ work and (our) teaching online workshop (TOW) how an online class supposed to be structured. So you have the three presences ${ }^{14}$ in it, you really can give the students the good solid experiences.

I kind of have two roles. One role is myself as a teacher (of which) I am doing this quarter a blended class and I am hoping Daniels (College of Business) would allow me to teach my other class in online format. They (DCB administrators) are

\footnotetext{
${ }^{13}$ Sloan-C offers many online workshops. Mary recently completed the 1-year online teaching certificate for her 1 year sabbatical.

${ }^{14}$ Cognitive, social, and teaching presences in community of inquiry framework
} 
still a bit hesitant because students say I pay so much money for tuition I want my teacher in the classroom. I am pointing out to them that these students are going to be working for global businesses where they may not be f2f with their team members and they really need to be able to feel very comfortable with the online tools we use in the online learning. So I am hoping by next year I will be able to teach more classes online.

However, in my role as an administrator, as the chair of the department, I told my people as they put their courses online, we are shooting for the quality matter standards with those classes. We are introducing a brand new online marketing certificate in fall that has 4 complete online courses in it. I felt it (Sloan-C certificate and TOW) really helps me learn things about learning, because my $\mathrm{PhD}$ was in marketing and logistics, not in education. I didn't know anything about what it really meant to help people learn, other than my professor got up there and lectured, I guess I will take the notes and provide my lectures to students. This (Sloan-C and TOW) has allowed me to completely change the way I offer it (the course.) It helps me in my f2f class too. It's not the same (f2f) class I would have taught 3-4 year ago.

\section{Q: What has changed?}

A: So, well. For example, they have to do this simulation in (f2f) class on brand management so they have to make all the decisions for the counter cough syrups. So rather than discuss with, talk with, talk at them about what the industry is like, they did some field work with their teammates to the various channels in real life. Each of them will go to convenience stores, mass merchandisers, chain drugstores, grocery stores, talk to the managers, take pictures of the display of the stores, take notes of 
other cough medicines and their prices, try to get a sense of it in real life on how are those things actually sold. And then hopefully bring that back to the classroom so we can discuss what their findings are with a pharmaceutical rep who is willing to come to discuss with those students what they assumed to be the methods of selling through those channels, such that by the time they are doing their simulations they really have a foundation to start building some of their ideas, rather than just reading this little book on simulation.

This particular class has lots of moving parts in it with lots of different things they (students) do. It's been that way since I took over (the department) and redesigned it. They will still do their casework but we are having them reflect on the cases and submit a one-page summery to me prior to class. Before they are only doing the write up if it counts toward their grade, now they are doing the write up so they can contribute to the conversation in the class on that case.

I have inserted a big chunk of the class, say, customer experiences or marketing tactics (online). They will be required to reflect on what they learn to date and write it up and submit it to me, making the connection between what they learn from the resources I give them, how that can be attached to simulation to prove what works in the simulation. So there are a lot more reflections, lots more active learning than there was in prior iterations of this (f2f) class. There is not going to be a test so they are actually going to be graded on their writing and their speaking in class and their contribution to the classes as we go, rather than a multiple-choice midterm and a multiple-choice final in some cases. So the grading methods changed as well. It (changing the f2f class) has made quite a big impact there for me too. 
Q: The online course you taught, was that the same course?

A: No. But it was based on this course. The "public service marketing" course takes the models we know in marketing and applies it to governments. Our client was the government of the City of Littleton. They wanted to understand better how to reach their citizens in a more effective way. So we did an audit of their promotional programs and their marketing plan. We made recommendations. Students used Google Doc to construct their document, which we did not have fun with. At that time it wouldn’t hold formatting so students would be writing and adding to documents and they lose all their formatting, which was a nightmare. So ultimately we changed it so that people who added material to the plan and the report to the government, sent it to an editor and she incorporated it to the ultimate plan.

So we did that via discussion board to talk about the differences between public sector marketing and corporate marketing. We had this document that started growing with the bibliography on the promotional things they are doing currently and things we felt they should do. That was also a fairly active learning class. We (my GA and I) went to Littleton; videotaped all the council members with a set of questions we wanted to ask them. And posted the videos for them (online students) to watch to get a sense of what the council members are like and the politics of trying to make a change in government when it maybe completely sensible but may not occur.

Q: Was this an undergrad or graduate course?

A: That was a graduate course. 


\section{Q: Did the online students meet each other?}

A: The only time we (students and I) met was when we delivered the work to

Littleton. We did meet two days before to go over the presentation, the work they did, and questions to anticipate. And they delivered the work to the City Council of Littleton.

I did have a pre-meeting at the Schneider Board Room ${ }^{15}$ with them before the class started, because I wanted them to understand what they are getting into. In this environment here at Daniels, it seems that people think if you take an online class, it's simple and it's an easy A, it would be no problem. I wanted to make it clear to them (graduate students) they would easily not have an A, perhaps not even have a B, if they didn’t do the work. So we videotaped that (the pre-meeting) and posted it (on Blackboard) so students who couldn't come can listen to me chat about what this class is going to entail. No one dropped. They still wanted to take the class. At least I felt they know what they are getting into.

I am thinking about doing that (video communication on class expectation) for the undergrad (online) classes. I am very concerned with the undergrads, fill these classes instantly think it's easy, are going to find out elsewise when they get into the class.

Q: How many online courses does your department offer this summer?

A: Let's see. One, two, three, four, five classes.

\footnotetext{
${ }^{15}$ Schneider Board Room is a very nice corporate boardroom on the top floor of Daniels building where most important corporate executive meetings take place.
} 


\section{Q: Undergrad or graduate courses?}

A: Two are cross-listed for grad and undergrad both. Three are core undergrads marketing, mostly usually for juniors. Many of those people are going home for the summer or study aboard so they have to leave before summer quarter starts. So it (online) gives these students a little more flexibility.

Q: Are those intense courses?

A: Three of them (undergrad) are 4-week courses and the cross-listed ones are around 8 weeks. The students will really need to work in order to finish the materials they usually have 10 weeks to work on. We've been cautioned by OTL not to condense than them shorter than 4 weeks, so we are not. Additionally I am concerned that some of students are thinking in 4 weeks they will be done with consumer behavior, not realizing it's a lot of work. I think they are taught that online courses are simple.

\section{Q: By whom?}

A: Well, friends. There are many places you can take online classes not necessary at DU. Many places you can take classes online, read the power points online, take the quizzes while you have the materials on screen, you get your grade and you never hear from your professors. Ours (online classes) are not going to be like that. Hopefully I am wrong and they (students) realize it’s a regular high level Daniels type of class and the only difference is the venue. I don't know. 


\section{Q: How do you communicate that (expectation)?}

A: I was going to do a video, now I am not, so I rely on my teachers to communicate

it. (This interview took place the $2^{\text {nd }}$ day after she came back from the 1 year sabbatical and less than 2 weeks before summer quarter starts.) I have 3 teachers teaching those 5 sections, so at the beginning of the class professors will use video to communicate what entails in the class (in the 4 weeks) and here is how it's going to work, to put students on notice.

I noticed that the advising forks put an extra person in one of the classes so now we have 21 in one class and I know there is a DU requirement not to go over 20. There is always some movement with those classes so I am hoping it will go back under 20. Everybody else's class is between 15-18 (students) or so. If the class size grows, you lose the connection with students. Not taking to the extreme of MOOCs for example, you need to keep it (the class size) manageable.

When I went to the teaching online workshop they suggested 15 students and I had 12. I felt like I was operating on all cylinders to get those people continuing to check in with each other, making sure they are viewing things, I was a lot more hands-on back then than I know now, but it was a lot of work. It was also a lot of work for them (students.) I think the learning outcomes are fabulous though. I think (online) there is better chance to deliver excellent learning outcomes than f2f, because in $\mathrm{f} 2 \mathrm{f}$ people can hide or fake it if you haven't done the reading. While if you are discussing something online, there is nowhere to go, you have to discuss. 
Q: You mentioned 3 teachers are teaching online this summer, is this going to be their first time teaching online?

A: No. One of them has taught online for a long time before there was the teaching online workshop. One is teaching online for the first time this summer. And one will teach online for the first time in fall. Those (f2f) courses are not just offered (online) in the summer, they are part of our core curriculum (during the year.) Moving them online has seemed to be very well accepted by the students. We had a wait list and we have to open another section of one of the classes this summer. Students seem quite anxious to do that (online.)

Q: Are there more online courses during the regular academic year?

A: Uh-uh. This summer (online) is a record for us. Going into the year coming up, we are launching a digital marketing certificate, which is going to be $100 \%$ online for the 4 classes (for certificate) plus the undergrad one I mentioned. If I am allowed to teach my other class online, that will be 6 (sections online.)

Q: What's been the hold back?

A: Well, the administration doesn't know what to do with students say "hey, I am paying $\$ 4000$ for a course; I want a teacher in the classroom. I don’t want to read something online. If I want to do something online, I go to University of Phoenix.” So the trick is to explain to them how they are going to get a very similar but different experience online with me that will be far better than the one they will get at (University of) Phoenix. That's a bit of tricky situation because the folks at Phoenix 
have been doing it for a long time and it's not $\$ 4000$ a class. So I think that's the major thing that's gotten in the way of our offering more classes (online.)

Certainly it makes more sense from the institutional perspective because we are out of space. We are teaching as many students as we can, given the space that we have. If we can move part of them online, even spilt them (flip/blended classroom concept), we can teach more people. Our classrooms are full all the time. We can move some specialty class online, which tend to be smaller in size than the ones you are holding in the classrooms. So our core (f2f) classes are likely to be 30-40 people but when you get into the senior level say a pricing class, it might only have 12-13 people in it. And you have to offer those classes because it's part of the MS (Master of Science) program. Nonetheless it takes up classroom space. And it's not like our f2f classes go up to several hundreds like public institutions. For us, the f2f class max out at 40 .

\section{Q: What other concerns for online courses?}

A: There are the concerns of students who don't want to do this.

There are concerns that some of the faculty who has been lecturing forever and now has to learn a new skillset in teaching in online classes. Having gone through the process myself on a deep level, I can assure you that it is quite different. I took my sabbatical to learn it. Many people are not willing to take their sabbatical and put into teaching. They are going to do their research work. If they are going to teach online, having to take the 3-week OTL course seems onerous. I think there are some faculty resistances there. In some ways they say yeah it would be nice to have the flexibility and in other ways they say they don't have the time to learn that. 
And there is a risk that you are changing the calculus. When you teach f2f certain way for a longtime, you can pretty much guarantee what your teaching scores are going to be. Now you have to do something different online and your teaching score might suffer. Teaching score is the only thing we use to measure teaching at this point. Those of us are tenured, I often use myself as a guinea pig as an example, really, what are they going to do to me, it's not like they are going to fire me. But most in my department are untenured, instructors, or adjunct. Those three groups it matters what their teaching scores are. So that's another barrier. They need to have good teaching scores so they will get tenured or their contract get renewed.

So we have students as a barrier and faculty as a barrier. The school is interested in it because they sense it's a way to relieve the capacity issues (like CSUColorado State University) and to get people to go through the program quicker, better throughput is good for students. But as a department chair, you are not going to drag your faculty to teach online.

Luckily, in my view, often there are people who do poorly as f2f teachers, they are wonderful online teachers. I haven't studied this at all. I just have anecdotal evidence here. People who made the best online teachers are very detail oriented. They are very careful with the classes to make sure every little thing is the way it needs to be. Some of us when we teach in class, we are kind of free ranging, someone brought something here and now we are over there, and we bring it all together at the end. You know your topic so well you can do things on the spot. You can’t do that online. I have one person quit (teaching online.) She said: “I can’t do this online. I don't know what happened here but this isn’t working for me, so I am 
done.” Because people have very different teaching styles, it may not translate from the (f2f) classrooms to online. (Teaching) style has to change a bit, you have to think about it, plan a little more, and be more detailed in your rubrics and things you put up for them (students). Even the syllabus has to be written so much differently. I think a lot of faculties just don’t want to do it or may not have the skillsets to do it. They think it's silly (to teach online), or they don't believe in themselves.

\section{Q: Why do you do it?}

A: I do it because I think our students that are coming up now they are the age of my grandkids in high school. That's all they know. And they are very happy with these devices. I believe by the time they (my grandkids) go through college, they will be able to do some of their classes on their phones. Well, I am not saying DU needs to invent a MOOC, but I am saying that we need to be prepared for that generation to give them the choice of doing something online or doing something the traditional way.

We also have larger numbers of people returning to school, as I did, who may not have the time to come here. I really sympathize with them because I got all my degrees when I was working. So I get it about managing a lot of things like family and work. I am also a first generation (that is) far away the most educated person in my family. I didn’t know any boundaries yet I can empathize with people who have never gone to college before may not fit in with the campus environment because it is not who they are but they want the education. 
I also like to learn things. Going through this experience myself has been very energizing for me. I really learn a lot I can apply to my f2f and online classes.

Q: Have it (teaching online) changed your teaching philosophy?

A: Yes! I have not rewritten it but as I reflect on it I will.

I use to be a good deal more control oriented and tight with my teaching in terms of you need to do this and this and it needs to be like such and such, not giving students a lot of choice to think about it themselves and come up with what works for them. Now after I've been away for a year and I am going back in a couple weeks, I am turning a lot of that over to the learner, I am here as a guide, not here as a sage. I will be right here to support you with whatever you need, but I am not dragging you through it.

I think a lot of faculties are afraid of that too because students are used to be dragged through it. And now we are making them responsible for their learning! Woo, I can hear teaching scores crashing around my ears! Because it’s easier to be a passive learner than an "active” learner. So we will see.

But I like the challenge, I always enjoyed teaching, I am not a researcher. I can do it, I was educated at the University of Maryland College Park, and I certainly have the skillsets to do it. But what I really love is to watch that light bulb go off in somebody's eyes (when) they get it. This method is so different from the power points method I've done my whole life and it's been challenging for me to think about it, and makes it more exciting for me. So I think that's why I do it. It's personal fulfillment for me. 


\section{Q: Any other incentives?}

A: Well, they say it's more flexible, once you have it developed it's in the can and doesn't take as much work to update it. I don’t really see those as particular incentives. My life is fairly flexible as is. To me doing it online, like the class on digital marketing, the marketing industry is changing so fast; I can't leave the class alone from quarter to quarter anyway. Would I be relived when I have it set up the first time to teach online? Yes. Because it is a lot of work to do that, so it won't be that much work to do it again. I suppose that's an incentive.

For me not having to be here to teach is irrelevant, because as an administrator I am here all the time anyway. I understand that there are faculties of mine who may see that attractive so they can do their research at home and teach class online. But a lot of what's happening here happens in the hallway; so if we all go home and do everything from home, then you lose the humanity of the whole thing, and lose the cross-pollination what everyone’s ideas are.

Q: So if it takes more time, it's harder, and I have to learn something new, as a tenure track person, what incentives are there for me (to do it)?

A: Right! That's a concern! Unless you are motivated as I am.

As old as I am, I suppose you can argue to stay young. I am 62 years old. I don't want to be one of these people who have no idea how to use the newest device or what a particular application is. I want to be able to communicate to my family's younger generations. I don't think I will be able to do that if I just stay put and do my 
lectures the way I've always done it. Nobody is going to say anything, but I am not giving value to the students.

I am also very customer centric, comes from my business background as an entrepreneur. Eventually students would want more from us than what we are giving them right now. They just don't know it yet. The trick is to help them see what they are missing, in terms of them rolling up their sleeves and learning something they can really remember.

For me, the idea I am continuing to use my brain, I am not going to have Alzheimer’s I hope (big laugh). I continue to love to learn, which many professors do.

There was one thing as I am thinking about it. When I go into (f2f) class to teach, it takes everything I have, because I am an introvert. I know it’s hard to believe the way I am telling you things. My idea of fun is not going to a cocktail party and mingling with people. My idea of fun is going home and read a book. So to get up in front of graduate students who are really demanding, and put on an act where I have to be bigger than life, and make sure they understand what they are doing and really engaging them in the conversations. When I am finished with that two hours, there is nothing left (in me.)

So I suppose moving it online venue once in a while would be a relief for me, because it would be more in my center of happiness. It would be quiet when I do it from home and I can really think about what those people are saying without having to worry about the circus I run in class (with all the activities around me.) I suppose 
that would be a benefit. As I think about it, it would be something that I would look forward to.

\section{Q: What about financial incentives?}

A: It's irrelevant. I get the same pay either online or f2f. Besides the OTL grant, at Daniels, you get a little bit bump when you teach it the first time (either online or f2f.) There is really no (financial) incentive I know of. For the faculties on my team to teach overload, they get the same pay whether teach online or f2f. It may save the halftime lecturer or adjunct a trip in so I guess it saves on wear and tear on their cars.

Q: Do you feel you are recognized for your teaching online efforts?

A: I do! That may be a pay off too.

Q: How are you recognized?

A: Well. It's kind of connected with how I got into it. Our Dean recognized that in higher education, the online area is growing. If we are going to compete and keep our masters, MBA in particular, competitive, we have to eventually move online.

Otherwise other schools will come into our world, like Washington University has, and start taking some of our executive students or other students because they have an online program. So to keep it parry, we have to get into the online space.

So last summer I was chosen by DU to attend Bryn Mawr (College) H.E.R.S. leadership program, which is 2 weeks very intense to learn how to be a leader in higher education. Part of it I have to do a project, so I asked the Dean what she 
wanted me to do for my project. She said I want you to develop an online certificate program. So I thought digital marketing will be a great one because of the nature of it.

At the time when I made the agreement with her (the Dean), I knew very little of it (online program) other than I've taken the TOW class and taught two courses online. But I really thought I needed more understanding on how to do that. So I went ahead with the Sloan course. The Dean talked about me a lot at faculty meetings in front of my peers. I have been on this committee with several others trying to unlock this method of judging teaching using student evaluations as ways to look at faculty teaching and presented it at faculty meeting about it. So I feel that people recognize me as someone who knows about online teaching.

I kind of like being an expert about something. We all do. We all have PhDs. (Laughs) We are experts in something or other. I am kind of reinventing myself as an online expert and I like that.

\section{Q: What does H.E.R.S. stand for?}

A: Higher education resource services. H.E.R.S. recognizes that the old white boys who are running our institutions right now have had that since they were young men and have learned how things work. Women haven't had that, in higher education especially in quantitative fields.

H.E.R.S. began 25 years ago to help women to advance in the administrative positions. To help them unlock the secret of how to become a college president or how to interview for it, what skills are needed, things like that. So they bring in 
people who are interested in that and put courses together for two weeks we lived in the dorm and interacted with each other. I came away with a set of friendship and very good resources. That's a wonderful leadership program.

Q: Why did you take the Sloan courses?

A: I took Sloan because I felt like I needed more detailed information about quality online classes. Because I knew when I am ready to launch those 4 digital marketing classes in September, they have to be great. They couldn’t be mediocre. That would be a recipe for disaster. In fact I will be putting Daniels' brand on the line with these classes. I learn about quality online (courses) from my Sloan classes. I have the quality online matrix. I am working with my professors in helping them understand that. We've sent out syllabi to (marketing) field professionals to see if they seem reasonable.

There is the content and the process. Sloan gives me the process and professionals will need the content. So we will match those up with some very dedicated teachers. I would know what they needed to do to give us a good program in the fall. Prior to this, I wouldn't have known a good one from a not good one. You voice over power points and you give people a test every once in a while and that's about it. That's not about it (laughs.) I didn't know that.

\section{Q: How long is the Sloan program?}

A: They give you a year. I started last October. So this summer I will finish my final project developing course content in Blackboard (what we use.) And (from Sloan) 
there is a mentor/teacher who will go in there to evaluate, grade, and give me feedback on it. Then I will have the certificate.

\section{Q: What's in this one-year Sloan program?}

A: I started last October with their short 3-week introductory class, which they suggested if you haven't taught regularly online. So I did. The intro class was very similar to the teaching online workshop here. But it was a good refresher because it's been a couple years. It was a great class. It introduced us to a lot of things we can read online, and I read them all and completed all the work in the 3-week timeframe.

About two weeks into the program, Sloan started up selling you the certificate. The certificate program is several months long with three additional classes. When I talked to my mentor in the intro class about the environment I find myself in, where people are not sold on online classes, she suggested I get three classes in the master blended series.

With those three classes, they were using backward design around assessing students and what types of tools and activities you need to construct this blended learning environment. And how you move students from f2f to online and back to f2f so it's one class not two parallel classes. So I followed her advice and completed those three classes in March.

Another class is running in the background all the time. There are things like backward design I did not know about at all, which is very applicable for online classes. I learned many more tools than before and continue to learn more. Not that we are just teaching people to use tools. I learned that I have the "course and half" 
syndrome where you try to put too much into a (online) course and everyone is overwhelmed. How do you judge how long a particular thing is going to take online, because it often takes longer? So they (Sloan) taught us this kind of general principle as well as give us time to reflect and work with each other on our projects.

They (Sloan) use Moodle ${ }^{16}$ (it’s free) so you can go into your class every day and see where you are and what you have to complete, read and reflect on the readings, helping a classmate reflect on theirs, so you are continuing with the same group of people through my master blended series. There are about 15 of us. It took a while to learn Moodle but they are very good at posting videos clearly shows us how to use the system, which is very similar to Blackboard.

It was very enlightening to be a student online for both the TOW class here and Sloan classes. With everything else going on in my life, I still have to make time to go in (Sloan class) everyday. I did not do that for TOW. I didn’t check in nearly as often as I should. I barely finished it (TOW.) So when I went to Sloan's, I knew I would need to be in that (online) classroom pretty much every day. It would be hard if I weren’t on sabbatical. I wanted to learn the information.

The staff at OTL warned us that we really needed to set aside the time to do it (TOW) but it did not sink in until we started but by then it’s hard to catch up. If you are not in there all the time, the discussions moved on without you. Oh my God, it moves so fast! That’s why I am concerned with (online summer) students. Of course I am projecting that (concern) on them, which may be completely unwarranted.

\footnotetext{
${ }^{16}$ Moodle (acronym for Modular Object-Oriented Dynamic Learning Environment) is a free source elearning software platform, also known as a Learning Management System (LMS) or Virtual Learning Environment (VLE).
} 
Nonetheless, it moves and it's not stopping for you. I think sometimes in f2f classes things can move quite a bit and people can get back in and fake their way through it. Not so online, it's all time-stamped. It's different! (laughs)

Q: Does synchronous or asynchronous make any difference then?

A: I don't think so. Even in the asynchronous part like discussion board, it really revolves around the classmates who are in the same caliber as you. If you are lackadaisical about it, then it's fine. Where you get in trouble is when you are really interested in it and they all waited till the deadline and swamp in at the last minute, then you are off sync.

I experienced that in my early (Sloan) class. There were a group (5 or 6 ) of us really doing what we are supposed to do. The rest of the class I didn't know where they were and I kind of forgot they were out there. All of a sudden around deadline time, they all come in with tons of comments. A lot of times I am already on the next topic. I wasn't going to go back to comment on theirs. I wanted to move on with my little group to the next topic. It happens to professors too! Absolutely! Asynchronous gives you some flexibility but not $100 \%$ flexibility because you are still moving with your class. There are more variances. You have a little bit of play on each side of the main theme, but once you move out of the window of opportunity, I don’t see how you can get caught up again.

And you lose so much because you lose the opportunity to communicate with your peers. Once I experienced as a "lagger" in the TOW class but I was the front- 
runner in my Sloan thing. I really feel for those people (laggers) because they are paying a lot of money and never going to catch up.

You can put your perfunctory comments in there but nobody is going to comment because they moved on. I have an example (of this experience) in my blended learning class. We had to do this one-page thing, which was a Venn diagram. I have to do a diagram using the part that's in f2f and the part that's going to transition between the two (formats.) It did not make sense to me. It still doesn't to this date. I charted and the teacher told me no, so I would chart again and again. The rest of the class got it the first time and moved on. I am still stuck there in the Venn diagram. Finally I got it good enough she said that's fine. But the rest of class is on the next thing and I found myself running in there and try to figure it out. That's a drawback as a student.

Now I have experienced that, if I see it happening, as a teacher I need to be there every day to check on them and to help them so they don't get into the same situation as I was. Some of them (students) are never going to catch up because they just don't want to participate. The ones who really care, if they didn't get something, I want to make sure I pull them through. You (as a teacher) don’t have to say something everyday but at least you need to peek in everyday to see what's going on and see who's present and what they are talking about. Make sure everyone is mostly in that window (of opportunity to communicate with their peers.)

Q: If I were a professor who is already short on time, why would I want to do it? A: I don’t know if you would! 
There are 168 hours a week for all of us. If you are commuting from the mountains 2 hours a day that could be the reason you are short on time. If you are always going to meetings that could be the reason you are short on time. If it's the commute, then it's a time trade off. You save money by doing it from home. On the other hand, if you are short on time because you are overcommitted to meetings, this (teaching online) is not going to be helpful. It's going to add to the burden.

I don't mean that (teaching online) as a burden. It's fun. But if you go into it thinking you are going to have more time to play tennis, that's an illusion. It's just you are using your time differently. It's not that you are going to get extra time.

I think you make more of an impact. The successful students will learn more in online classes. When I say that, people just roll their eyes and say are you kidding! But they haven't done that. I certainly learn more in my online classes than I ever learn in any f2f situation. But each person has to do what they think is right. It's their own decision. For me, it's worth looking at.

From an institutional point of view, it will help. From an individual's perspective, it's great to really learn something instead of sitting there and having someone talk to you. I learn a lot of great ideas about how to do webinars and retain the information that I wouldn't have gotten otherwise. So my ability to learn has increased by moving over to this (online) world because I have to approach things differently. That's exciting too. We all have our ways of learning. This is a new one and I like it (learning online.) But not everybody will. 


\section{Q: What other highlights for your journey to teach online?}

A: One highlight was I got to know Jenn from OTL. She was my teacher in my Sloan's blended learning class. She told me how she got involved with Sloan. She signed up for the same blended series (as I did.) At the end of the first session, she demanded her money back. She said she knows all the stuff already and she wasn't going to learn anything new. They (Sloan) asked her how they could make the class better. She said she had a lot of ideas on how to make it better, but she wanted her money back. In the end, Sloan hired her as the teacher because she did know more than the person who was teaching the class. Now she is starting at Daniels this month, it’s going to be great working with her and learn more from her.

Sometimes as professors we decided that we are experts in everything, because we can (big laughs). And I think it was a humbling experience to go through this and realize I don't know everything and I really need to pay attention to listen to those much more intelligent people tell me about how people learn.

When I was in high school I wanted to be a teacher. But life got in the way and I couldn't do it. So I ended up in business. Now I am a teacher many years later. I am learning about those theories and faculty blogs on ideas for teaching online.

One thing I would like to uncover is matching the precision of social science research to educational research. I don't know how to do that yet. But I think it’s fascinating.

When you do social research in the business schools, there is very little in the way of anecdotal that goes into research, it's very hard (solid). It's not interviews but rather send the surveys out, analyze the data and write it up. You and I both know 
there are a lot of flaws to it. We've been taught, and our literatures suggest, that to see if something is statistically significant or it's meaningless. When you read educational literature, it’s very much stories recap what people are doing, what they tried and what worked, like what you are doing for this project. Listening to people who have done it and seeing or drawing similarities on what works.

In our (business) literature, for education there is the journal of marketing education. They won't take pieces like that. You really have to make it more quantitative. You have to be able to measure if this person achieved these learning objectives, what worked and how it is going to work. I am thinking an example of comparing a class that's taught online and a class that's taught f2f by the same teacher for the same course. But students are where we run into problems. You can’t let them pick then you lose the randomization. If you do let them pick, you don't control where they go, then you have more bias because the people who choose online presumably wanted that and may be more successful than the ones in f2f. Those are people's lives, they are paying money to get this education and you can’t tell them which class they have to go. I sure like to figure out how to demonstrate that people are learning more online than they are in (f2f) class.

This last conference I went to I listened to a few women who tried to do this and found no difference and they were disappointed. They thought they should have found big differences in learning outcomes. I thought it was huge! From where I am from where everything is f2f, people think online is horrible, to say that you are getting the same learning outcomes is really good stuff! But the methods they were using may not be have been accepted by the journals I write. 


\section{Q: How did they do it (their studies)?}

A: It was qualitative or quasi (experimental) methods.

There has to be some kind of experimental design in my mind, my research background was in factor analysis and regression. So experimental design is a stepchild for me. I haven't done enough of it to know if it works. But it sure would be nice to figure out how to demonstrate the contrasts (between f2f and online) in learning.

\section{Q: Any other comments on teaching online?}

A: Way back when I first got involved. I thought I would have more time and more flexibility. I am not a techie at all. I have this aura that computers just don't work when I am around. Who knows it turned out to agree more with my introvert self?

It's kind of "bait and switch" when you tell your faculty that it's more flexible. Once you got it made then you just have to tweak it here and there. If that's how you got them interested, it's really not a good thing because you oversold the promise. Once they get in there, either they are turned off by the unanticipated extra efforts to set everything up; or they get excited like I did.

As it (learning to teach online) morphs, now I feel that it’s just the right thing

to do. It's fascinating to learn how to teach people how to learn online. How do I use those tools to help students learn? Nowadays we are getting so much information so quickly, like drinking from the fire hose. We need to help students cope and learn how to learn in this world. Not in the world of textbooks but in the world of the Internet. How do you approach that? How do you categorize things you are 
learning? How do you make decisions on whether this material is the right material or not the right material to learn? They need to know how to navigate and how to be literate online. Many of them can't get beyond Wikipedia or Google. That's not turning out good business decision makers I think businesses need. They need to know how to pick the right stuff and use the information the way it needs to be used to be successful. That's a huge motivation for me.

As we are designing (digital marketing) classes, one of the learning objectives it to teach people how to learn, absorb the information that's important, and leave the rest alone. This is what we all face everyday. Your boss gives you a project and you have the whole Internet to look at. How do you do it? We are not using any textbook for those (online) classes because they are outdated. The textbook I use for marketing (f2f) classes, the gold standard in marketing where MIT, Harvard all use it, it's outdated. It (the gold standard textbook) does not give enough treatment to digital marketing.

I can imagine in the horizon once I learn how to drink from the fire hose, it would be incumbent on me to help them (students) learn how to do that. So they can use the information at their fingertips in an efficient way. It's murder right now. I typed my dissertation back in the dark ages. Those students now have more and more information and quicker and quicker. We have to help them (students.) That's my motivation. 
Q: How do you propose institutions market teaching online to their faculty members?

A: Well, I am having to entice my own faculty here (in my department.) I just pointing out how much information is out there, how they are handling that themselves in their own life and in their own discipline, and also the reach they can have when they are online (to people not in Denver) they can draw people from allover, if that's of interest to them. There is some flexibility, for the introverts like me; even a little flexibility not having to go into the classroom can be appealing.

The people who are teaching online for me right now, the flexibility is important to them. Two of them (un-tenured) have small children. One tenured faculty is going abroad to be with his family. They are very motivated to try this because this gives them at least more physical presence with their family.

I am not suggesting my assistant professors to try it because it takes a lot of time. Their first six years have to deal with how much they publish in the targetlisted journals. The rest is irrelevant because they won't be here if they don't publish. It is unfortunate because we say we are a balanced school, where teaching is first (she raised two fingers) and research is second (she raised one finger.)

One tenure-track faculty on my digital marketing development team is not teaching (online) because he has to focus on publishing, although online marketing would be a great area for research.

The academe is starting to accept digital marketing research. They are quite interested in people's behavior online compare with typical consumer behavior like pricing products online, or look up prices online before they shop in stores. But those researches are mostly for commercial use. I think he (the assistant professor in 
digital marketing team) will do it for the same reason I do it -- because he’s interested in a new way of doing things.

I also think at Daniels, first we have f2f, then web-enhanced by using Blackboard as much as we can, and then blended and finally fully online. That's more gradual and less abrupt. There is something to say about moving gradually, mastering each piece before you move on to the next one.

This digital marketing online certificate we are launching this fall is targeted to working professionals, which is an additional market (of students) for us. When those people (working professionals) were in school, digital marketing wasn’t invented but now they are facing it all the time. As a department, we have the financial incentives for teaching online. Indirectly that will give us more money for faculty research and travel.

\section{Q: Any other challenges?}

A: The key one is time and attitude. Changing people's attitude or helping them to see the benefits of doing something like this. Most of us are used to doing the same old thing the same old way. Try to get people to give it a try without be able to incent them with money or time, like course release.

(Intrinsically) trying to get people to see what's in it for them like learning new things or how to manage information. The same reason why they work here rather than working in the industries, it’s certainly not for the money. Relatively speaking, even our accountants for the college can go into industry and make twice as 
much as they make here. As a teacher, you are inclined to help people. You want people to succeed. So here is a new way to help.

You have to change how you reward people. Right now is very one-sided and leave people not wanting to take a chance. To change the reward structure to allow them to be creative and take chances. And if you can give them course releases and additional training in a variety of ways, and help them to see the links on how others have done it successfully. They all want to be successful.

Depends on the individual situations, a little flexibility goes a long way. That's happening to several people in my department. That's a small incentive. I think we need to use different teaching evaluations for online courses according to quality matters $(\mathrm{QM})^{17}$, and not only evaluating the class from the students point of view, but more of a 360 evaluation to get the person to self-evaluate and the administrator to check this against the rubrics he or she used for the (online) class. It is easier to do this online than in the classrooms behind the closed doors. For the good teachers, they will be happy to be finally recognized for their teaching efforts. Whereas the ones that kind of scrape-by either by making the class real easy or not holding class, they will be reluctant to teach online because they will get caught with the easiness.

I like to get to know the people I am working with and see what they value. And try to put together a program to fit their values. Rather than say this is how we are going to approach all tenured faculty, because we are not all the same. We are at different stages of our careers, different skillsets, and different family situations.

\footnotetext{
${ }^{17}$ Quality Matters (QM) is a national standard on online course content.
} 
We have to meet with each faculty and point out the pieces that resonate with them. Having gone through the Sloan program, I can try to identify pieces that may be rewarding, even though it's not monetary. And try to match up with individuals. So far it has worked for my department. It's very much a one-to-one conversation. And appeal to them on an emotional level to design a package for them. For example, for professors with small children, they save on travel time and baby-sitting. For a full professor who has written textbooks, try to appeal to the person that this is the way of the future and technology is important to marketing, so it would be important to demonstrate that by teaching online, using your textbooks, and giving your expertise to the world, not just the 20 people in the classroom. It's going to be a different message for each different person.

Right now there is no motivation for change, none, you are better off if you don't!

So you have to come up with something else. What's the package for you? If someone likes to play golf a lot and teach two classes at night, then maybe say more golf time (laughs jokingly). It's going to be case by case by making the reward structure fit better for them without changing the reward structure as a whole. It's on a very micro level, very time consuming, and not easily done. If you look at Coursera, edX, or Udacity, those professors are just in it because it's fun for them. They tend to be technology driven at the first plan, granted that they are not operating those courses. They have made their names in their fields so the sky is the limit for them. But we are not talking about the same group of people here. ONE SIZE DOES NOT FIT ALL! 
Q: What do you think about the news on Coursera signing with the 10 largest public universities?

A: It will be really interesting to see how they monetize it. Coursera is not just for MOOCs anymore. They are talking about it as a learning management system (LMS) with video contents from world famous professors in their library that you can choose from. I will be shaking in my boots if I am Blackboard, because Blackboard is a pretty "flat" system. If you get Coursera involved and they put their mind to it where they have the best technical people delivering the content, and you supplement it with people like me who can figure out the connections with students, it is unstoppable! They have the content and the logistics figured out.

Most learning management systems are horrible with barely enough to get by. Since they (companies like Coursera) look at content, in such different way, I wouldn't put it past them to look at the delivery in a very different way and come up with something stunning! Since they already have the top 10 major universities signed up, they can pay for sales force to hit smaller universities like DU and other places. That will be so amazing. But that's just me, data point one, as I tell my students (hahaha!)

I have been learning a lot so fast so I haven't had time to reflect on a lot of your questions. I would certainly love to continue the conversation.

\section{Summary for Mary}

Mary recently returned to teaching after her one-year sabbatical, which she devoted to online teaching development. She will finish her one-year Sloan-C online 
teaching certificate this summer. She is probably the only professor on campus that has completed the Sloan online master series, although she admits she is not a techy at all. She initially signed up for learning to teach online in 2010 because she likes to learn something new. The flexibility was not a big incentive for her at this stage of her life. However, as she learned to teach online, she felt online format provided more active collaborative learning environment for the students. She wants her students to have the actual field experiences in marketing and use online venue to interactively share their experiences, rather than just read about the concepts in outdated textbooks and take a few multiple-choice exams. It is important for her to learn how to drink from the fire hose (in describing the vast velocity and volume of information available) and teach students how to do the same.

In addition, after she taught online in summer of 2010, she found out that the online venue actually agrees more with her introvert personality. Therefore she feels a little bit of flexibility goes a long way in perhaps encouraging others faculty members in learning to teach in this new platform. She felt the experience of being an online student help her understand what online learning environment is like. In addition, as an administrator, she felt it was important for her to understand how to design and implement quality online courses and subsequently decided to complete her Sloan-C certificate. She is spearheading the development of a new complete online “digital marketing” certificate for her department for marketing professional to be launched this fall. As a department chair, she prompted 6-7 faculty members in her department getting certified to teach online since she completed her TOW training program in 2010. This summer, her department will offer five courses online 
including both undergraduate and graduate courses. She feels recognized for her teaching online effort by her peers and the administration in the Daniels College of Business. She is proud and invigorated that she has reinvented herself as a teaching online expert in the later stage of her teaching career. However, she is concerned that the traditional institutional reward structure and the rigid academic scholarship culture have not recognized the changing demographical environment in our society with regards to online education. She believes "one size does not fit all" and urges higher education administrations to consult individual faculty member in finding ways to help their transition into teaching online. In addition, she finished all her degrees while working and became a teacher after her business career, thus she empathizes and appreciates the opportunity to continue to renew herself though online learning and wants to offer other faculty and non-traditional students the same opportunities she had.

As a grandma, she wants to be able to communicate with her grandchildren who will be going to college in few years. As a teacher, she enjoys teaching online and believes the active learning environment will provide better student learning outcome. As a learner, learning to teach online has been a humbling and personally fulfilling experience for her. As an administrator, she felt it was important for her to really understand what quality online course is, and to customize training and incentives for her faculty members to encourage their participants and continuous involvement in online teaching. As a scholar, she is looking for ways to integrate qualitative educational research methods and quantitative business research methods for research in the online learning area. As a marketing expert, she suggests ways for 
institutions to market teaching online to their faculty members. Overall, she wants more time to continue to reflect on her experiences in all aspects of her lives and would love to continue our conversations. 


\section{Chapter Five: Discussions}

“We must become the change we want to see.”---Mahatma Gandhi

One reporter asked Bill Gates once: "You are the richest man on earth, what would you like to buy?” Gates replied: “More time.” Two words basically summarized the dilemma of living in the digital age. Everyone is feeling information overload. Everyone wants to learn more but not having enough time to catch up. How to drink from the fire hose (in describing the volume and speed of information) as described by one participant? For the faculty, they continue to deal with the frustration of not having enough time to do everything with regards to scholarship, teaching and service. For the students, the challenge of learning how to learn and building wisdom while they mature into adulthood in this digital environment is not

without concern. The waves of MOOCs tsunami have impacted the structural integrity of postsecondary institutions and are changing their landscapes as we speak. The story of teaching online is still writing itself with no end in sight. This is only the beginning of a long journey into the digital future, for the students, the faculties, the institutions, and the society.

Nonetheless, as a researcher, trying to capture the fast moving moments in people's cyber experiences, it's been an evolving process for me as well. Ultimately, this study is my attempt to get people to pause, reflect, and conceptualize what this 
whole thing means, rather than trying to hold on to another theory or fit into another online faculty development model. These individual stories are meant to inspire new ideas and new ways to conceptualize the problem of integrating online education for the faculty, the institution, and the industry. In the individual stories, our participants demonstrated some of the reasons on why they teach online and some of the obstacles and highlights they encountered on their journeys to teaching online. Their narratives painted a landscape of faculty acceptance in institutions and the online learning phenomena in our society. Interestingly enough, I get the sense that they did not feel that they have reached their destination. On the contrary, they merely embarked on the voyage of learning how people cope and learn in the modern days. They want to learn as much as they want to help others learn along the way. I really appreciate their willingness to share their insights on their experiences so far. I hereby offer my interpretations of the overall phenomena as follows.

In chapter 4, I summarized the responses from each participant directed to answer the original research questions:

1. Why did faculty members decide to teach online and why do they continue to do so?

2. What characterizes the journey taken by faculty members in learning to teach online?

In this chapter, I will summarize the participants' narratives as a group in answering the two research questions in three areas: individual characteristics, transformational exchanges, and environmental concerns according to complex adoptive systems theory. 


\section{Group Summary}

\section{$\underline{\text { Individual Characteristics }}$}

For these few brave souls, despite feeling unsure of the future, they still went forward with their journey. They share some common characteristics: they are great teachers who would never stop finding ways to improve students learning; they all love to learn as learners; and they all demonstrate the desire not to fall too far behind

their students' generation. Although they work within the same institution, they have presented different trajectories into cyberspace. One faculty member remains very critical of online education. She is not uncomfortable with teaching online but rather not knowing why we are doing it is making her uncomfortable. Yet her criticism on online education is also her initial motivation in her involvement in teaching online since she wants to be an informed and experienced critic in the national conversation on online education. While the other three faculty members started out wanting to learn how to do something different, nonetheless, they all got involved in online teaching mostly because of intrinsic motivations, and their intrinsic motivations have sustained their continuing involvement in teaching online.

As they continue teach online, they have experienced the lack of extrinsic motivations within the institutional environment. As a group, their journey to online teaching has been marked by their sense of isolation, dealing with the anxiety caused by peers and student perceptions, the uncertainty of how teaching online fit into their professional development, and the lack of camaraderie, recognition or support within the institutional structure. Somehow they managed to persevere and thrive. Now they have been through the trenches in the cyber front line per se. They did not suffer 
from Posttraumatic stress disorder (PTSD). Instead, they are renewed and continue to enjoy immersing themselves in their inner and outer dialogues on their role as a teacher, their role as an agent in the institution, the purpose of higher education, and the meaning of education in life in this digital world. For them, teaching online is no longer a pie in the sky, it is here and now, although challenging at times, it has been quite edifying for them to learn to teach online.

When I asked these pioneers to reflect on their journey, in most cases, technology is not the issue, regardless of whether they are technically savvy or not. Most have found pedagogically learning to teach differently to a changing student population has challenged their traditional concept of teaching. Similarly, they all took the time to reimagine, redesign, and reconstruct the online courses to try to achieve the best learning outcomes by using the tools they know. All have found that it takes more time to develop online curriculum. The online classes usually enroll between 12-20 students. All except one find it takes more time to teach online. However one argues that although it takes her more time, it really saves her energy by not having to manage all the activities in the f2f class, and thus allow her time and energy to reflect and really focus on students' learning outcomes. The flexibility offered by online format is an added bonus for all but not the most important motivation for some.

One faculty member still uses a textbook but the rest felt textbooks are outdated and prefer open source materials for their online contents. For most of them, the student learning outcomes have been equivalent or better than their f2f classes. Being able to provide students more individual attentions has been rewarding for 
most. Online students mostly like having the option to advance their study while being away in the summer or while they work and try to manage their personal lives. Most students find the online active learning environment help their learning outcome, although a small percentage find they needed more structure. While they all admit it's been an ongoing, evolving, and challenging journey for them, they have managed to find the time to reflect, examine their own beliefs and practices, question themselves, search for answers, and renew themselves along the way. The most admirable characteristics of all, is they all put student needs and how and what they hope their students can learn the most, above and before their personal motivations.

However, while they believe postsecondary institutions need to provide more online options for students, they would not want to teach all their courses online. They believe the social interactions between students and among faculty outside of classes are important contributing factors to the values of higher learning and scholarship. They would not want to see the collective human elements taken away from students' or the faculty’s overall academic experiences.

\section{Transformational Exchanges}

As far as training is concerned, the participants all felt the Teaching Online Workshop (TOW) was very helpful in preparing them to launch their online course. They liked the experience of being an online student in the online faculty-training program. However, they felt that sometimes the OTL pedagogical approach does not necessarily translate well into their subject matters or their styles. Also all have expressed needs for resolving ongoing concerns on pedagogically how to transfer and 
content wise how to adapt additional courses online. They often had to adjust, improvise, and adapt along the way on their own. In addition, most find it hard to allocate additional time for further training or developing additional courses online. Since they all developed their own courses, one faculty member mentioned it would be great to see more training on different pedagogical approaches for different disciplines and perhaps get help from curriculum and instructional designers for transferring additional courses online.

Perception, or shall we say misconceptions, of online learning continues to create unnecessary obstacles in institutionalizing distance education. Some students have the misconception that the flexibility offered by online learning means less commitment on their part. Among faculty, seasoned faculty, who have not taught online perceive the faculty teaching online as slacking off from their job requirements. For some of the administrators, managing student demands of needing more options, and satisfying varying expectations with increasing tuition costs from a much more diverse student population has been an ongoing battle. Often administrators underestimated the level of commitment required from faculty to learn, design, implement, and continue to teach online, and thus overestimate the speed of the teaching online adaptation process.

Also the camaraderie, or shall we say the lack of it is causing some distress on their online teaching moral. One faculty member would like to see more of his online teaching peers on campus through informal gatherings like picnics so they can compare notes and be recognized as a group by the administration for their accomplishment. One faculty member actually spent her one-year sabbatical to 
attend the one-year Sloan online master series training. However, she does not see how or why other faculty would make the same choice as she did. Another faculty felt that one training program (TOW), regardless of how good it may be, would not be sufficient to move most faculty along the adoption process. He is concerned that things would not change much without full commitment by the administration to transform the institutional culture and needed paradigm shifts by tenured faculty. As far as for the students, they all commented that online is the future. They all think students are very comfortable using technologies. However all expressed concerns whether students know how to navigate and learn with the vast amount of information available at their fingertips. They felt, as teachers, they needed to guide students and help them learn how to learn by utilizing technologies to advance students’ educational and professional pursuits.

\section{$\underline{\text { Environmental Concerns }}$}

Looking across postsecondary institutions as an industry, what we have in higher education is a mobile $21^{\text {st }}$ century society shackled to a sclerotic elite mentality. After the study, I changed my own misconception about the process of faculty adaptation of innovation. My prior assumption of technological competence as a prerequisite in moving faculty to teach online no longer holds true. What I found is, it basically comes down to willingness (rather than ability.) I am talking about the willingness to look at online learning without any preconceived bias or mental constraint. The willingness to take the time and risk to step into the unknown, allow the space and try something totally different, stumble along the way, and 
survive it. At the same time, the willingness to be open to the infinite possibilities online learning can offer to students, faculties, the institution, and the society.

For the faculty who stepped forward and took the journey to teaching online, it has been a psychological and philosophical journey as much as a pedagogical one. For every single one of them, it is not only a private journey for oneself but also a public journey as part of the engine driving the institutional future. Those pioneers all demonstrated a heightened sense of awareness of their environment and desire to look into the future. Thus they allowed themselves to look beyond the confines of academe, think about the macro environment, and try to understand their relationship with the world. Their intrinsic desire to learn new things, their fear of getting left behind, their sense of accomplishment of being able to teach in different formats, and to know oneself as a learner and a teacher in the new realm, have helped them overcome the anxieties of having taken the paths less travelled by peers and kept them going.

Meanwhile, they have and will continue to experience ambivalence in institutional structure on how to speed up faculty adoption and how to please different student expectations at the same time. For the few pioneers who have made the journey to teaching online, not knowing where the path is leading to is not exactly pumping the much needed momentum into their further development in the process. Conversely, they felt until the leadership, administrators, and other faculty in higher education institutions are willing to face the changing relationship of online learning as part of our society in the future, online learning will continue to be viewed as an unwelcomed stepchild wishing to challenge the monarch in their institutions. In the 
meantime, they feel perplexed as how to initiate and engage the much needed paradigm shifts and culture change within the institutional context.

In addition, these pioneers continue to search for ways to contribute to scholarship in their disciplines about their experiences in teaching online. However, challenges as discussed in Chapter 2 with regard to research in the online space still remain. First, when scholars try to measure certain learning outcomes or pedagogy, the assessment methods change from their f2f classes. Therefore there is no consistent "unit of analysis” per, se. Second, the different discipline presents different adaptation of online learning models and thus makes it difficult to streamline any coherent research framework. In addition, most research or online faculty development models are based on institutional or students' point of views rather than from faculties’ perspectives. Further, most academic journals still prefer quantitative studies of learning outcomes rather than in-depth qualitative conceptual understanding of the new way of teaching and learning. Therefore there are no incentives for scholarly contribution in their discipline in the online space, nor does the institutional reward structure provide additional incentives for their willingness to take the risks in moving into the online space as a teacher or a scholar. Until the postsecondary institutions are willing to change the current reward structure for the professorate, the alarming gap between faculty acceptance and institutional demands will certainly continue to widen. 


\section{Discussions}

When Gandhi delivered his famous quote, he probably did not see a future where we often can’t even imagine what changes lie ahead. Not because we do not have enough information to make decisions, but rather we have too much information in an ever-faster changing environment in which we might be content to just try to catch up in the limited amount of time we have every day. Gandhi certainly did not ask his people why they wanted to change because he simply knew they had to. If he were alive today, he would probably say change first, and then you will see if you like it.

The study has taught me that those pioneers have been actively seeking ways to change and better themselves as an individual, a learner, a teacher, an agent for the institution and the society. I also learned how the faculty members themselves learned to teach online, how they teach online, what changes they made to their $\mathrm{f} 2 \mathrm{f}$ classes, how their teaching style and philosophy have been transformed, what their aspirations are, and what they think the future entails. This study revealed the reasons and the processes of their journey to teaching online. Ultimately, their stories are really about change.

In their stories, the distinction complex adoptive systems made between “competency” and "capability” seemed irrelevant in their motivation to teach online. Rather, their willingness to confront their own fears and be open to the unknown has propelled them into action as they learned to harness the digital currents. During our interviews, several light bulbs went off for me along the way. Our long conversations have become part of my journey in searching for ways to conceptually map the road 
ahead in the digital frontier. So, staying true to my style of inquiry, I will finalize my thoughts in the following two areas: (1) what has changed? And (2) what do we need to change? I hope this study will help others to conceptually map their road ahead for their journeys to teaching online.

\section{What Has Changed?}

\section{The Shared Context of Change Has Changed}

These stories of those online professors are not just their personal stories. They are a vivid illustration of the changing environment. Complex adoptive systems theory (CAS) (Olsen \& Eoyang, 2001) provides the theoretical framework for examining the organizational transformation at the micro level by categorizing the influences resulting in individual changes in three areas: organizational environment, individual differences, and transformation exchanges. And thus conceptualizes how organizations transform themselves through emerging behavioral patterns and shared values of those "change agents." However, CAS does not provide the reasons why change agents are willing to change at the first place. In addition, the parameters of CSA framework focus on the organization and its agents, which don't provide the larger macro social context in which the organization resides.

Echoing Siedman’s (2006) statement: "how their individual experiences interact with the powerful social and organizational forces that pervade the context in which they live and work, and we can discover the interconnections among people who live and work in a shared context” (p.130). Not to exaggerate, 1.3 Billion people share Facebook, the social networking community that could be an example of 
“shared context." Those changes, as pointed out by Gersick (1991), like biological evolution, are not always incremental. Among our participants,

- Holly, the sociologist, who wanted to learn to teach online because she sees online learning may transform us as a society and wants to participate in the national discussions on online education.

- John, the international journalist, multilingual, held international real time discussion boards on Blackboard with students from three universities on three different continents before he ever thought about teaching online. He believes when student look beyond their familiar news sources, they gain new perspectives in life.

- Bill, the organization management consultant, also multilingual, lived and worked on various countries, understands the values technology provide in working in real corporate environments and wants to help his students learn how to learn with technology in the global economic context. He does not believe the traditional higher educational model will last beyond the next 10-15 years.

- Mary, the marketing guru and online experts, who claims to be technology incompetent at times, managed to reinvent herself as a teaching online expert, wants to provide her professional students the same opportunities she had using online venue to renew themselves in their professions.

Yin stated: "A case study is an empirical inquiry that investigates a contemporary phenomenon in depth and within its real life context, especially when 
boundaries between phenomenon and context are not clearly evident” (2009, p.18).

The concept of "shared context" has indeed changed, and is not based merely on

temporal, spatial, personal, or institutional considerations. Our participants’ new understanding of the "shared context” supports Bonk’s (2009) “WE-ALL-LEARN” framework for understanding the impact of technology on learning in the $21^{\text {st }}$ century. The " $21^{\text {st }}$ Century Skills" Trilling and Fadel (2009) argue for learning for life in our times are not only necessary for students in learning, but also for professors in their professions as well. Leu (Leu, et. al, 2004) further illustrates the interconnectivity of new literacy to our day-to-day learning. Technology has and is changing how we interact, socialize, and function locally and globally. It is a reality, not an assumption. Postsecondary institutions are not immune to this global social transformation.

\section{Change Is No Longer A Choice, It's A Must}

As I review those individual stories, I am reminded again of the parallel of our present day circumstances as described in Spencer Johnson’s (1998) book “Who moved my cheese?” “Teaching and learning,” the bread and butter in higher education, is analogously “the cheese” in Johnson's story. The economic and social forces promoting the use of technology in all aspects of society have metamorphosed. Students, as well as professors, need the flexibility offered by online courses in order to manage their personal and professional lives (Epper \& Bates, 2001) as seen in national student enrollment in online courses of over $30 \%$ of postsecondary institution total enrollment (Allen\& Seaman, 2013). 
In the recent decade in higher education, not only "the cheese” has been moved, it takes on a life of it's own as evidenced by MOOCs. The competitive landscape for higher learning is changing as we speak. Instead of looking at technology as a necessary and important part of our survival for mankind, most people are taking the convenience offered by technology for granted, without reflecting on how and where "the cheese" is taking us. So what do we do and how do we do it? Do we move by "the cheese," move with "the cheese," take the initiative and move "the cheese" to where we like, or better yet, imagine and develop "the new cheese"? Which begs the question if the end, e.g., success of the organization, justifies the means in our attempts to adapt to change, in this case, using technology to teach and learn. What is the role of higher learning institutions in society?

Most criticisms of online learning focus on the lack of human elements. While our participants Bill and Mary believe online learning enables more social interactions and better learning outcomes than in person formats, Holly and John felt online students are deprived of the sense of community, which promotes personal and community growth. With all the rhetoric around the need for new literacy, the ability to cope and learn in the modern world, are we taking those discussions into consideration when designing and developing the "new cheese"? Campbell and her colleagues (Campbell, et. al, 2009) evoke Herda's notion and argue that when discussing online education, not only it is an instructional design issue, but also our moral obligation to engage in such social discourse. This argument resonates with the sense of duty as agents of higher education institutions expressed by all our participants. In addition, as our participants pointed out in their narratives, education 
is only a part of the overall academic experience for both the students and the faculty. These faculty members also view themselves as social agents in promoting social and professional transformations in their students (Beyers, 2009; Bransford, et. al, 1999; Carlson, 2005: Carr, 1998; Dewey, 1910 \& 1938). Although their individual competence and capability as defined by complex adoptive system were not motivational factors when they first decided to teach online, those factors will influence their subsequent professional development as online instructors. In addition, institutionally the extent to which individuals can adapt to change, generate new knowledge, and continue to improve their performance will affect both the faculty's and the institutional capabilities in online programs. A higher learning institution, including its assets, i.e., the faculty, needs to integrate technology into furthering its mission in contributing to the larger society.

\section{What Do We Need to Change?}

Now we have added additional variables into the equation of teaching online. How do we actually incorporate them into the design and hopefully the implementation? I summarized the following observations as consideration for online course development.

\section{Observations for Online Course Development}

All participants from this study emphasized the fundamental change in curriculum development from $20^{\text {th }}$ century teaching from a book and corresponding lecture in a classroom, to a $21^{\text {st }}$ century mobile approach involving active and 
cooperative learning environment (Beyers, 2009; Collins \& Halverson, 2010; Dede, 2008; Johnson, 2005). Although they liked the intellectual challenge, they all admitted being staggered by the commitment required to pedagogically transform f2f courses to online courses. All our participants indicated the students learning outcomes are comparable or better than f2f environment, which is a motivating factor for their continuous involvement. They also believe an interactive collaborative virtual learning environment promotes learning skills and new literacies needed for the $21^{\text {st }}$ century (Bonk, 2009, Collins \& Halverson, 2010, Johnson, 2005, \& Leu et. al, 2004.)

Institutionally, over $85 \%$ of 33 instructors surveyed in 2012 by the OTL taught the courses $100 \%$ online with $58 \%$ of the courses taught in a condensed format, i.e., 4-5 weeks versus 10 weeks. Most instructors reported the intense nature of the condensed format for online courses is similar to the condensed format in traditional courses. Besides having to make some pedagogical and assessment adjustments, instructors felt the online format did not impede students' learning and most reported increases in student participation. In some cases, instructors were able to provide more one-on-one attention to individual student, which was not possible in the traditional courses. Students also take more responsibility for their learning.

Several additional issues arose from analysis of faculty survey comments:

- The faculty member is not only learning to teach online but also learning to develop course content and curriculum based on a new web-based tool. Faculty responded spending an average of 160-200 hours in developing 
course content. Unlike a traditional course in which there is time during the course to build the course content, the online course container needs to be fully completed before going live. On the positive side, once the course is developed, repeat offering of the same course is easier to manage and scalable.

- Instead of a regular 10-week quarter, some online courses are offered in 4-5 weeks. This presents additional challenges in time management for both students and faculty while trying to adopt new pedagogy and rubrics.

- Some faculty expressed concerns about academic honesty and integrity in a virtual learning environment.

- Instructors need to budget additional time for unexpected technical issues.

Almost all instructors surveyed felt they were able to transfer and adapt the pedagogies and rubrics from online courses and adopt them in the traditional and blended courses. In other words, the online instructors are using the tools and skills in their f2f classes as well. From the institutional point of view, the teaching online workshop (TOW) helps the overall technical competency of faculty members regardless of whether they continue to teach online.

\section{Considerations for Online Faculty Development}

As our participants in this study pointed out, the experience of being a student online was extremely helpful for them in reimagine how to help student learn in the virtual environment. These faculty members presented different levels of technical expertise before and after the teaching online workshop (TOW). They felt the TOW 
training is a good start for other faculty interesting in teaching online but should continue to learn, adjust, and redesign their courses. Their TOW experiences have helped them launched their online courses. They also changed their perceptions of what a quality online course look like after the training. They did not feel the lack of competency as described in study by Guzman and Nussbaumt (2009) after a training involving technology. In addition, they also utilized the tools and skills they learned in transforming their f2f classes as well.

Our participants' subsequently changed their teaching styles for both online and f2f classes. Their adaptation behaviors disputed Fetters and Duby’s (2011) staged blended learning faculty development model (Figure 8, p.57). It further disputed Rogers’ $(1962,1995)$ five-stage innovation adaptation process. However, all have expressed the need and the desire for more training and support in developing more online courses, but are concerned about how their online teaching development fits in to their overall professional development as a professor within the institutional and their academic context. In addition, one participant expressed concerns on whether pedagogically online would be the most appropriate delivery method for most of her courses. In one study, Feist (2003) interviewed instructors and concluded they were more likely to sign up for training that could be used right away, fit into their schedules, matched their learning styles, focused on curriculum, included leadership and direction from their department chairs, and included a support person they could all use later. In order to integrate technology into students’ learning, technology proficiency training should be “relevant and recurring”(Corcoran, 2003). 
In addition, faculty may consider partnering with curriculum and instructional design experts to digitally integrate their course content for both their traditional and online courses.

In an effort to connect faculty to the values of utilizing technology and the mission of the University, the current phase of TOW aims to empower faculty participants' technological competence across overall teaching. Besides encouraging faculty grant applications, the OTL is contemplating ways to get more faculty members technically qualified (TQ). Although DU established institutional policies for online courses, it has yet to develop clear policies for ongoing support, course development, and evaluation. Boyd-Barrett (2000) suggests institutions should not make decisions about distance education "without adequately considering the broader institutional context” (p.1, 2000). In order to foster the institutional teaching online effort, I offer the following observations as considerations:

- First of all, not all faculty participants are familiar with a new delivery format. In addition, although all students are considered “digital natives” ${ }^{18}$ and comfortable using technology in their personal lives, most students are new to the online learning environment. This suggests student readiness and student expectations need to be addressed. digital immigrants who learn to use computer after their formative school years. 
- Second, each online faculty development (TOW) cohort consisted of faculty participants with different levels of technical expertise and different levels of teaching experience. Web-based tools compel pedagogical shifts (Bishop \& White, 2007) and the online teaching environment also requires faculty to adopt new assessment practices and students learning strategies (Arend, 2006). This is not a unique issue to DU, given that industry leaders such as the Sloan Consortium don't always have a good solution for screening and placing their online students, which comprised primarily instructional developers and professors.

- Third, teaching online workshop (TOW) participants are attempting to apply the training to a wide variety and levels of online programs and courses. Some faculty may enjoy the freedom of developing their own curriculum while others may need more experience and support from their colleagues in their academic discipline or from professional curriculum and instructional developers.

- Fourth, not all TOW participants have completed their second half of the grant by actually teaching a course online due to issues such as no time to develop the course, low enrollment for the course, or lack of ongoing commitment from their academic units.

- Fifth, not all programs or colleges provide administrative backing and/or recognition for their faculty in their online development efforts. One faculty member commented that the traditional university appointment, 
tenure, and promotion (APT) structure does not support participation in the online faculty development program. This faculty statement reiterates Sloan-C’s finding concerning no major changes in faculty reception of online teaching since 2003 (Allen \& Seaman, 2013).

- Sixth, for the faculty members who have taught online, there is no clear institutional requirement, support, recognition, or reward for them to continue to teach online.

- Seven, there is no separate teaching evaluation available for online courses, nor does an APT committee distinguish teaching scores for f2f and online courses.

- Eighth, in order to facilitate online faculty adaptation process, institutional leaders and administrators need to solicit input from faculty members themselves on how to encourage faculty "buy-in" and their continuous involvement.

- Ninth, the existing culture of academic publication does not encourage or motivate faculty contributions to scholarship relating to online course development or online learning. Online teaching and learning has and will increasingly challenge the limitations of traditional modes of scholarship. New conceptual frameworks and research methodologies are needed for research in this erratically charted frontier.

Palloff and Pratt (2011) suggested the five phases of online faculty development from visitor, novice, apprentice, insider, to master (see figure 9 in Ch. 2). Each phase prioritizes the four common online teaching components: personal, 
pedagogy, content, and technology differently. The OTL may design different levels of training to gradually advance faculty competency along all four elements in the Palloff and Pratt online faculty development framework. In addition, the OTL may develop tools to assess or help faculty self-assess their online teaching readiness in order to place them in different levels of training. For example, the OTL may offer an introductory and shorter version of the existing TOW program as an alternative to faculty members who are interested in utilizing technology in teaching but don't necessarily have time to participate in TOW. Furthermore, the OTL may wish to increase capacity to develop, assess, and further cultivate its online faculty training efforts as a university center as well as with the various levels of academic programs.

Since current faculty development models (Epper \& Bates, 2001, Ko \& Rossen 2010; Palloff \& Pratt, 2011; Simonson et. al 2009) do not address issues in (1) the changing job requirement of a modern day professorate in the unchanged ivory tower reward structure, and (2) how to contribute to scholarship in their academic disciplines in the digital space, the institution will likely need to develop its own best practice in online faculty development by incorporating those additional considerations.

\section{$\underline{\text { Ideas for Institutionalization }}$}

Dewey (1910) articulated the human interest for "self-realization” is sympathetic, socially and aesthetically sympathetic, rather than cognitive. "This sympathetic interest provides the medium for carrying and bringing together what would otherwise be a multitude of items, diverse, disconnected, and of no intellectual 
use” (p.189, Dewey, 1910). Dewey’s concept explained the digital impacts in various aspects of their own lives our participants felt and how they are trying to make meaning (Eisner, 1994) of those experiences in actualizing themselves as an online teacher.

Maslow's hierarchy of needs details the human motivation and personal development's intricate interplay within the societal context (1943 \& 1954). When I asked these participants why they teach online and continue to do so, often their primarily motivations are not extrinsic in nature, but rather the individual desire to stay current, their drive to excel, their fear of getting left behind, their willingness as a learner, their openness to new possibilities offered by technology, their sense of moral obligation, their belief in delivering values in students learning, the satisfaction as a teacher in seeing students transform, their desire to facilitate personal and professional development while they teach, and their commitment in contributing to the social transformation. Most of those motivations are based on the selfactualization level of Maslow's hierarchy. Although Campbell's (Campbell, et. al, 2009) multivariate emerging model of change agency identifies intentional and operational dimensions in the center of "zone of moral coherence", it did not detail the process or the motivations in actualizing intentions into operations within the institutional context. Nonetheless, our participants offer some advices for colleagues interested in learning to teach online as follows:

- Holly: “Take the TOW class. The experience of being an online student was invaluable. It allowed me to recognize the different learning styles 
among students in f2f classes as well. However, only do it if your department supports it and make sure you get teaching evaluations at least around the department average or better.”

- John: "Try it. Take the risk. Open to the possibility of teaching online. Try to put your preconceptions aside. Enjoyed the flexibility ad other positive components. Maybe hybrid works better for some people. If it's not for you, at least you know.

- Bill: "I think my colleagues need to jump. Not if, but how high and how fast. Sometimes you just have to take the plunge, the same way I learned how to swim. There is no way we can compete with other schools who are doing it. I don’t know if students are willing to pay $\$ 40,000$ a year or $\$ 100,000$ a year in a few years to listen to us bore them to death. The students are changing. I've been teaching for 20 years but I am not ready to retire. I better do something."

- Mary: “I am very customer centric, comes from my business background as an entrepreneur. Eventually students would want more from us than what we are giving them right now. They just don't know it yet. The trick is to help them see what they are missing, in terms of them rolling up their sleeves and learning something they can really remember. I like to learn things. Going through these experiences myself has been very energizing for me. The idea I am continuing to use my brain, I am not going to have Alzheimer’s I hope.” 
However, all our participants expressed the need for additional training, recognition, support, and reward in furthering their teaching online efforts. Furthermore, institutional online faculty development programs require commitment of resources from not only administration but also faculty and students who participate in those online courses. Questions remain about how the institution and the faculty members participating in those online faculty development programs determine the values of their efforts. Pina’s (2008) study indicates, “Faculty by and large are not rewarded or credited professionally for engaging in distance education activities” (p.436). When considering institutionalization of distance education, Pina (2008) argues institutions should establish priorities in technological capacity, support, policy, and relevant professional incentives. Our participants suggested the following ideas for institutionalizing online learning.

- Holly would like to see clear institutional goals on pedagogically how to enhance students learning online and have trainings relating to those goals as an ongoing institutional effort. In addition, she is concerned any reason other than enhancing students learning outcome will cost institutional foci and its brand. She believes more institutional discussions with a clearly defined context will create the coherent efforts needed in transforming the institution.

- John would like to see more recognition from peers and the administration. He would also like to have more formal and informal social gatherings with other online faculty on campus to stay current and have a sense of a community working toward the institutional teaching online process. He 
believes more recognition and rewards will help the momentum of faculty who are teaching online in furthering their efforts.

- Bill believes the institution should be fully committed in the online faculty development process by providing additional training, recognition, support, and rewards in order to speed up the adoption process. Bill believes the administration should put teaching online as a job requirement for new faculty. In addition, in order to improve the "buy in" from and reduce the fear factors for existing faculty members, institutions should take out risk factors such as teaching evaluations, teaching scores, APT reviews for those who choose to teach online in their initial adoption period. Bill believes without major paradigm shifts and culture change, many higher learning institutions will lose out to their competitors in the next 10-15 years.

- Mary believes “One Size Does Not Fit All.” Therefore, in order to appeal to individual faculty member's interest in teaching online, the administration needs to have one-on-one talk with each faculty member and try to develop a package to fit that person, without having to change the overall reward structure. In addition, she believes there should be different teaching evaluation methods for online courses to reward good online teachers. She also believes the administration needs to clearly communicate the commitment and expectations for online faculty and online students.

Alternatively, academic programs may consider requiring new faculty members to become TQ within the first two years of hiring. In conjunction, 
administration either at the program or college level may consider offering existing faculty course releases and/or additional grants for developing online courses for the department. Other universities have developed tenure-track positions for faculty functioning as experts specifically for designing and developing online courses and supporting colleagues' online efforts within their academic unit. Finally, the institution's leadership may direct all colleges and programs to assess and strategize its own needs and commitment to online learning. Each academic program will be better able to identify the type of courses best suitable for online teaching through its self-assessment process and thus afford the opportunity for the OTL to plan online faculty development accordingly. This last approach presents a needs-based paradigm when designing and providing future online teaching training programs.

On the institutional level, the perennial questions regarding the other two Sloan-C framework pillars on: (1) Scale -- cost effectiveness and level of commitment and (2) Access—-meeting students' needs, can only be addressed by the central administration. Discussions surrounding an institutional vision for online learning and strategies for future online faculty development efforts will directly and indirectly influence faculty perception toward, and institutional culture about, online teaching as a whole.

Further surveys and in-depth research may yield contextual understanding of the institutional virtual learning environment as well as on how teaching online faculty development programs impact institutional culture relating to online teaching and learning. Academic journals and publications will need to address teaching and 
learning in their academic disciplines in order to encourage scholarship in the online teaching and learning area as well. Reiterating Colbeck’s (2002) suggestion regarding institutionalization, which requires changes in rules, values, norms, beliefs, and behaviors, institutions are encouraged to use multiple indicators to assess and provide evidence of lasting change. Institutions, in this case, include postsecondary institutions as well as academic research and development organizations. However, only an institution can decide what kind of change is needed and define what constitutes as evidence of lasting change. After all, the institutional future, including the future of all its members, is at stake. We can either learn to ride the digital waves and enjoy the ride, or get swept away by its sheer forces, and the choice, my friend, is yours.

\section{Limitations of the Study}

The intention of this study was to examine why faculty members teach online and what characterizes their journey in learning to teach online. In addition, through their narratives, we also learn how they teach online, the adjustment and adaption they made along the way, the highlights and challenges they encountered, and their reflections of their experiences from various aspects of their lives. With regards to limitations,

- First of all, this study intentionally oriented its perspective from the faculty members' point of view. Although two of four participants also hold administrative duties, this study did not intend for nor seek out opinions 
from the leadership or administration of the institution where those participants work.

- Second, the participants chose to answer the interview questions the way they feel comfortable with, in the available amount of time during our interviews. Therefore, we may not have the full extent of their experience of learning and teaching online. However, they all expressed interest in continuing the conversations down the road, which suggests that this is an area of interest for them in their professional development.

- Third, any mention of current online faculty development models or MOOCs in this study is for reference only, and thus is not intended to constitute a criticism or endorsement.

- Fourth, although all participants expressed their concerns about the future of higher education, and the need for cultural and paradigm shifts in postsecondary institutions, this study does not examine institutional motivations in distance education, nor intends to provide predictions on the future of higher education as a whole.

\section{Implications}

This study aimed to unveil the journeys of those few faculty members who pioneered and continue to teach online in a traditional private university. By understanding their journeys, this study's goal was to provide considerations for others to conceptually map their road ahead in teaching online. The researcher hopes that this study may be used by institution leaders, faculty developers, and other faculty members to (1) assess the level of progress of their current and future distance 
learning program, (2) determine how distance learning programs should be established, (3) evaluate faculty development efforts (4) better strategies and implementations for institutionalization of their distance education programs, including academic programming and faculty reward structure, and (5) improve online student retention and learning outcomes.

\section{Epilogue}

I shared a quote or verse at the beginning of each chapter, not as "handwriting on the wall” in Johnson's (1998) fable, but rather a memento to the wonderful readers who have stuck with me though this journey of discovery. As this case study concludes, I would like to dedicate the following verse to all the faculty who teach online:

\footnotetext{
"Life is no straight and easy corridor along which we travel free and unhampered, but a maze of passages, through which we must seek our way, lost and confused, now and again checked in a blind alley.
}

But always, if we have faith, a door will open for us, not perhaps one that we ourselves would ever have though of, but one that will ultimately prove good for us."

\section{A.J. Cronin}




\section{References}

Albirini, A. (2006). Teacher's attitudes toward information and communication technologies: the case of Syrian EFL teachers. Computers \& Education, (47), 373-398.

Allen, I. E., \& Seaman, J. (2013). Changing course: Ten years of Tracking Online Education in the United States. Babson Survey Research Group.

Allen, I. E., \& Seaman, J. (2011). Going the distance: Online education in the United States Babson Survey Research Group.

Allen, I. E., \& Seaman, J. (2010). Class differences: Online education in the United States. Babson Survey Research Group.

Arend, B. D. (2006). Course Assessment Practices and Student Learning Strategies in Online College Courses. (Doctoral dissertation). Retrieved from UMI Dissertations Publishing.

Ash, K. (2010). States struggle to put together programs for sharing K-20 data. Education Week, 29(16), 10.

Barnes, K., Marateo, R., \& Ferris, S. (2007). Teaching and learning with the Net Generation. Innovate Journal of Online Education, 3 (4).

Beyers, R.N. (2009). A five dimensional model for educating the Net Generation, Educational Technology \& Society, 12(4), 218-227. 
Bhattacharya, K., \& Han, S. (2001). Piaget and cognitive development. In M. Orey (Ed.), Emerging perspectives on learning, teaching, and technology, from http://projects.coe.uga.edu/epltt/.

Bishop, M. J., \& White, S. A. (2007). The Clipper Project: Discovering what online courses offer residential universities. Educause Quarterly, number 1, 14-20.

Bolliger, D. U. \&Wasilik O. (2009). Factors influencing faculty satisfaction with online teaching and learning in higher education. Distance Education, 30(1), 103-116.

Bonk, C. (2009). The world is open, how web technology is revolutionizing education. San Francisco: Jossey-Bass.

Boyd-Barrett, O. (2000). Distance education provision by universities: How institutional contexts affect choices. Information, Communication \& Society, 3(4), 474-493.

Boyer, N. R., Maher, P. A., \& Kirkman, S. (2006). Transformative learning in online settings: the use of self-direction, metacognition, and collaborative learning. Journal of Transformative Education, 4 (4), 335-361.

Bransford, J., Brown, A., \& Cocking, R. (1999). How people learn, Brain, Mind, Experience, and School, from http://books.nap.edu/html/howpeople1/ch6.html. 
Burbules, N. C, (2008). E-Lessons learned. Information and communication technologies: Considerations of current practice for teachers and teacher educators. National Society of Study of Education Yearbook (NSSE), 106(2), 207-216.

Burns, R.B. (2000). Introduction to Research Methods. London: Sage.

Carlson, S. (2005). The Net Generation Goes to College, from http://chronicle.com/free/v52/i07/07a03401.htm.

Carr, W. (1998). The curriculum in and for a democratic society. Pedagogy, Culture \& Society, 6 (3), 323-340.

Campbell, K., Schwier, R. and Kenny, R. (2009). The critical, rational practice of instructional design in higher education: an emerging model of change agency. Education Tech Research Development, 57: 645-663.

ChanLin, L. (2009). Applying motivational analysis in a Web-based course. Innovations in Education and Teaching International, 46 (1), 91-103.

Cogburn, D. (1998). Globalization and the state in the information age: Thoughts on requirements for education and learning, from http://www.unesco.org/webworld/infoethics_2/eng/papers/paper_23.htm.

Colbeck, C. L. (2002). Assessing institutionalization of curricular and pedagogical reform. Research in Higher Education, 43(4), 397-421.

Collins, A. \& Halverson, R. (2010). The second educational revolution: rethinking education in the age of technology. Journal of Computer Assisted Learning, 26 (1), 18-27. 
Creswell, J.W. (2007). Qualitative Inquiry \& Research Design: Choosing among five approaches. Thousand Oaks, CA: Sage.

Curry-Corcoran, D. E. (2003). Intern Student Teachers and Technology Training: An integrated approach for pre-service teacher training and support. (Doctoral dissertation). Retrieved from UMI - Dissertations Publishing.

Dede, C. (2008). A seismic shift in epistemology. EDUCAUSE Review 43(3), 80-81.

Dede, C. (2008). Reinventing the role of information and communications technologies in education. Information and communication technologies: Considerations of current practice for teachers and teacher educators. National Society of Study of Education Yearbook (NSSE), 106 (2), 11-38.

Dewey, John (1938). Experience and education. New York: Touchstone.

Dewey, John (1910). How We Think. Boston: D.C. Heath \& CO.

Dey, E. L., Burn, H. E. \& Gerdes, D. (2007). Bringing the classroom to the web: Effects of using new technologies to capture and deliver lectures, Research in Higher Education, 50, 377-393.

Du, H. \& Wagner, C. (2007). Learning with weblogs: Enhancing cognitive and social knowledge construction. IEEE Transactions on Professional Communication, 50(1), 1-16.

Eisner, E. W. (1994). Cognition and curriculum reconsidered. New York: Teachers College Press. 
Eisner, E. W. (1998). The Enlightened Eye: Qualitative Inquiry and the Enhancement of Educational Practice. Prentice-Hall Inc., Upper Saddle River, NJ.

Ellis, R. A., Ginns, P., \& Piggott, L. (2009). E-learning in higher education: some key aspects and their relationship to approaches to study. Higher Educational Research \& Development, 28 (3), 303-318.

Ellsworth, J. B. (2000). Surviving change: A survey of educational change models. Syracuse, NY: ERIC Clearinghouse on Information and Technology.

Epper R. M. \& Bates, A. W. (2001). Teaching faculty how to use technology: Best practices from leading institutions. The American Council on Education and The Oryx Press.

Farmer, E. A. (2004). Faculty development for problem-based learning. European Journal of Dental Education, 8:59-66.

Endres, M. L., Hurtubis, C.A., Chowdhury, S., \& Frye, C. (2009). The multifaceted nature of online MBA student satisfaction and impacts on behavioral intentions, Journal of Education for Business, 84(6), 304-312.

Facer, K. \& Sandford, R. (2010). The next 25 years? future scenarios and future directions for education and technology. Journal of Computer Assisted Learning, 26(1), 74-93.

Farrington, G. \& Yoshida, R. (2000). Darwin goes to college: Educational competition in a Dot-com world. EDUCAUSE Review, pp. 12-17, Nov/Dec 2000. 
Feist, L. (2003). Removing barriers to professional development. T.H.E. Journal, 30 (11), 30-36.

Fetters, M. L. \& Duby, T. G. (2011). Faculty development: A stage model matched to blended learning maturation. Journal of Asynchronous Learning Networks, 15:1, pp. 77-86.

Friedman, T. (2005). The World is Flat: a Brief History of the Twenty-First Century. New York: Farrar, Straus and Giroux

Gladwell, M. (2000). The Tipping Point: How Little Things Can Make A Big Difference. Little Brown \& Company.

Gardner, Howard. (2006). Multiple Intelligences. New York: Basic Books.

Gardner, Howard. (2004). The Unschooled Mind. New York: Basic Books.

Garrison, D. R. \& Anderson, T. (2003). E-learning in the $21^{\text {st }}$ century: A framework for research and practice.

Garrison, D. R., Anderson, T., \& Archer, W. (2000). Critical inquiry in a text-based environment: Computer conferencing in higher education. The Internet and Higher Education, 2(2-3), 87-105.

Gee, J. P. (2008). Social linguistics and literacies: Ideology in discourses. New York: Routledge.

Gee, J. P. \& Hayes, E. R. (2011). Language and Learning in the Digital Age. New York: Routledge.

Gersick, C.J.G. (1991). Revolutionary change theories: A multi-level exploration of the punctuated equilibrium paradigm. Academy of Management Review, 16, 10-36. 
Guzman, A., \& Nussbaumt, M. (2009). Teaching competencies for technology integration in the classroom. Journal of computer assisted Learning, 25, 453469.

Hall, M., \& Elliott, K. M. (2003). Diffusion of technology into the teaching process: Strategies to encourage faculty members to embrace the laptop environment. Journal of Education for Business, 78(6), 301-307.

Halverson, R., and Clifford, M. (2006) "Evaluation in the wild: A distributed cognition perspective on teacher assessment.” Education Administration Quarterly, 42(4). 578-619.

Hancock, D.R. \& Algozzine, B. (2006). Doing Case Study Research. New York: Teachers College, Columbia University.

Herda, E. A. (1999). Research conversations and narrative: A critical hermeneutic orientation in participatory inquiry. London: Praeger.

Hrastinski, S. \& Keller, C. (2007). Computer-mediated communication in education: A review of recent research. Educational Media International, 44 (1), 61-77.

James, M., Applefield, R., \& Mahnaz, M. (2001). Constructivism in Theory and practice: Toward a Better Understanding, North Carolina: The University of North Carolina Press.

Johnson, Spencer (1998). Who moved my Cheese? New York: Putnam.

Johnson, Steven (2005). Everything bad is good for you. New York: Penguin Group.

Kember, D., Leung, D., \& Ma, R. (2007) Characterizing learning environments capable of nurturing generic capabilities in higher education. Research in Higher Education, 48(5). 
Khan, Badrul Huda (2005). Managing e Learning: Design, delivery, implementation, and evaluation. London: Idea Group Inc.

Ko, S. S. \& Rosen, S. (2010). Teaching Online: A Practical Guide. New York: Routledge.

Lemke, C. (2003). enGauge 21st Century Skills. Literacy in the Digital Age, from http://www.metiri.com/21/21\%20Century\%20Skills\%20Final.doc.

Leu, D. J., Jr., Kinzer, C.K., Coiro, J.L., \& Cammack, D.W. (2004). Towards a theory of new literacies emerging from the Internet and other information and communication technologies. In R. B. Ruddell \& N.J. Unrau (Eds.).

Theoretical models and processes of reading ( $5^{\text {th }}$ ed., pp. 1570-1613). Newark, DE: International Reading Association.

Liaw, S. (2002). An Internet survey for perceptions of computers and the World Wide Web: relationship, prediction, and differences. Computers in Human Behaviour, 18, 17-35.

Luke, C. (2003). Pedagogy, connectivity, multimodality, and inter-disciplinarity, Reading Research Quarterly 38 (3): 397-402.

Lyons, H. (2009). Case study research methodology for publishing developments in ICT-Facilitated learning in higher education - a prescriptive approach. Innovations in Education and Teaching International, Vol. 46, No. 1, February 2009, 27-39. 
Ma, Y., \& Runyon, L.R. (2004). Academic synergy in the age of technology: A new instructional paradigm. Journal of Education for Business, 79(6), 367-371.

Margetson, D. (1991). Why is problem-based learning a challenge? In D. Boud \& G. Geletti (Eds.), The challenge of problem based learning (pp.42-50). New York: St. Martin’s Press.

Mayer, R. E. (2001). Multimedia learning. New York: Cambridge University Press.

McGrath, B. (1998). Partners in learning: Twelve ways technology changes the teacher-student relationship. Technological Horizon in Education, 25(9), 5862. Merriam, S. B. (1998). Qualitative Research and Case Study Applications in Education. San Francisco: Jossey-Bass.

Miller, A. (2000a). Differences between the 'Traditional' and 'Outcomes Based' Education, from http://www.metagroup.co.za/difference_sys3.htm.

Miller, A. (2000). Differences between the 'Traditional' and 'Outcomes Based' Education, Meta Group on Communications, from http://www.metagroup.co.za/difference_sys.htm.

Miller, A. (2000b). Differences between the 'Traditional' and 'Outcomes Based' Education, Meta Group on Communications, from http://www.metagroup.co.za/difference_sys.htm.

Miller, A. (2000c). Differences between the 'Traditional' and 'Outcomes Based' Education, Meta Group on Communications, from http://www.metagroup.co.za/difference_sys2.htm. 
Miller, R. (2000). From Schools to Learning Communities: A Historic Shift, from http://www.creatinglearningcommunities.org/book/overview/miller1.htm.

Oakley, B. (2004). The value of online learning: Perspectives from the University of Illinois at Springfield. In J.C. Moore (ed.) Elements of quality online education into the mainstream: Wisdom from the Sloan Consortium. Needham, MA: The Sloan Consortium.

O’Brien, D.G., \& Bauer, E.B. (2005). New literacies and the institution of old learning. Reading Research Quarterly, 40(1), 120-131.

Olson, E.E. \& Eoyang, G.H. (2001). Facilitating organization change: lessons from complexity science. San Francisco, Jossey-Bass.

Olson, C. A. (2002). Leadership in online education: Strategies for effective online administration and governance. In K.E. Rudestam \& J. Schoenholtz - Read (Eds.), Handbook of online learning: Innovations in higher education and corporate training. Thousand Oaks, CA: Sage.

O’Shea, P., Kidd, J., Baker, P. Kaufman, J., Siao, Y., \& Allen, D. (2009). Traditional textbook vs. Student-authored Wikibook: A quasi-experimental study of student academic outcomes. Working paper presented in AERA conference. San Diego, CA.

Palloff, R., \& Pratt, K. (2011). The excellent online instructor: Strategies for professional development. San Francisco: Jossey-Bass. 
Picciano, A. G. (2001). Distance learning: Making connections across virtual time and space. Upper Saddle River, NJ: Merrill/Prentice Hall.

Pina, A. (2008). Factors influencing the institutionalization of distance education in higher education. The Quarterly Review of Distance Education, Vol. 9(4), pp.427-438.

Pina, A. (2008). How institutionalized is distance learning: A study of institutional role, locale and academic level. Online Journal of Distance Learning Administration, Vol. X1, No. I, Spring 2008, University of West Georgia, Distance Education Center.

Prensky, M. (2001). Digital Natives, Digital Immigrants, Part II: Do They Really Think Differently? The Horizon, 9 (6), 15-24.

Radford, A. (2011). Learning at a distance: Undergraduate enrollment in distance education courses and degree programs. Stats in Brief, US Department of Education, October 2011, NCIS (National Center for Education Statistics) 2012-154.

Reeves, D. (2010). The Board's Role in Innovation. American School Board Journal, 30-32.

Rogers, E. M., (2003). Diffusion of Innovation, New York: Free Press.

Seidman, I. (2006). Interviewing as Qualitative Research. New York: Teachers College. 
Simonson, M., Smaldino, S., Albright, M., Zvacek, S. (2012). Teaching and Learning at a Distance. Pearson.

Stake, R. E. (1995). The art of case study research. Thousand Oaks, CA: Sage.

Stake, R. E. (2004). Stake and responsive evaluation. In M.C. Alkin (Ed.), Evaluation roots: Tracing theorists' views and influences (pp.203-217). Thousand Oaks, CA: Sage.

Surry, D. W., \& Brennan, J. P. (1998, February). Diffusion of instructional innovations: Five important, unexplored questions. Paper presented at the annual conference of the Association for Educational Communications and Technology. St. Louis, MO.

Tallent-Runnels, M. K., Thomas, J.A., Lan, W.Y., Coopers, S., Ahern, T.C., Shaw, S.M. \& Liu, X. (2006). Teaching courses online: A review of the research. Review of Educational Research, 76(1), 93-135.

Tan, L. \& Guo, L. (2009). From Print to Critical Multimedia Literacy: One Teacher’s Foray Into New Literacies Practices. Journal of Adolescent \& Adult Literacy. 53(4), 315-324

Tapscott, D. (1988). Growing up Digital: The rise of the Net Generation, New York: McGraw-Hill. 
Taylor, J. C. (2001). Fifth generation distance education. Higher Education Series Report No. 40. Canberra, Australia: Australia Commonwealth Department of Education, Science and Training, Higher Education Division.

Trilling, B. \& Fadel, C. (2009). $21^{\text {st }}$ Century Skills: Learning for Life in Our Times. San Francisco: Jossey-Bass.

Wolcott, H. F. (2001). Writing Up Qualitative Research. Thousand Oaks, CA: Sage.

Wolcott, L. (2003). Dynamics of faculty participation in distance education: Motivations, incentives, and rewards. In M. Moore (Ed.), Handbook of distance education (pp. 549-565). Mahwah, NJ; Erlbaum.

Wriston, W. B. (1992). The twilight of sovereignty: How the information revolution is transforming our world. New York: Macmillan.

Xu, J. \& Quaddus, M. (2007). Exploring the factors influencing end uses’ acceptance of knowledge management systems: development of a research model of adoption and continued use. Journal of Organizational and End User Computing, 19(4), 57-79.

Wriston, W. B. (2007). Bits, bytes, and balance sheets: The new economic rules of engagement in a wireless world. Stanford: Hoover Institute.

Yin, R. K. (2009). Case study research: design and methods $-4^{\text {th }}$ edition. Thousand Oaks, CA: Sage. 